\title{
Autonomous Changes in the Concentration of Water Vapor Drive Climate Change
}

\author{
William A. Van Brunt \\ JFA, LLC, Wayzata, MN, USA \\ Email: WaterVapor@JustForumAccess.com
}

How to cite this paper: Van Brunt, W.A. (2020) Autonomous Changes in the Concentration of Water Vapor Drive Climate Change. Atmospheric and Climate Sciences, 10, 443-508.

https://doi.org/10.4236/acs.2020.104025

Received: June 30, 2020

Accepted: August 18, 2020

Published: August 21, 2020

Copyright $\odot 2020$ by author(s) and Scientific Research Publishing Inc. This work is licensed under the Creative Commons Attribution International License (CC BY 4.0).

http://creativecommons.org/licenses/by/4.0/

\section{(c) (i) Open Access}

\begin{abstract}
When compared to the average annual global temperature record from 1880 , no published climate model posited on the assumption that the increasing concentration of atmospheric carbon dioxide is the driver of climate change can accurately replicate the significant variability in the annual temperature record. Therefore, new principles of atmospheric physics are developed for determining changes in the average annual global temperature based on changes in the average atmospheric concentration of water vapor. These new principles prove that: 1) Changes in average global temperature are not driven by changes in the concentration of carbon dioxide; 2) Instead, autonomous changes in the concentration of water vapor, $\triangle \mathrm{TPW}$, drive changes in water vapor heating, thus, the average global temperature, $\Delta T_{\text {Avg }}$, in accordance with this principle, $\Delta T_{\text {Avg }}=0.4 \Delta \mathrm{TPW}$ the average accuracy of which is $\pm 0.14 \%$, when compared to the variable annual, $1880-2019$, temperature record; 3 ) Changes in the concentration of water vapor and changes in water vapor heating are not a feedback response to changes in the concentration of $\mathrm{CO}_{2}$; 4) Rather, increases in water vapor heating and increases in the concentration of water vapor drive each other in an autonomous positive feedback loop; 5) This feedback loop can be brought to a halt if the average global rate of precipitation can be brought into balance with the average global rate of evaporation and maintained there; and, 6) The recent increases in average global temperature can be reversed, if average global precipitation can be increased sufficiently to slightly exceed the average rate of evaporation.
\end{abstract}

\section{Keywords}

Carbon Dioxide, Climate Change, Water Vapor, Global Warming, Driver, Average Global Temperature, Change in Concentration Water Vapor, Water Vapor Heating 


\section{Introduction}

\section{Objectives}

- Develop wholly new principles of atmospheric physics;

- Identify and prove the cause of climate change;

- In so doing, assess the role, if any, changes the increasing concentration of $\mathrm{CO}_{2}$ may play;

- Posit a possible solution to the existential problem that is global warming.

\section{Global Warming}

Since 1976, the average global temperature has been increasing at the rate of $\sim 0.2^{\circ} \mathrm{C} /$ decade. This is a very serious problem, becoming increasingly so and likely to become an existential threat to certain of those living on the margin around the globe.

Like any problem, to find a solution, the cause must be understood.

The increasing concentration of atmospheric carbon dioxide is NOT the cause of climate change. Therefore, limiting the increase of or reducing carbon emissions is irrelevant.

The cause is the continuing increase in the concentration of water vapor, the primary greenhouse gas (GHG) with an average heating power significantly greater than $\mathrm{CO}_{2}$. As the annual average water vapor concentration changes, the average annual greenhouse heating from water vapor, varies year to year.

As shown below, the changes in the concentration of water vapor are driven in an autonomous positive feedback loop between evaporation variability as a result of changes in water vapor surface heating, WV, driving changes in the average global atmospheric concentration of water vapor and therefore, water vapor surface heating.

Until that is understood, appropriate solutions found and implemented, this is an ever increasing threat to humankind. The good news is that this problem, including the reduction of past increases, at least theoretically, lends itself to solutions.

Figure 1 sets out the average global temperature record [1] [2] [3]. The variability is significant, real and not "noise" in the data. (The data underlying Figure 1 is set out in Table S1, which like all of the charts in this paper is set out in the referenced Tables in Appendix 2, Supplementary Materials).

\section{Background-The Physics of Climate Change}

As illustrated in Figure 2, Earth's surface is warmed by the Sun and the greenhouse gases (GHG) and cooled by surface radiation, evaporation and thermal convection. As shown, at steady state, the total heating of $494 \mathrm{Wm}^{-2}$ was equal to the power of and in balance with the surface radiation, evaporation, thermal convection and the sub-surface heating of the sea of $493.9 \mathrm{Wm}^{-2}$.

Between 1880 and 2019, the energy of Earth's land surface increased by $0.7 \%$, an average increase of $0.005 \%$ per year, which is greater than the increase in the surface energy of the seas. No appreciable fraction of the radiant energy heating the surface is stored in the land. Therefore, determining the average annual 
change in average global temperature from a change in average total heating is a straightforward exercise in thermodynamics. Deduct the percentage of total heating that drives evaporation and thermal convection and, given that the average surface radiation, $\mathrm{Rad}_{U}$, cannot exceed the remaining net heating, $\mathrm{NaH}$, for small changes in net heating, the change in the average surface temperature from temperature $T_{o}$ is,

$$
\Delta T=\mathrm{NaH} /\left(4 \sigma T_{o}^{3}\right){ }^{\circ} \mathrm{C}
$$

\section{Climate Models}

Various models of surface heating, based upon the supposition that changes in the concentration of $\mathrm{CO}_{2}$ drive global warming, have been developed. These can be compared to the average global temperature record.

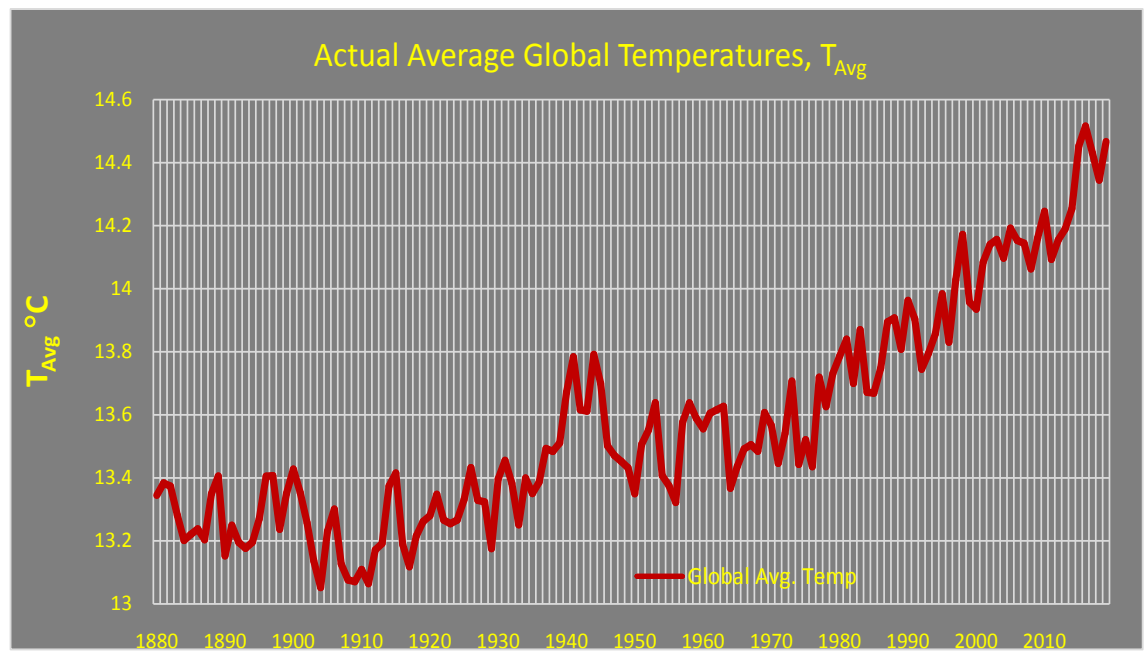

Figure 1. Average global temperature record [1] [2] [3] (Table S1).

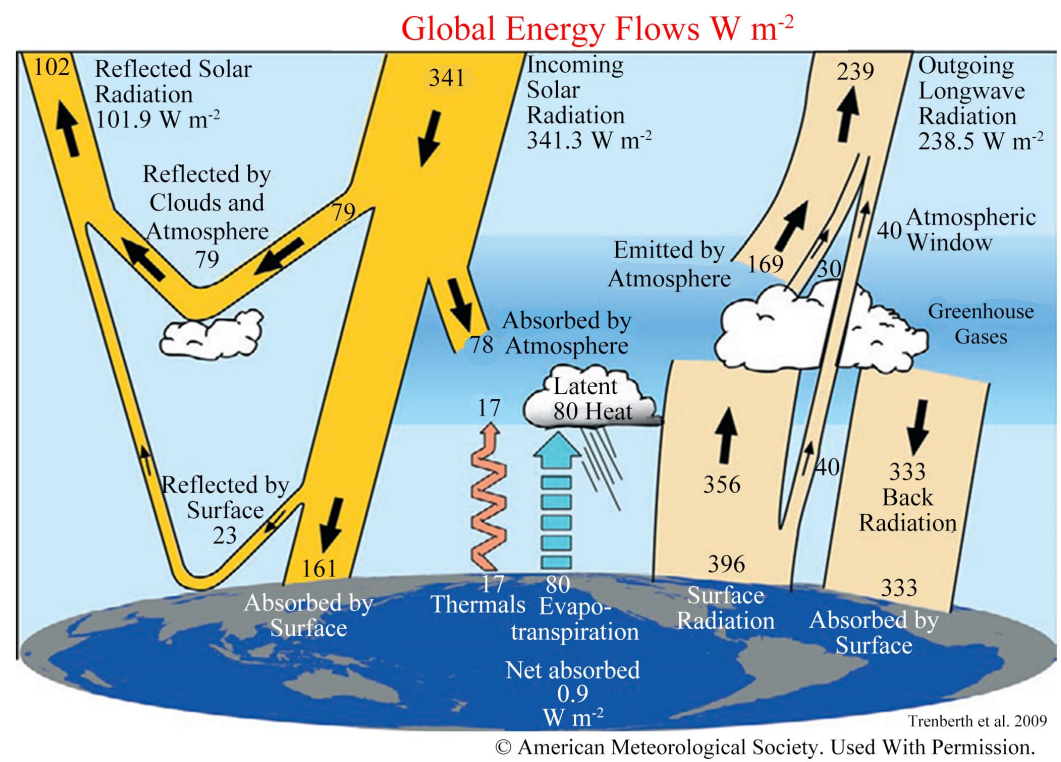

Figure 2. Global energy budget between Mar. 2000 and May $2004 \mathrm{Wm}^{-2}$ [4]. (When referred to in this paper, it is assumed that this budget represents the year 2002). 
Many of these models attempt to calculate the changes in heating from water vapor as a feedback response to changes in the theoretical heating from $\mathrm{CO}_{2}$, when, since 1880, except for the period 1900-1903, the concentration of $\mathrm{CO}_{2}$ [5] [6], thus the theoretical heating, increased year over year, while out of the 139 changes in temperature, there were 64 reductions in total heating. A year over year increase in heating from $\mathrm{CO}_{2}$ cannot cause a reduction in heating as a feedback effect one year and an increase in another.

Referring to Figure 3, that some of these $\mathrm{CO}_{2}$ models are wrong is clear from the fact that they calculate temperatures measurably greater than actual. For each year, the average global surface temperature is at the temperature the average net absorbed heating, $\mathrm{NaH}$ (total heating less the power driving evaporation and thermal convection) can drive. For the modeled surface temperature to exceed the actual surface temperature would require the IR radiation emitted by the surface, which is directly proportional to the surface temperature raised to the fourth power, to exceed the actual net absorbed heating, a violation of Kirchhoff's law of thermal radiation and the first law of thermodynamics. The physics underlying models that return such results and these models are facially incorrect.

Many individual models show:

1) year to year variances greater than $20 \%$ of the actual year to year temperature increase between 1880 and 2018;

2 ) increases in temperature when the average temperature declined.

In addition, no published model tracks even the 10 largest year to year variations in average global temperature.

These hindsight comparisons illustrate the failings of many of these models.

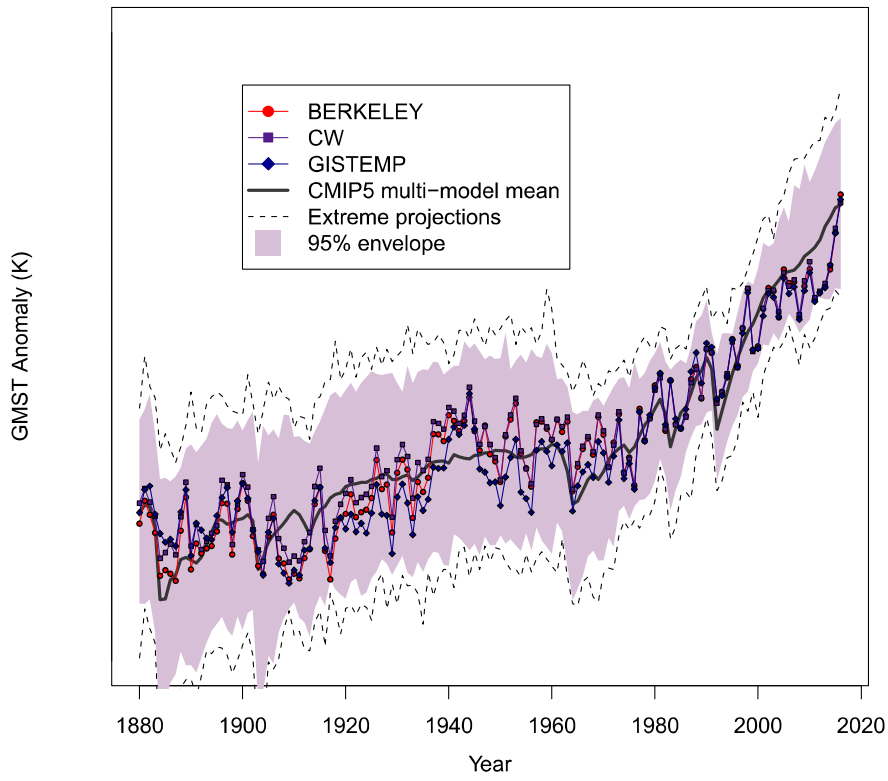

Figure 3. Typical results of computer models of changes in average global temperature [7] (p. 10, Figure 3(a)). 
The reason that the calculated changes in heating, $\Delta \mathrm{TH}_{\mathrm{CO} 2}$, from changes in the concentration of $\mathrm{CO}_{2}, C$, applying this expression,

$$
\Delta \mathrm{TH}_{\mathrm{CO} 2}=5.35 \ln \left(C / C_{o}\right) \quad[8]
$$

are referred to as theoretical, is that the results of this study demonstrate that, in actuality, changes in the concentration of $\mathrm{CO}_{2}$ have no measurable effect on changes in average global temperature, therefore this expression significantly overstates the changes in heating that changes in $\mathrm{CO}_{2}$ can drive.

\section{New Principles}

Therefore, new Principles to first determine changes in the average concentration of water vapor and then the changes in heating and surface temperature these changes drive, are set out. (The derivation of all of these principles is set out in Appendix 1).

Like $\mathrm{CO}_{2}$ and all greenhouse gases, the heating impact of water vapor is a function of its atmospheric concentration, but there are no methods set out in the literature to correctly determine changes in the average concentration of water vapor.

Therefore, wholly new Principles of climate physics for calculating changes in the concentration of water vapor and water vapor heating and resulting changes in average global temperature have been developed. The results of the application of these principles prove that:

1) The determination of changes in the concentration of water vapor match and are consistent with published data;

2) Changes in average global temperature are driven by and are directly proportional to changes in the concentration of water vapor matching the historic record from 1880 -2019 with $\pm 0.14 \%$ accuracy;

3) Climate change is not driven by changes in the concentration of carbon dioxide, nor are changes in water vapor heating a feedback response to, related to or a function of, changes in heating from $\mathrm{CO}_{2}$;

4) Instead, evaporation in excess of precipitation and water vapor heating have been in an autonomous positive feedback loop driving a 14\% increase in the concentration of water vapor and a $3 \%$ increase in water vapor heating since 1976 which accounts for the increase in average global temperature since then;

5) While affected by sea surface temperature, since 1976, evaporation has been primarily a function of the changes in total heating, absorbing, on average, $64 \%$ of the changes in heating of the seas.

Changes in the Concentration of Water Vapor

Changes in the concentration of water vapor, total precipitable water, $\triangle \mathrm{TPW}$, are determined from the NOAA data [1] [2] set out in Table S1 as,

$$
\Delta \mathrm{TPW}=0.157 \Delta \mathrm{TH}+17.53\left\{\mathrm{e}^{[0.0686(\mathrm{SSTo}+\Delta \mathrm{SST}-288)]}-\mathrm{e}^{[0.0686(\mathrm{SSTo}-288)]}\right\} \mathrm{kg} \cdot \mathrm{m}^{-2}
$$

where $\mathrm{TH}$ is the average total solar and greenhouse gas (GHG) heating, $\mathrm{Wm}^{-2}$ And SST is the global average sea surface temperature, $\mathrm{K}$. 
A comparison of the percentage changes in average global temperature and the concentration of water vapor plotted on a $53 \%$ relatively reduced scale is set out in Figure 4. The scaled changes in the concentration of water vapor, $\triangle \mathrm{TPW}$, closely match each and every one of the 139 annual percentage changes in average global temperature, $\Delta T_{\text {Avg }}$. The correlation coefficient is 0.997 .

This is climate change explained.

Computed Change in Concentration of Water Vapor

That Equation (1) is correct can also be seen from Figure 5 showing the average global concentration of water vapor and the computed concentration of water vapor, $\mathrm{TPW}_{\text {Tot }}$, calculated in accordance with Equation (1) for the years 1996-2007, set out in Table 1 and shown as green dots, along with their trendline (dashed red line).

Further confirmation of the computed changes in the concentration of water vapor follows:

1) "In the SSM/I data, $\left(W_{\mathrm{o}}\right)$ increases over the period $1988-2006$ by $0.41 \mathrm{~kg} / \mathrm{m}^{2}$ per decade, with a $95 \%$ confidence interval of $\pm 0.21 \mathrm{~kg} / \mathrm{m}^{2}$ per decade" [9].

2) The concentration of water vapor from Equation (1) between 1988 and 2012 is shown in Figure 6.

The trendline for the computed results for, $\mathrm{TPW}_{\mathrm{Tot}}$, from Equation (1) for the period 1988 to 2006 as set out in Table S2 and shown in Figure 6, is 0.533 $\mathrm{kg} \cdot \mathrm{m}^{-2}$ per decade, well within the confidence interval of $\pm 0.21 \mathrm{~kg} / \mathrm{m}^{2}$ per decade around $0.41 \mathrm{~kg} / \mathrm{m}^{2}$.

3) On July 1, 2010, "The precipitable water ranged from 0.1 to $78.1 \mathrm{~mm}$ with a global average of $21.6 \mathrm{~mm}$ " [10]. From Equation (1), in 2010 the global average concentration was $20.8 \mathrm{~mm}$.

4) Evaporation and Precipitation-See discussion of Figure S1 \& Figure $S 2$ in Appendix 2, Supplementary Materials, which shows that there is no significant disagreement between the computed results for changes in evaporation, $\Delta \mathrm{EV}$, relative to precipitation, $\triangle \mathrm{PR}$, for the period 1901-2015, where

$$
\Delta \mathrm{EV}=\Delta \mathrm{TPW}+\Delta \mathrm{PR} .
$$

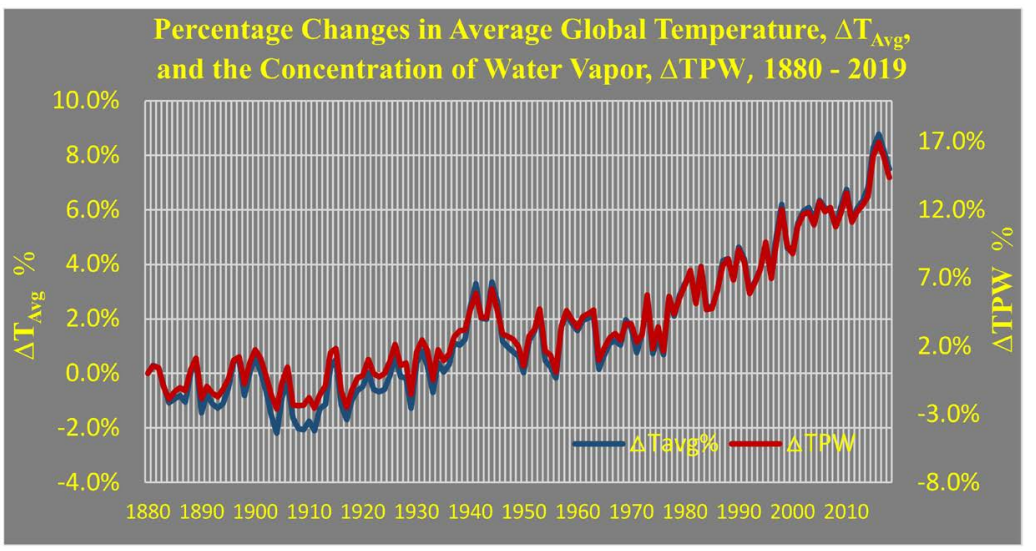

Figure 4. Percentage changes in average global temperature and the concentration of water vapor, $\triangle \mathrm{TPW}[1]$ [2] [3] (Table S2). 


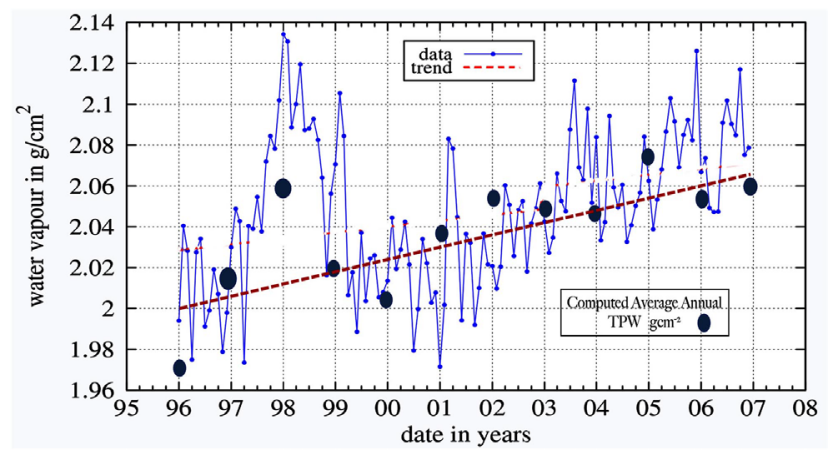

Figure 5. Results of the Application of Equation (1) are set out in Table 1 in $\mathrm{gm} \cdot \mathrm{cm}^{-2}$ and shown as Green Dots for the period 1996-2007 [11] (p. 498, Figure 8 with original trendline regarding autocorrelations removed).

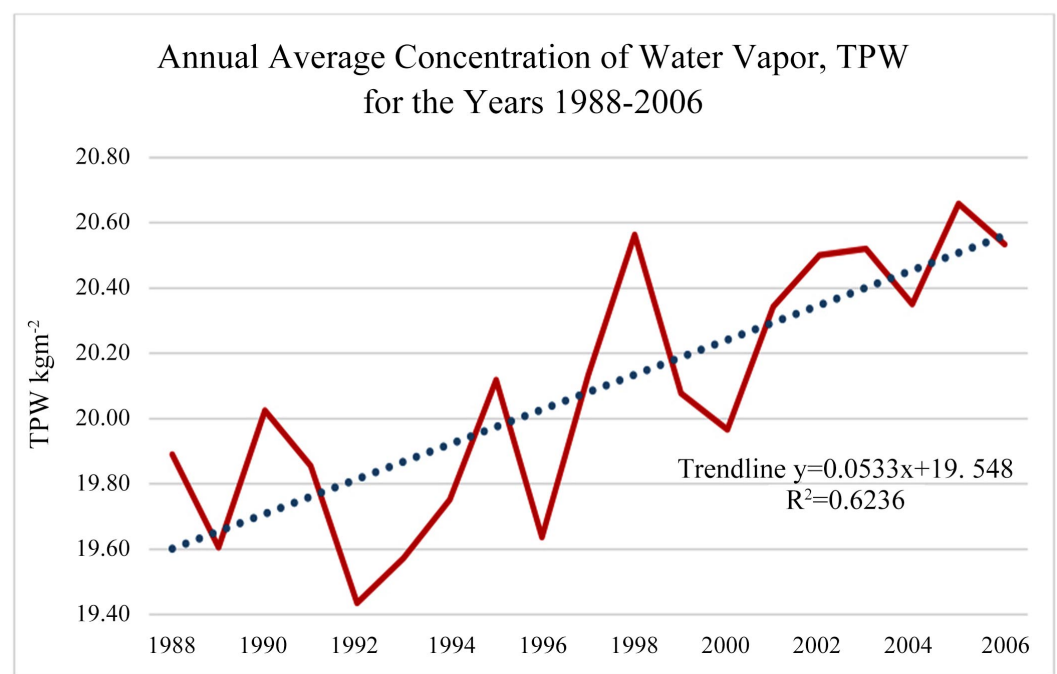

Figure 6. Concentration of Water Vapor for the Period 1988-2006 (Table S2).

Table 1. Concentration of water vapor.

\begin{tabular}{cc}
\hline Year & $\mathrm{gm} \cdot \mathrm{cm}^{-2}$ \\
1996 & 1.96 \\
1997 & 2.01 \\
1998 & 2.06 \\
1999 & 2.01 \\
2000 & 2.00 \\
2001 & 2.03 \\
2002 & 2.05 \\
2003 & 2.05 \\
2004 & 2.04 \\
2005 & 2.07 \\
2006 & 2.05 \\
2007 & 2.06 \\
\hline
\end{tabular}


5) The match in changes in the average global temperature from Equation (5) based on the calculated changes in the concentration of water vapor from Equation (1).

In sum, this proves that Equation (1) for calculating the concentration of water vapor is correct.

Changes in Water Vapor Heating

The new principle for determining changes in average global water vapor heating is:

$$
\Delta \mathrm{WV}=73.3 \ln \left(1+\Delta \mathrm{TPW} / \mathrm{TPW}_{\mathrm{o}}\right) \mathrm{W} \cdot \mathrm{m}^{-2}
$$

If changes in water vapor heating were a feedback response to increases in heating from $\mathrm{CO}_{2}, \Delta \mathrm{TH}_{\mathrm{CO} 2}$, as some assert, a plot of changes in water vapor heating, $\Delta \mathrm{WV}$, should show a growing increase as $\Delta \mathrm{TH}_{\mathrm{CO} 2}$ increases. The calculated relationship between the two is shown in Figure 7.

Changes in Temperature and Water Vapor Heating are Unrelated to Changes in Heating from $\mathrm{CO}_{2}$

Referring to Figure 7, while attention is typically focused on and comparisons are made to long term trends in the average global temperature record, the actual variable changes in temperature are significant.

For example, in just one year, 1913-1914, the average global temperature increased by $0.16^{\circ} \mathrm{C}, 14 \%$ of the $1.1^{\circ} \mathrm{C}$ change over the 139 year period between 1880 and 2019 , a rate of change 22 times as great as the average long-term rate of change. This $0.16^{\circ} \mathrm{C}$ rise required an increase in total heating of $1.7 \mathrm{Wm}^{-2}$, to which the change in radiative heating from $\mathrm{CO}_{2}, \Delta \mathrm{TH}_{\mathrm{CO} 2}$, theoretically contributed no more than $0.004 \mathrm{Wm}^{-2}, 0.24 \%$. Further, over a period of 35 years, there was an increase of $0.77^{\circ} \mathrm{C}$ between 1909 and $1944,97 \%$ of the $0.8^{\circ} \mathrm{C}$ change over the period between 1880 and 2019 and a rate of change nearly three times as great as the long-term rate of change. This $0.77^{\circ} \mathrm{C}$ increase required an increase in total heating of $4.2 \mathrm{Wm}^{-2}$, to which $\Delta \mathrm{TH}_{\mathrm{CO} 2}$ theoretically contributed no more than $0.16 \mathrm{Wm}^{-2}, 4 \%$. This variability is clearly significant.

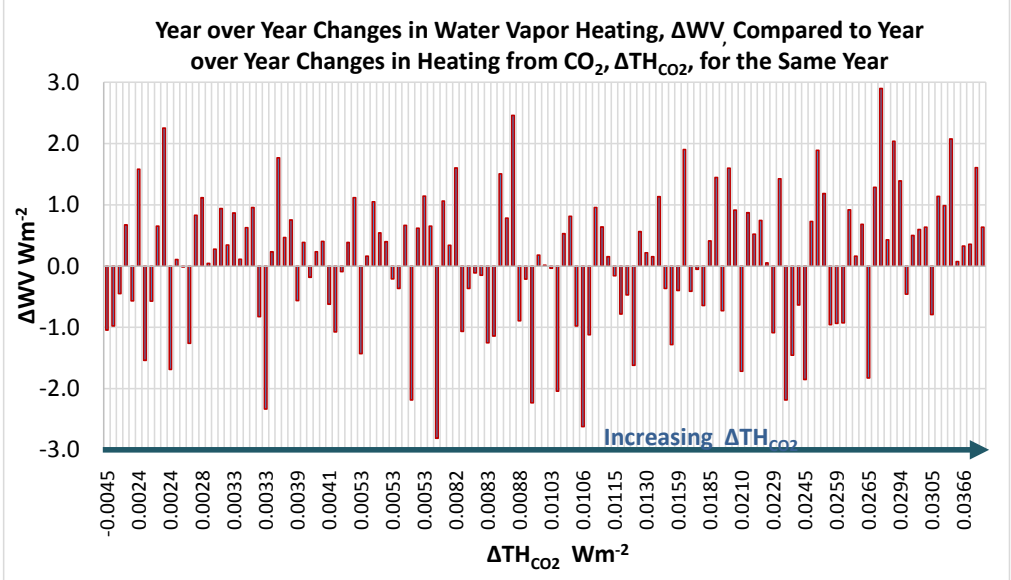

Figure 7. Year over year changes in water vapor heating, $\Delta \mathrm{WV}$, compared to year over year changes in heating from $\mathrm{CO}_{2}, \Delta \mathrm{TH}_{\mathrm{CO} 2}$, for the same year (Table S3). 
The assertion is made that water vapor heating is a feedback response to changes in heating from $\mathrm{CO}_{2}$ and provides the change in heating necessary to drive such feedback responses and resulting changes in temperature.

A not atypical observation when it comes to global warming is:

"Taken on its own, water vapour feedback roughly doubles the amount of $\mathrm{CO}_{2}$ warming" [12].

Doubling would hardly compensate for the need to increase $\mathrm{CO}_{2}$ heating by a multiple of 25 in one case or by a multiple of 425 in another, as required in the examples discussed above.

Given that changes in $\mathrm{TH}_{\mathrm{CO} 2}$, alone, can theoretically account for no more than $15 \%$ of global warming between 1976 and 2019, the claim is made that the difference is made up by water vapor heating as a feedback response to changes in $\Delta \mathrm{TH}_{\mathrm{CO} 2}$.

Common misperceptions:

- Increases in $\mathrm{CO}_{2}$ increase heating increase water vapor, a greenhouse gas which amplifies warming.

- Without an independent increase in heating, the concentration of water vapor cannot increase.

- And after comments such as “... rising average temperature increases evaporation rates and atmospheric water vapor concentrations," a common follow on is something to the effect that, since, "Water vapor cannot itself catalyze temperature increases in the short time (estimated at around 10 days) that a discrete water vapor influx would remain before precipitating out. A sustained increase in tropospheric water vapor requires a strong external forcing to provide the initial temperature increase [13]."

This ignores the fact, that, when the average precipitative rate is less than the average evaporative rate, the concentration of water vapor, TPW, is increased and, therefore, water vapor heating, WV.

This does not require any increase in heating from $\Delta \mathrm{TH}_{\mathrm{CO} 2}$, much less " $\mathrm{a}$ strong external forcing". (See discussion with respect to Figure 15).

These comments may stem from the belief that an increase in TPW requires a corresponding increase in evaporation.

That is not correct.

After 1976, the average annual increase of TPW over the 1976 concentration of water vapor of $18.67 \mathrm{~kg} \cdot \mathrm{m}^{-2}$ was $0.05 \mathrm{~kg} \cdot \mathrm{m}^{-2} / \mathrm{yr}$. or $0.29 \%$. From Equation (5), the resulting annual increase in average global temperature,

$$
\begin{gathered}
\Delta T_{\text {Avg }}=0.4 \Delta \mathrm{TPW}^{\circ} \mathrm{C} \\
\Delta T_{\text {Avg }}=0.4 \times 0.05=0.02^{\circ} \mathrm{C} / \mathrm{yr} .
\end{gathered}
$$

over 43 years for a total of:

$$
\Delta T_{\text {AvgToT }}=43 \times 0.02=0.86^{\circ} \mathrm{C}=\text { the actual average change of } 0.86^{\circ} \mathrm{C}
$$

Further proof of the validity of these water vapor concentration and water vapor heating calculations and the impact on climate change. 
After 1976, there was a continuing slight imbalance between average precipitation and evaporation, with annual precipitation of $0.06 \mathrm{~mm} \cdot \mathrm{m}^{-2} / \mathrm{yr}$. < evaporation. For an annual average precipitation of $949 \mathrm{~mm} \cdot \mathrm{m}^{-2}$, this is $0.007 \%$ of average annual precipitation. If this were all due to an increase in cumulative evaporation, this would at most require a $0.007 \%$ increase in annual evaporation over precipitation.

However, if it were thought that in order to achieve the average annual increase of TPW over the 1976 concentration of water of $0.33 \%$ it would require evaporation to increase by $0.33 \% / y r$, that would be

$$
0.0033 \times 949=3.13 \mathrm{~mm} \cdot \mathrm{m}^{-2} \text { or } \mathrm{kg} \cdot \mathrm{m}^{-2}
$$

Then the resulting increase in temperature would be an annual increase of $1.15^{\circ} \mathrm{C}$

$$
\Delta T_{\text {Avg }}=0.4 \times 3.13=1.25^{\circ} \mathrm{C}
$$

compared to actual annual increase of $0.021^{\circ} \mathrm{C} / \mathrm{yr}$., as determined above, or

$$
1.25 / 0.021=60
$$

60 times greater or over the entire 43 year period, this would be an increase of $47^{\circ} \mathrm{C}$. Clearly any such assumption would be incorrect.

This author appears to seek to downplay the role of water vapor with statements like, "the amount held in the atmosphere as water vapour varies greatly in just hours and days as result of the prevailing weather in any location. So even though water vapour is the greatest greenhouse gas, it is relatively short-lived" [12]. This ignores the fact that, just since 1988, "Satellites have observed an increase in atmospheric water vapour by about $0.41 \mathrm{~kg} / \mathrm{m}^{2}$ per decade since 1988 " [14].

The fact that there is a changeover is irrelevant. It is the average global concentration of water vapor that is important and that changes gradually. The global TPW average in 2019 was $21.4 \mathrm{~kg} \cdot \mathrm{m}^{-2}$ (Table S2).

Further, if changes in water vapor heating were a function of changes in $\mathrm{TH}_{\mathrm{CO} 2}$, a change in radiative heating from $\mathrm{CO}_{2}$ should cause a predictable change in water vapor heating and therefore temperature change, such as,

$$
\Delta T_{\mathrm{Avg}}=\lambda \Delta \mathrm{TH}_{\mathrm{CO} 2}
$$

where $\lambda$ is a constant.

In the above case, for 1913-1914 and 1909 and 1944, would require that $\lambda=425$ in one case and 25 in another. This formulation is clearly incorrect.

Water Vapor Heating is Unaffected by the Theoretical Changes in Heating from $\mathrm{CO}_{2}$

To test just this basic concept, for the same year, the year over year theoretical changes in $\Delta \mathrm{TH}_{\mathrm{CO} 2}$ and changes in total water vapor heating, $\Delta \mathrm{WV}$, determined by Equation (2) are compared in Figure 7, with increasing $\Delta \mathrm{TH}_{\mathrm{CO} 2}$ plotted from left to right on the horizontal axis. This is set out in Table S3.

If year over year changes in water vapor heating, $\Delta \mathrm{WV}$ were a feedback re- 
sponse to year over year increases in $\Delta \mathrm{TH}_{\mathrm{CO} 2}$, the plot should show a growing increase in year over year changes in water vapor heating, $\Delta \mathrm{WV}$, as $\Delta \mathrm{TH}_{\mathrm{CO} 2}$ increases.

There is no such correlation. For virtually the same year over year change in $\mathrm{CO}_{2}$ heating, the change in water vapor heating can be quite different. For example, for a theoretical YoY change from 0.002402 to $0.002405 \mathrm{Wm}^{-2}$ (both $0.002 \mathrm{Wm}^{-2}$ ) in $\mathrm{CO}_{2}$ heating, the YoY change in water vapor heating, $\Delta \mathrm{WV}$, varied from a reduction of $-1.54 \mathrm{Wm}^{-2}$ to an increase of $2.25 \mathrm{Wm}^{-2}$ and for a theoretical YoY change from 0.00879 to $00.00883 \mathrm{Wm}^{-2} \mathrm{YoY}$ in $\mathrm{CO}_{2}$ heating, (both $0.009 \mathrm{Wm}^{-2}$ ) the YoY change in water vapor heating, $\Delta \mathrm{WV}$, varied from an increase of 2.46 to a reduction of $-2.23 \mathrm{Wm}^{-2}$.

While, except for the period 1900-2003, the theoretical heating from $\mathrm{CO}_{2}$ increased year over year, year over year water vapor heating declined, $40 \%$ of the time. This is set out in Table S3.

A superficial examination of these changes clearly shows that there is no correlation between the theoretical changes in heating from $\mathrm{CO}_{2}$ and changes in water vapor heating. This is random. The same is true if percentage changes in year over year average global temperatures, $\Delta T_{\mathrm{Avg}}$ are plotted against year over year percentage changes in the concentration of $\mathrm{CO}_{2}$ for the same year. See Table S3. These changes and changes in $\Delta \mathrm{WV}$, are not driven, triggered or caused by, or a feedback response to, changes in $\Delta \mathrm{TH}_{\mathrm{CO} 2}$. They are autonomous, wholly unrelated.

This also means that if the formula,

$$
\Delta T_{\mathrm{Avg}}=\lambda \Delta \mathrm{TH}_{\mathrm{CO} 2}
$$

were correct, $\Delta T_{\mathrm{Avg}}$ could be negative only during years 1900-1903, when the concentration of $\mathrm{CO}_{2}$ declined slightly. That is not the case. Except for years 1900-1903, for the other 53 reductions in water vapor heating, there are no reductions in heating from $\mathrm{CO}_{2}$.

The changes in the concentration of water vapor and water vapor heating determined by these new principles are shown to be wholly independent of and not feedback to changes in $\mathrm{CO}_{2}$ heating.

\section{Changes in Average Global Temperature}

As noted above, the theoretical direct heating effect, $\Delta \mathrm{TH}_{\mathrm{CO} 2}$, from changes in the concentration, $C$, of $\mathrm{CO}_{2}$, alone, is [8],

$$
\Delta \mathrm{TH}_{\mathrm{CO} 2}=5.35 \ln \left(C / C_{o}\right)
$$

Including this factor along with the contributions from water vapor heating, the expression for determining changes in the average global temperature $\Delta T_{\text {Avg, }}$, would be,

$$
\Delta T_{\text {Avg }}=0.096\left(5.35 \ln \left(C / C_{o}\right)+\Delta \mathrm{WV}_{\text {Tot }}\right){ }^{\circ} \mathrm{C}
$$

where $C$ is the concentration of $\mathrm{CO}_{2}$.

From NOAA data [1] [2], the results of the application of Equation (3) are shown in Figure 8. 


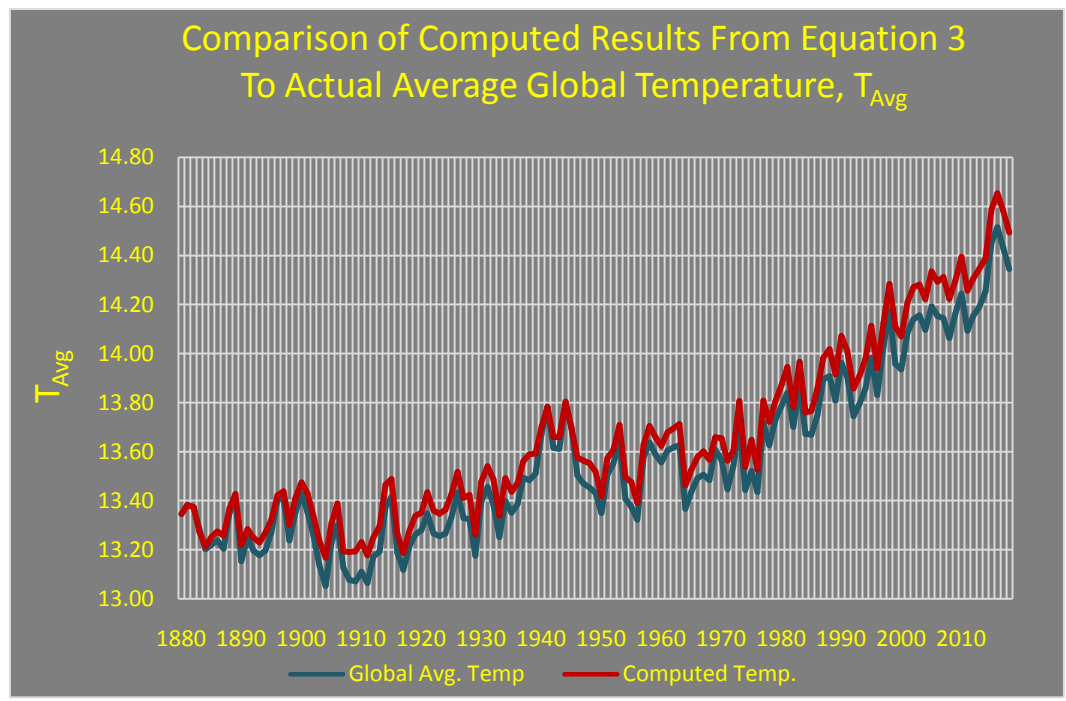

Figure 8. Comparison between calculated changes in the average global temperature applying Equation (3) and the record [1] [2] [3] (Table S4).

Between 1880 and 2019, the theoretical increase in heating from the increase in $\mathrm{CO}_{2}$ was $1.8 \mathrm{Wm}^{-2}$; from Equation (2) for water vapor, it was $11.3 \mathrm{Wm}^{-2}$.

Compared to the record, the results set out in Figure 8 are, on average, far more accurate than published models, within $0.64 \%$.

Percentage temperature accuracy is measured as the absolute value of the actual average global temperature less the computed average global temperature, which result is divided by the Actual Average Global Temperature measured in Celsius.

$$
\left|\left(T_{\text {Avg }}-T_{\text {AvgComp }}\right)\right| / T_{\text {Avg }}
$$

Average temperature accuracy is the average of the values for each determination.

While, with $0.64 \%$ accuracy, this is far more accurate than any published models and clearly illustrates the impact of changes in the concentration of water vapor, the calculated temperatures exceed actual $97 \%$ of the time and by as much a $0.16^{\circ} \mathrm{C}, 14 \%$ of the total increase between 1880 and 2019 . Therefore, this formulation does not comply with Kirchhoff's law of thermal radiation and the First Law of Thermodynamics, thus, Equation (3) is incorrect.

Water Vapor Heating

While the $\mathrm{CO}_{2}$ heating component of Equation (3)

$$
\Delta \mathrm{TH}_{\mathrm{CO} 2}=5.35 \ln \left(C / C_{o}\right)
$$

is consistent with the literature, it is based on the assumption that the absorption of the IR radiation from Earth's surface by $\mathrm{CO}_{2}$ occurs without significant interference from the other GHG.

Analyzing the results of the application of Equation (3), it becomes apparent that the increase over actual primarily results from the inclusion of $\mathrm{CO}_{2}$ heating. 
When the $\mathrm{CO}_{2}$ dependent function is removed from Equation (3), it becomes,

$$
\Delta T_{\text {Avg }}=0.096 \times 73.3 \ln \left(1+\Delta \mathrm{TPW}_{\text {Tot }} / \mathrm{TPW}_{\text {Toto }}\right){ }^{\circ} \mathrm{C}
$$

The results are set out in Figure 9.

Excluding $\mathrm{CO}_{2}$, the results from the application of Equation (4) are mathematically more accurate, within $0.27 \%$ on average. This clearly shows the calculated effect from water vapor heating, alone.

However, while excluding the effects of $\mathrm{CO}_{2}$, Equation (4) still overstates the temperature increase in violation of Kirchoff's law and the first law of thermodynamics. 114 out of 139 or $82 \%$ are higher than actual, some as great as $0.1^{\circ} \mathrm{C}$, Therefore, Equation (4) is also not advanced as correct.

Why?

The Effects of Relative Emissivity and Overlapping Absorption Bands

The theoretical GHG back radiation in 2002 was $333 \mathrm{Wm}^{-2}$ with $301 \mathrm{Wm}^{-2}$ and $32 \mathrm{Wm}^{-2}$, from $\mathrm{H}_{2} \mathrm{O}$ and $\mathrm{CO}_{2}$, respectively, a difference of a factor of 10 and between 2002 and 2019, the theoretical heating from $\mathrm{CO}_{2}$ increased by $0.5 \mathrm{Wm}^{-2}$ and water vapor by $3.4 \mathrm{Wm}^{-2}$, the latter the equal to the total increase in back radiation. See Table S3.

Figure 10 shows that there is significant absorption band overlap between the absorption wave lengths for $\mathrm{CO}_{2}$ and water vapor.

The overlapping wave lengths at which water vapor and $\mathrm{CO}_{2}$ absorb surface radiation are dominated by water vapor. This suggests that water vapor can interfere with IR absorption by $\mathrm{CO}_{2}$.

This is consistent with a finding by Evans [15] comparing three summer measurement of GHG heating to winter measurements in Peterborough, Ontario: "The $\mathrm{H}_{2} \mathrm{O}$ flux has increased from about $100 \mathrm{~W} / \mathrm{m}^{2}$ to $200 \mathrm{~W} / \mathrm{m}^{2}$. $\mathrm{CO}_{2}$ is reduced from $33 \mathrm{~W} / \mathrm{m}^{2}$ to $11 \mathrm{~W} / \mathrm{m}^{2 "}$ p. 4 and Soares [16] who found no correlation between current changes in the concentration of $\mathrm{CO}_{2}$ and changes in surface temperature, but a correlation of 0.5 with changes in specific humidity. Reviewing various data for periods prior to 2010, the author states:

"The main conclusion one arrives at the analysis is that $\mathrm{CO}_{2}$ has not a causal relation with global warming and it is not powerful enough to cause the historical changes in temperature that were observed ... The greenhouse effect of the $\mathrm{CO}_{2}$ is very small compared to the water vapor because the absorbing effect is already realized with its historical values. So, the reduction of the outcoming long wave radiation window is not a consequence of current $\left[\mathrm{CO}_{2}\right]$ enrichment ..." [16] (p. 111).

Possible explanations:

- In $2009 \mathrm{CO}_{2}$ was at a concentration of 387 ppm and water vapor, on average, 2662 ppmv, which is consistent with the total precipitable water for 2009 of $20.56 \mathrm{~kg} \cdot \mathrm{m}^{-2} \sim 7$ times greater than $\mathrm{CO}_{2}$. (The authors [17] use 10,200 ppm-water vapor at an average of $1 \%$. If this were correct, these results would be increased by a factor of 3.8). 


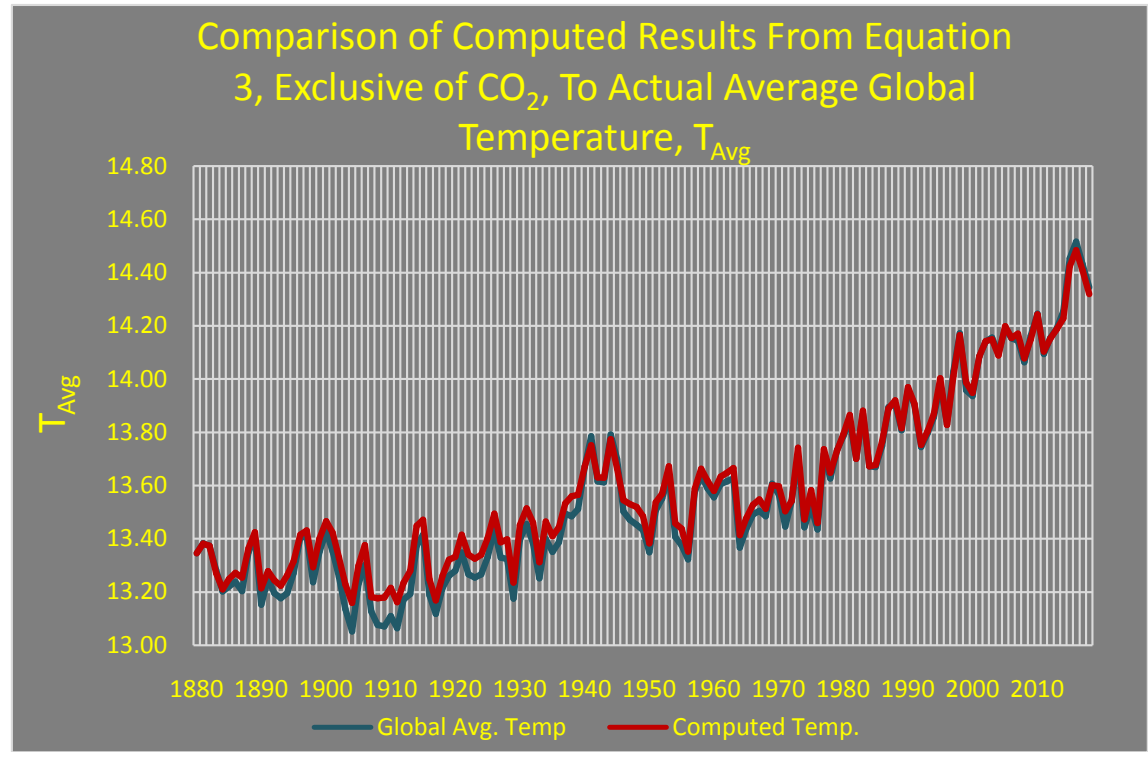

Figure 9. Results of the application of Equation (3) eliminating changes in heating from $\mathrm{CO}_{2}$, as a factor [1] [2] [3] (Table S4).

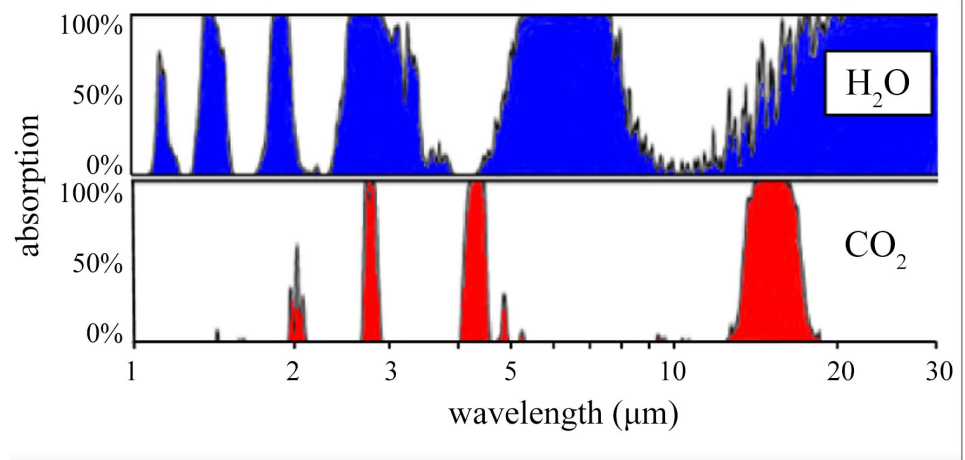

Figure 10. Atmospheric absorption spectra for water vapor and $\mathrm{CO}_{2}[18]$ (Figure 3).

- Imagine a stream of photons emitted from Earth's surface at an absorption wavelength common to both $\mathrm{CO}_{2}$ and $\mathrm{H}_{2} \mathrm{O}$ approaching an atmosphere containing 2662 ppmv water molecules and 387 ppmv molecules of $\mathrm{CO}_{2}$, all on the same plane. It would appear that the odds of that photon interacting with a molecule of $\mathrm{CO}_{2}$ would be $387 / 2662$ or $14 \%$.

- However, with each water vapor molecule 43 times more efficient in absorbing and emitting energy, the odds would be reduced to $14 \% / 43$ or $0.3 \%$. See [17] (p. 351, Figure 4), where the authors state: "Another important point is how fast reradiation occurs. The faster the gas molecule emits the stored energy, the sooner it is ready to accept a new portion of electromagnetic radiation, and so the more effective this greenhouse gas is. Thus, in determining the effectiveness of a greenhouse gas, it is important to know not only the absorbed energy but also the rate of transfer of electromagnetic radiation", which the authors gauge as its "efficiency". 
- See [17] (p. 351, Figure 3(a)). This shows that the emissivity (therefore the absorptivity) of an $\mathrm{H}_{2} \mathrm{O}$ molecule is 60 times greater than a $\mathrm{CO}_{2}$ molecule, on a molecule to molecule comparison. Thus, the odds of a water molecule interacting with a photon are 60 times greater than an interaction with a molecule of $\mathrm{CO}_{2}$.

- Finally note that, "The average frequency of emission for $\mathrm{CO}_{2}$ is 1.6 times lower than that of the other considered gases. Therefore, the energy efficiency of the resulting $\mathrm{CO}_{2}$ emission, proportional to $\omega$, is almost five times lower than that of the other gases." See [17] (p. 349, Figure 2).

- Thus, assuming no effects of altitude, the relative likelihood that effects of changes in the concentration of $\mathrm{CO}_{2}$ would be felt at the surface would be reduced to less than $0.01 \%$, well within the error band of Equation (5). Hence, in 2009, in accordance with the Equation (5), the heating effect of changes in the concentration of water vapor should have effectively accounted for the average changes in heating.

Regardless of whether these explanations are correct or account for the entire difference between water vapor and $\mathrm{CO}_{2}$ heating, what is clear from Equation (5), changes in the concentration of water vapor, alone, control global warming.

There Is a Strong Correlation between Changes in $\Delta T_{\mathrm{Avg}}$ and Changes in Concentration of Water Vapor, $\triangle \mathrm{TPW}$

While there is no correlation between changes in the concentration of $\mathrm{CO}_{2}$ and the actual changes in the average global temperature or in changes in $\mathrm{TH}_{\mathrm{CO} 2}$ and changes in water vapor heating, as shown in Figure 4, there is a clear correlation between changes in the average global temperature from temperature records commencing in 1880 [3] and calculated changes in the concentration of water vapor from Equation (1). See Figure 11.

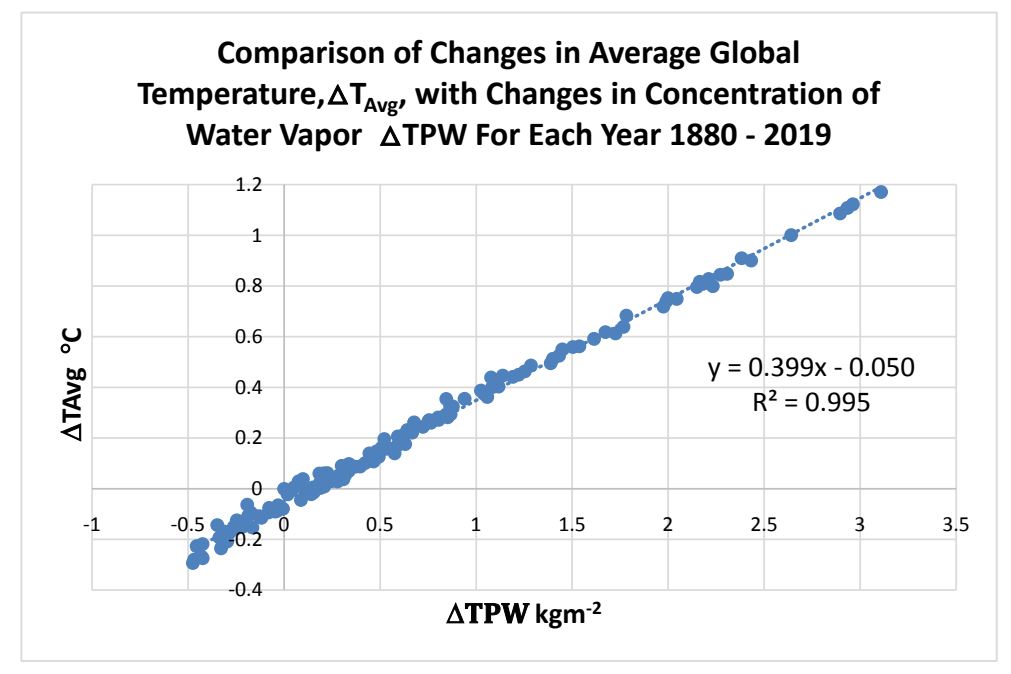

Figure 11. Correlation of changes in average global temperature with changes in concentration of water vapor [1] [2] [3] (Table S2 Appendix 2, Supplementary Materials). 
This relationship is:

$$
\Delta T_{\text {Avg }}=0.4 \Delta \mathrm{TPW}-0.05^{\circ} \mathrm{C}
$$

with an $R^{2}$ of 0.9953 .

This correlation is exclusive of heating from $\mathrm{CO}_{2}$.

The results of employing this relationship to determine the average global temperature is shown in Figure 12.

While the theoretical heating by $\mathrm{CO}_{2}$ is also removed in Equation (4), Equation (5) is based upon a comparison to the actual temperature record.

The results from the application of Equation (5) have a correlation coefficient of 0.9976 , exceeding the average global temperature $68 \%$ of the time, but never by more by more than $0.05^{\circ} \mathrm{C}$, which is itself well within the error band of average global temperature estimates for the period in which this occurred, 1904-1910 [19].

Equation (5) captures the relationship between changes in the concentration of water vapor and the average global temperature-demonstrating the mechanism driving climate change and at an average accuracy of $\pm 0.14 \%$, validating the physics set out herein. It is, therefore, is advanced as The Principle of Climate Physics accounting for climate change, which along with the foregoing, demonstrates that:

1) Changes in the concentration of water vapor, not $\mathrm{CO}_{2}$, drive climate change;

2) Equation (1) is a valid principle of climate physics;

3) Changes in the concentration of water vapor are sufficient, in and of themselves, to drive all of the changes in heating;

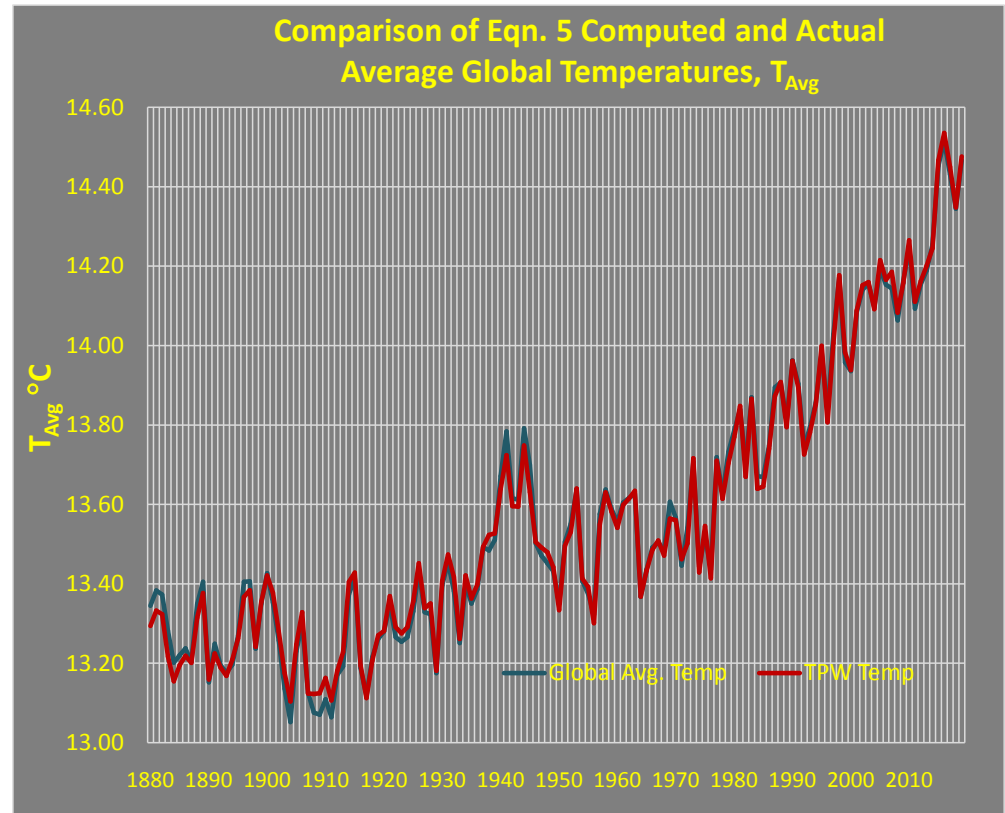

Figure 12. Comparison of the results of the application of the new principles, Equations (1) \& (5), in red, to the average global temperature record, in blue, for the period 1880-2019 [1] [2] [3] (Table S4). 
4) These changes in water vapor heating and concentration, together with changes in the relative rates of evaporation and precipitation, are sufficient to autonomously and independently drive climate change independently of any other climate factors, in a positive feedback loop, as discussed below.

\section{This is Why I Care}

\section{Water Vapor is The Key Factor}

In 1977 was the year of the largest single year increase in the concentration of water vapor since $1880,0.76 \mathrm{~kg} \cdot \mathrm{m}^{-2}$ or $4 \%$, which was the start of a major and continuing increase. Before that, the concentration of water vapor increased at a rate of $0.002 \mathrm{~kg} \cdot \mathrm{m}^{-2}$ per year and after 1977 at a rate of $0.06 \mathrm{~kg} \cdot \mathrm{m}^{-2}$ per year, corresponding to an increase of $3.3 \%$ per decade.

The average global temperature increased at a rate $\sim 25$ times greater than the prior 96 year period.

While there is variation and the rate of precipitation for some years exceeded the evaporative rate, since 1977 , on average, the increase in the rate of precipitation was less than the average increase in the rate of evaporation. Thus, the precipitation/evaporation imbalance that arose in 1977 was, on average, maintained as global warming commenced in earnest.

A simple linear regression:

$$
\Delta T_{\text {Avg }} / \text { decade }=0.2^{\circ} \mathrm{C} / \text { decade }
$$

matches these results with an $R^{2}$ of 0.85 . This rate of increase is 4.3 times greater than the rate of increase for the period 1880-1975.

Set out in Figure 13 is a chart of year over year percentage changes in global average temperature, $\Delta T_{\mathrm{Avg}}$, since 1976 , shown in blue. Shown in red is a curve fit to this data:

$$
\begin{aligned}
\Delta T_{\text {AvgN }}= & \{0.245+0.02(\mathrm{Yr}-1976)+0.11 \sin [1.8(\mathrm{Yr}-1976)]\} / T_{\mathrm{Avg} 1976} \\
& -0.0257-\Delta T_{\mathrm{AvgN}-1}
\end{aligned}
$$

\section{Changes in Average Global Temperature from 1976}

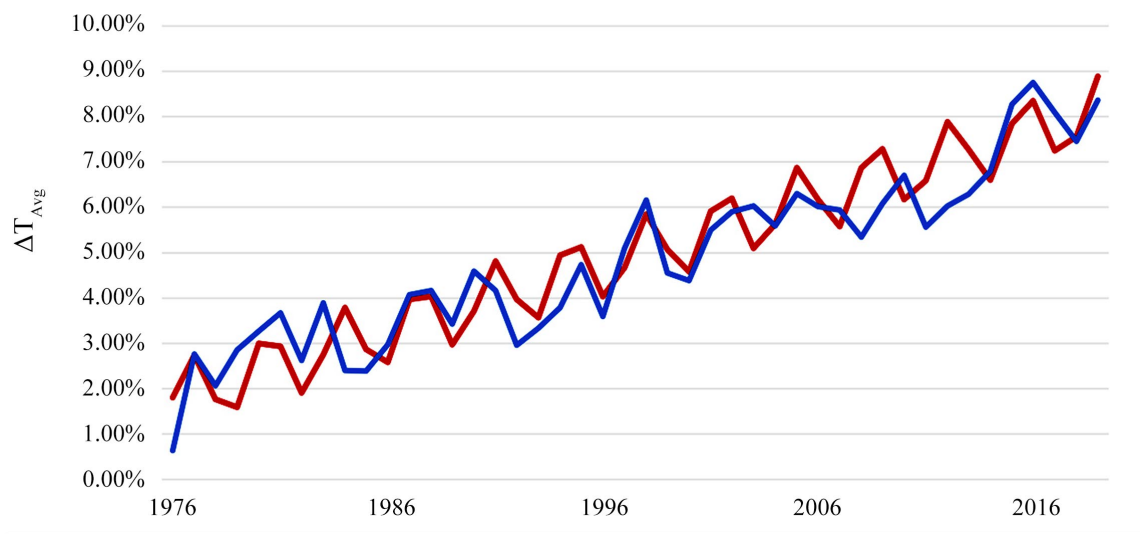

Figure 13. Change in average global temperature 1976-2019 [1] [2] [3] (Table S1). 
This expression has a correlation coefficient of 0.925 . This would predict an increase of an additional $1.4^{\circ} \mathrm{C}$, by the end of the century, $0.2^{\circ} \mathrm{C}$ less than the linear regression set out in Figure 14.

From Figure 4, Figure 11, Figure 14, this chart and this expression, it is evident that this increase in average global temperature $\Delta T_{\mathrm{Avg}}$ is ongoing and the result of the change in average global water vapor concentration, in a roughly 3.5 year, autonomous, positive feedback cycle with changes in the concentration of water vapor, $\triangle \mathrm{TPW}$.

As shown in Figure 15, evaporation and water vapor heating are in an autonomous, positive feedback loop. As the concentration of water vapor increases, water vapor heating and evaporation increase.

"The trends of TPW in our data set, which are heavily biased toward middle latitudes ... are higher than previous global estimates over earlier time periods by about a factor of 4 to 6 . As also shown by the regional distribution of TPW trends ..., the large positive trends in these latitudes, ... are a strong confirmation of the water vapor-temperature feedback in a warming global atmosphere ..." [20].

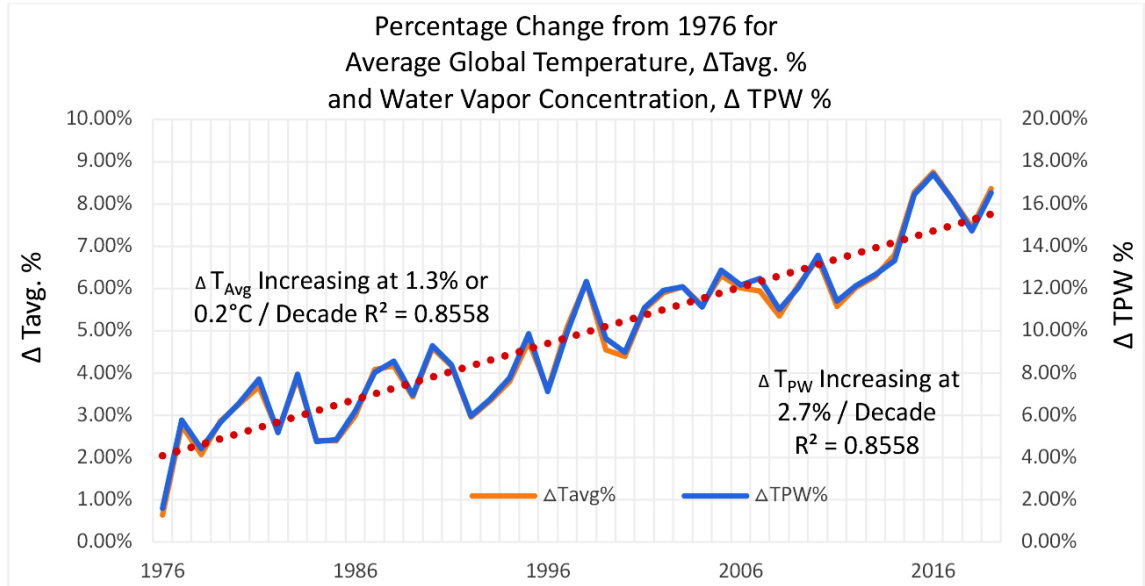

Figure 14. Changes in average global temperature and the concentration of water vapor between 1976 and 2019 [1] [2] [3] (Table S2).

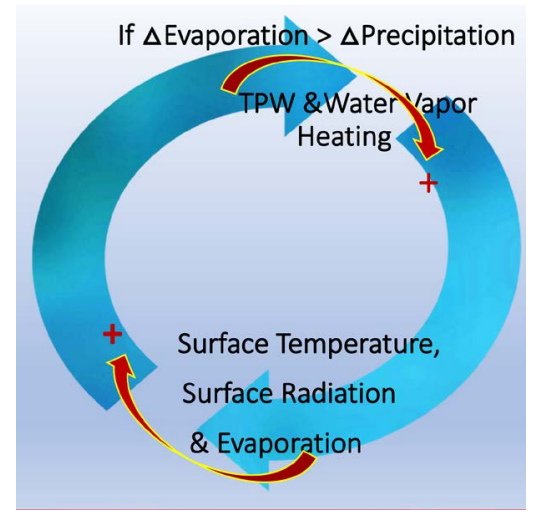

Figure 15. Self-sustaining increase in heating. 
If the rate of evaporation exceeds precipitation, the concentration of water vapor increases; on and on. The heating from water vapor drives a rate of evaporation sufficient to maintain this totally autonomous cycle.

A characteristic of positive feedback loops is that, absent external intervention, they continue. Therefore, to the extent evaporation exceeds precipitation, this continues. The result-every 50 years there will be a $1^{\circ} \mathrm{C}$ increase driven by changes in the concentration of water vapor.

Limiting or reducing carbon emissions can have no effect.

\section{Discussion}

\section{Temperature Responses of Land and Seas}

In addition to determining changes in the concentration of water vapor without regard to changes in the concentration of $\mathrm{CO}_{2}$, these new principles take into consideration the significant differences in the temperature response of the seas compared to land for the same changes in total heating resulting from their differences in evaporative responses.

See Figure 16 and Table 2 \& Table 3, which show that the average global temperature of land and ocean change at different rates in response to the same changes in total heating.

A major factor driving this difference is the response of the seas to changes in total heating, with $64 \%$ of the change in total heating of the seas driving evaporation, while for land $8 \%$ is lost to evaporation and $18 \%$ to thermal convection in the response to changes in total heating. See Table 2 and Table S3. This explains the comparative lag that is evident in Figure 16. Therefore, when determining changes in water vapor concentration, the effect of changes in total heating on evaporation, in addition to changes in sea surface temperature, SST, must be taken into account.

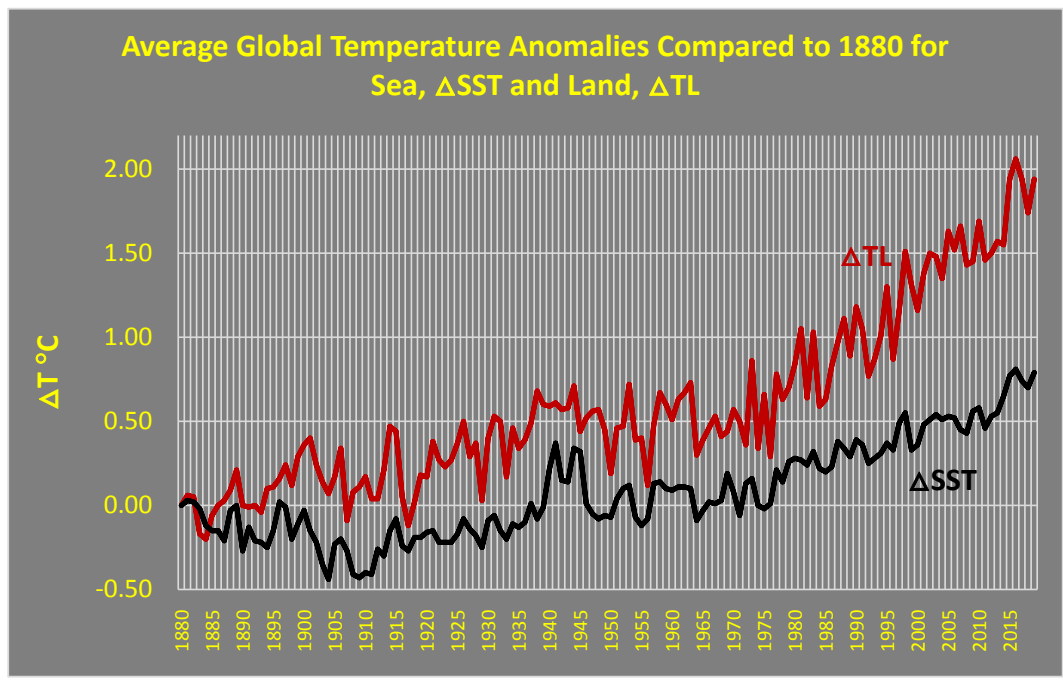

Figure 16. Global surface annual mean temperature anomalies 1880-2019 [1] [2] [3] (Table S1). 
As shown in Figure 2, on average and at steady state temperatures, evaporation and convection together reduce the total heating, $\mathrm{TH}$, of $494 \mathrm{Wm}^{-2}$ by 97 $\mathrm{Wm}^{-2}$ or $20 \%$, a significant fraction. The average net absorbed heating fraction, $\mathrm{NaH}$, that drives the surface heating, is, therefore, $80 \%$ of $\mathrm{TH}$, which for steady state temperature is denominated as the average steady state heating efficiency,

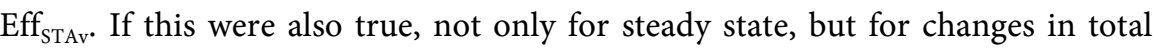
heating, the change in total heating between 1880 and 2019 required to drive the change in average global temperature could be gauged solely on the basis of the change in average global temperature. This would mean that the change in total heating required to drive the $1^{\circ} \mathrm{C}$ increase in average global temperature between 1880 and 2019, would be:

Table 2. Global average land, ocean and average steady state heating budgets for 1880 , 1976 and $2002\left(\mathrm{Wm}^{-2}\right)$.

\begin{tabular}{|c|c|c|c|}
\hline Year & 1880 & 1976 & 2002 \\
\hline Total Heating (TH) & 485 & 486 & 494 \\
\hline Radiant Emittance $\operatorname{Rad}_{\mathrm{UL}}$ & 389 & 390 & 396 \\
\hline Solar Radiation (Sol) & 161 & 161 & 161 \\
\hline Back-Radiation (BR) & 324 & 325 & 333 \\
\hline Evaporative Power $\left(\right.$ Evap $\left._{\text {Avg }}\right)$ & 78 & 78 & 80 \\
\hline Thermal Convection $\left(\right.$ Conv $\left._{\text {Avg }}\right)$ & 18 & 18 & 18 \\
\hline $\mathrm{Eff}_{\text {Avg }}$ Steady State & 0.80 & 0.80 & 0.80 \\
\hline \multicolumn{4}{|c|}{ Land Heating Budget } \\
\hline Year & 1880 & 1976 & 2002 \\
\hline Total Heating (TH) & 485 & 486 & 494 \\
\hline Radiant Emittance $\operatorname{Rad}_{\mathrm{UL}}$ & 354 & 356 & 362 \\
\hline Solar Radiation (Sol) & 161 & 161 & 161 \\
\hline Back-Radiation (BR) & 324 & 325 & 333 \\
\hline Evaporative Power $\left(\right.$ Evap $\left._{L}\right)$ & 41 & 41 & 42 \\
\hline Thermal Convection $\left(\operatorname{Conv}_{\mathrm{L}}\right)$ & 89 & 89 & 91 \\
\hline Eff $_{\mathrm{L}}$ Steady State & 0.73 & 0.73 & 0.73 \\
\hline \multicolumn{4}{|c|}{ Ocean Heating Budget } \\
\hline Year & 1880 & 1976 & 2002 \\
\hline Total Heating (TH) & 485 & 486 & 494 \\
\hline Radiant Emittance $\operatorname{Rad}_{\mathrm{UO}}$ & 394 & 394 & 397 \\
\hline Solar Radiation (Sol) & 161 & 161 & 161 \\
\hline Back-Radiation (BR) & 324 & 325 & 333 \\
\hline Evaporative Power (Evapo) & 89 & 91 & 96 \\
\hline Thermal Convection $\left(\right.$ Conv $\left._{0}\right)$ & 2 & 2 & 2 \\
\hline Eff $_{\mathrm{O}}$ Steady State & 0.81 & 0.81 & 0.80 \\
\hline
\end{tabular}


Table 3. Breakdown of the increase in the heating $\left(\mathrm{Wm}^{-2}\right)$ required for an increase in the global average land and global average ocean temperature between 1880-2002 and 1976-2002.

\begin{tabular}{|c|c|c|}
\hline Global Average & $1976-2002$ & $1880-2002$ \\
\hline Increase in the average global temperature $\left({ }^{\circ} \mathrm{C}\right)$ & 0.7 & 0.8 \\
\hline $\begin{array}{l}\text { Increase in total heating, } \Delta \mathrm{TH} \text { required for this increase in } \\
\text { temperature } \mathrm{Wm}^{-2}\end{array}$ & 7.7 & 9.4 \\
\hline Increase in radiant emittance $\left(\Delta \mathrm{Rad}_{\mathrm{UAvg}}\right) \mathrm{Wm}^{-2}$ & 5.6 & 7.2 \\
\hline Change in solar radiation $(\Delta \mathrm{Sol}) \mathrm{Wm}^{-2}$ & 0.0 & 0.0 \\
\hline Increase in back radiation $(\Delta \mathrm{BR}) \mathrm{Wm}^{-2}$ & 7.7 & 9.4 \\
\hline Increase in evaporative power $\left(\Delta\right.$ Evap $\left._{\text {Avg }}\right) \mathrm{Wm}^{-2}$ & 1.8 & 1.6 \\
\hline Change in thermal convective power $\left(\Delta\right.$ Conv $\left._{\mathrm{Avg}}\right) \mathrm{Wm}^{-2}$ & 0.4 & 0.5 \\
\hline Eff $_{\triangle T H T o t A v}$ & 0.73 & 0.77 \\
\hline Land & $1976-2002$ & $1880-2002$ \\
\hline Increase in the average global land temperature $\left({ }^{\circ} \mathrm{C}\right)$ & 1.2 & 1.5 \\
\hline $\begin{array}{l}\text { Increase in total heating, } \Delta \mathrm{TH} \text { required for this increase in } \\
\text { land temperature } \mathrm{Wm}^{-2}\end{array}$ & 7.7 & 9.40 \\
\hline Increase in radiant emittance $\left(\Delta \mathrm{Rad}_{\mathrm{UL}}\right) \mathrm{Wm}^{-2}$ & 6.2 & 7.5 \\
\hline Change in solar radiation $(\Delta \mathrm{Sol}) \mathrm{Wm}^{-2}$ & 0.0 & 0.0 \\
\hline Increase in back radiation $(\Delta \mathrm{BR}) \mathrm{Wm}^{-2}$ & 7.7 & 9.4 \\
\hline Increase in evaporative power $\left(\Delta \operatorname{Evap}_{L}\right) \mathrm{Wm}^{-2}$ & 0.0 & 0.0 \\
\hline Change in thermal convective power $\left(\Delta \operatorname{Conv}_{\mathrm{L}}\right) \mathrm{Wm}^{-2}$ & 1.5 & 1.9 \\
\hline Eff $_{\Delta \text { THTotL }}$ & 0.80 & 0.80 \\
\hline Ocean & $1976-2002$ & $1880-2002$ \\
\hline Increase in the average global ocean temperature $\left({ }^{\circ} \mathrm{C}\right)$ & 0.5 & 0.5 \\
\hline $\begin{array}{l}\text { Increase in total heating, } \Delta \mathrm{TH} \text { required for this increase in } \\
\text { ocean temperature } \mathrm{Wm}^{-2}\end{array}$ & 7.7 & 9.4 \\
\hline Increase in radiant emittance $\left(\Delta \mathrm{Rad}_{\mathrm{UO}}\right) \mathrm{Wm}^{-2}$ & 2.7 & 2.8 \\
\hline Change in solar radiation $(\Delta \mathrm{Sol}) \mathrm{Wm}^{-2}$ & 0.5 & 0.0 \\
\hline Increase in back radiation $(\Delta \mathrm{BR}) \mathrm{Wm}^{-2}$ & 7.7 & 9.4 \\
\hline Increase in evaporative power $\left(\Delta\right.$ Evap $\left._{\mathrm{o}}\right) \mathrm{Wm}^{-2}$ & 5.0 & 6.6 \\
\hline Change in thermal convective power $\left(\Delta \operatorname{Conv}_{0}\right) \mathrm{Wm}^{-2}$ & 0.0 & 0.0 \\
\hline Eff $_{\Delta \text { THTotO }}$ & 0.36 & 0.30 \\
\hline
\end{tabular}

$$
\begin{gathered}
\Delta \mathrm{TH}=\sigma\left(T_{\text {Avg2019 }}^{4}-T_{\text {Avg1880 }}^{4}\right) / \mathrm{Eff}_{\mathrm{STAv}}=5.67 \times 10^{-8}\left(289.46^{4}-286.67^{4}\right) / 0.8 \\
\Delta \mathrm{TH}=5.4 \mathrm{~W} \cdot \mathrm{m}^{-2}
\end{gathered}
$$

where, $T$ is the global average absolute temperature, $\mathrm{K}$.

However, over the same time period, the increase in average global land tem- 
perature was $1.94^{\circ} \mathrm{C}$. Referring to Table $2 \&$ Table 3, the percentage reduction in heating for evaporation and thermal convection losses for land in response to changes in heating is $20 \%$. Thus,

$$
\begin{gathered}
\Delta \mathrm{TH}=\sigma\left(T_{\mathrm{L} 2019}^{4}-T_{\mathrm{L} 1880}^{4}\right) / \mathrm{Eff}_{\mathrm{S} \Delta \mathrm{THL}}=5.67 \times 10^{-8}\left(283.08^{4}-281.14^{4}\right) / 0.8 \\
\Delta \mathrm{TH}=12.35 \mathrm{~W} \cdot \mathrm{m}^{-2}
\end{gathered}
$$

Therefore, the total heating required to drive the $1.1^{\circ} \mathrm{C}$ increase in average global temperature change is $12.35 \mathrm{Wm}^{-2}$, not $5.4 \mathrm{Wm}^{-2}$.

If there were no change in heating efficiency in response to changes in total heating, for the seas, using solely the change in ocean temperature, the required change in total heating to drive the $0.7^{\circ} \mathrm{C}$ increase over this period, would be calculated as $4.3 \mathrm{Wm}^{-2}$, but the average total heating is the same, $12.35 \mathrm{Wm}^{-2}$.

Since 1976, changes in total heating, $\Delta \mathrm{TH}$, have been the primary driver of evaporation. The resulting increase in water vapor, $\triangle \mathrm{TPW} \mathrm{WTH}_{\Delta \mathrm{T}}$ and water vapor heating, $\Delta \mathrm{WV}_{\Delta \mathrm{TH}}$, is the most significant change in heating, responsible, on average, for $\sim 60 \%$ of water vapor heating.

Global Efficiency Budgets

Estimates of Earth's global average energy budget broken out for the seas and land for 1880, 1976 and 2002 are set out in Table 2. 1976 is chosen because this was the inflection point in global warming.

This is based on changes in average global temperature and average global land and sea temperatures from Table S1 and the data set out in Figure 2, for the global annual mean Earth's energy budget for the March 2000 to May 2004 period, setting 2002 as the year to which this is applied.

These are the Bases for the construction of Table 1 and Table 2.

1) Radiant Emittance, $\operatorname{Rad}_{\mathrm{UL}}$ : For 2002 , and land temperature of $282.6 \mathrm{~K}$, the radiant emittance or surface radiation of land, $\operatorname{Rad}_{\mathrm{UL}}$, was,

$$
\operatorname{Rad}_{\mathrm{UL} 2002}=\sigma T_{\mathrm{L} 2002}^{4}=\sigma 282.6^{4}=362 \mathrm{~W} \cdot \mathrm{m}^{-2}
$$

Similarly, for 2002, and ocean temperature of $289.2 \mathrm{~K}$, the global average radiant emittance of the seas, $\operatorname{Rad}_{\mathrm{UO}}$, was

$$
\operatorname{Rad}_{\mathrm{UO} 2002}=\sigma T_{\mathrm{O} 2002}^{4}=\sigma 289.2^{4}=397 \mathrm{~W} \cdot \mathrm{m}^{-2}
$$

The radiant emittance for 1880 and 1976 for each surface is the radiant emittance so determined for 2002 multiplied by the ratio of the respective surface temperatures raised for each year raised to the fourth power. Thus, for land,

$$
\operatorname{Rad}_{\mathrm{ULN}}=\operatorname{Rad}_{2002 \mathrm{~L}}\left(T_{\mathrm{LN}} / T_{\mathrm{L} 2002}\right)^{4}
$$

2) Steady State Efficiency Factor, Eff: The steady state efficiency factor, Eff $_{\text {LSst }}$ for land for 2002 can then be determined as:

$$
\begin{gathered}
\operatorname{Eff}_{\mathrm{LSst} 2002}=\operatorname{Rad}_{\mathrm{UL} 2002} / \mathrm{TH}_{2002} \\
\operatorname{Eff}_{\mathrm{LSst} 2002}=362 / 494=0.73
\end{gathered}
$$

For the seas: 


$$
\begin{gathered}
\operatorname{Eff}_{\mathrm{OSt} 2002}=\operatorname{Rad}_{\mathrm{UO2002}} / \mathrm{TH}_{2002} \\
\operatorname{Eff}_{\mathrm{OSst} 2002}=397 / 494=0.8
\end{gathered}
$$

3) Evaporation: For 2002, $85 \%$ of global evaporation is assumed to come

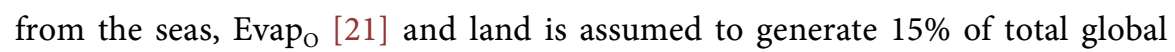
evaporation. For the other years for land this is held constant and for the seas, it is calculated as,

$$
\operatorname{Evap}_{\mathrm{O}}=\mathrm{TH}_{\mathrm{O}}-\operatorname{Rad}_{\mathrm{O}}-\mathrm{Conv}_{\mathrm{O}}
$$

4) Convection: For 2002,

$$
\operatorname{Conv}_{2002}=\mathrm{TH}_{2002}-\operatorname{Rad}_{\mathrm{U} 2002}-\operatorname{Evap}_{2002}
$$

for the other years,

$$
\operatorname{Conv}_{\mathrm{N}}=\operatorname{Conv}_{2002} \operatorname{Rad}_{\mathrm{UN}} / \operatorname{Rad}_{\mathrm{U} 2002}
$$

5) Total Heating, TH: The total heating in 2002 was $494 \mathrm{Wm}^{-2}$. For and for each year it is calculated as,

$$
\mathrm{TH}=\operatorname{Rad}_{\mathrm{UL}}+\operatorname{Evap}_{\mathrm{L}}+\operatorname{Conv}_{\mathrm{L}}
$$

6) Back Radiation: Solar heating is assumed to be effectively constant, therefore, the change in back radiation is equal to the change in total heating.

7) Efficiency Factor for the change in Total Heating Land: The efficiency factor for the change in total heating, $\mathrm{Eff}_{\Delta \mathrm{THL}}$ from Table 3 is then, the change in radiant emittance, $\Delta \operatorname{Rad}_{\mathrm{U}}$ divided by the change in total heating, $\Delta \mathrm{TH}$. So,

Between 2002 and 1976, for land

$$
\operatorname{Eff}_{\Delta \mathrm{THL}}=\Delta \mathrm{Rad}_{\mathrm{UL}} / \Delta \mathrm{TH}=6.2 / 7.7=0.8
$$

Between 2002 and 1880,

$$
\mathrm{Eff}_{\Delta \mathrm{THL}}=\Delta \mathrm{Rad}_{\mathrm{UL}} / \Delta \mathrm{TH}=7.5 / 9.4=0.8
$$

8) Efficiency Factor for the change in Total Heating Seas: Averaging the annual changes in the efficiency factor for changes in heating for the sea, $\mathrm{Eff}_{\Delta \mathrm{THO}}$,

$$
\Delta \operatorname{Rad}_{\mathrm{UO}} / \Delta \mathrm{TH}
$$

for the period 1880-2019, as shown in Table 3,

$$
\operatorname{Eff}_{\Delta \mathrm{THL}}=0.36
$$

See discussion of Figure 16 which shows that the temperatures of land and sea increase at different rates while subjected to the same changes in heating. In terms of increasing surface temperature, this is far less efficient for the sea, because

"The specific heat of dry land is roughly a factor of four-and-a-half less than that of sea water (for moist land the factor is probably closer to two). Moreover, heat penetration into land is limited and only the top 2 metres or so typically play an active role (as a depth for most of the variations on annual time-scales, say). Accordingly, land plays a much smaller role in the storage of heat ..." [22] (p. 2688).

Moreover, taking into account the depth of sea water playing a role, for short 
wave solar heating, it is necessary to raise the temperature of a greater mass, all of which means that for the same temperature increase as land, the seas require more heat energy and more heat energy is lost to evaporative phase change than would result from simply maintaining the same surface temperature.

Further, heating water by long wave IR radiation is inherently inefficient. While shortwave radiation can transfer energy meters under the surface of the seas, longwave radiation penetrates less than a millimeter [23] and from 1976, essentially the entire increase in heating came from longwave radiation. Evaporation from this thin layer increases in response to an increase in heating. The increase in evaporation reduces surface temperature below what it would otherwise be and results in an increase in the rate of subsurface waters coming to the surface than, at steady state, which takes time to heat, as evaporation continues. These combine to require greater heating power to raise surface temperatures than land.

\section{Results}

This methodology:

1) Proves that:

a) It is an imbalance between average evaporation and precipitation rates in which evaporation exceeds precipitation that drives increases in the concentration of water vapor, water vapor heating, evaporation and on and on as long as this average imbalance continues;

b) Changes in heating driven by changes in the concentration of water vapor are wholly independent of, and not a feedback response to, the changes in heating from $\mathrm{CO}_{2}$.

2) Takes into account changes in heating from changes in the concentration of water vapor, driven by:

a) Sea surface temperature, SST;

b) The evaporative response of the seas to changes in heating.

3) Demonstrates that the recent upsurge in average global temperature was driven by increases in the concentration of water vapor.

4) Demonstrates, that compared to steady state, increases in total heating are the primary drivers of evaporation.

5) Shows that, after 1976, the increase in average global temperature was and is driven in a positive feedback loop and so, will likely, continue.

6) Is validated by the determinations of average global temperatures, going back to 1880 , which, from the application of Equations (1) \& (4) are shown to be a function of changes in the concentration of water vapor,

$$
\Delta T_{\text {Avg }}=0.4 \Delta \mathrm{TPW}-0.045^{\circ} \mathrm{C}
$$

with a $R^{2}$ of 0.9959 (See Figure 11) and an average accuracy of $\pm 0.14 \%$.

\section{The Future}

Since 1976, there has been a marked rate of increase in global temperature. A simple linear regression: 


$$
\Delta T_{\text {Avg }} / \text { decade }=0.2^{\circ} \mathrm{C} / \text { decade }
$$

matches these results with an $R^{2}$ of 0.85 . This rate of increase is 4.3 times greater than the rate of increase for the period 1880-1975.

As noted, this is not driven by the buildup of $\mathrm{CO}_{2}$ or from a resultant water feedback effect.

\section{Relative Changes in Precipitation}

In 1977 there was the largest single year increase in the concentration of water vapor since $1880,1.09 \mathrm{~kg} \cdot \mathrm{m}^{-2}$ or $5.7 \%$, which was the start of a major and continuing increase. Before that, the concentration of water vapor increased at a rate of $0.002 \mathrm{~kg} \cdot \mathrm{m}^{-2}$ per year and after 1977 at a rate of $0.05 \mathrm{~kg} \cdot \mathrm{m}^{-2}$ per year, which corresponded to an increase of $4 \%$ per decade.

While there is variation and the rate of precipitation for some years exceeded the evaporative rate, since 1977 , on average, the increase in the rate of precipitation was less than the average increase in the rate of evaporation. Thus, the precipitation/evaporation imbalance that arose in 1977 was, on average, maintained as global warming commenced in earnest. The average global temperature increased at a rate $\sim 25$ times greater than the prior 96 year period. The result is illustrated in Figure 1.

Referring to Equations (3) \& (5) and Figure 4, there can be no doubt that changes in the concentration of water vapor drive changes in water vapor heating and therefore, in average global temperature. The correlation coefficient between changes in water vapor concentration and average global temperature is 0.993. Changes in water vapor heating drive changes in evaporation. To the extent that the average evaporative rate exceeds the average rate of precipitation, the concentration of water vapor will increase. There is no drag on the system. This a classic positive feedback loop, which means that, absent some external intervention, as long as this imbalance continues, global warming will increase. See Figure 15.

As noted above, after 1976, there was a continuing slight imbalance between average precipitation and evaporation, with average annual evaporation exceeding annual precipitation of $0.06 \mathrm{~mm} \cdot \mathrm{m}^{-2} / \mathrm{yr}$. This slight imbalance is the forcing function driving the post 1976 increase in average global temperature stemming from the average rate of evaporation exceeding the average rate of precipitation and, possibly, a periodic insufficiency in the atmospheric density of cloud condensing nuclei, $\mathrm{CCN}$, over certain parts of the globe as air pollution was reduced and precipitation increased, precipitating out more $\mathrm{CCN}$.

\section{Conclusions}

\section{In Sum}

Climate change is a function of changes in the concentration of water vapor. The results from the application of Equation (1) to determine changes in the concentration of water vapor closely tracks the recent record of changes in in the concentration of water vapor and Equations (5) \& (7) to determine changes in 
the average global temperature, track, almost exactly, changes in the average global temperature.

The climate reached a tipping point in 1977 when the concentration of water vapor jumped by $4 \%$, the greatest short-term increase. Thereafter, the rate of increase in evaporation on average, continued to exceed the rate of increase in precipitation.

Unfortunately, as noted above, the physics are self-perpetuating. Until such time as there is an increase in cloud condensing nuclei sufficient in critical regions to ensure that average precipitation continually equals or exceeds evaporation, the buildup in atmospheric water vapor will continue, increasing atmospheric heating, which increases evaporation and so on. As noted above, this is a positive feedback loop.

The good news is that the solution is at least mathematically simple. If average annual global precipitation can be increased by $3 \mathrm{~mm} \cdot \mathrm{m}^{-2}(0.3 \%$ of average annual precipitation of $949 \mathrm{~mm} / \mathrm{yr}$.) over evaporation and thereafter maintained in equivalence with the evaporative rate, global warming can be halted and if precipitation can be increased further relative to evaporation, reversed. (A similar $5.5 \%$ water vapor driven increase in average global temperature which commenced in 1904 and concluded 41 years later in 1945 after a 9.24\% increase in the concentration of water vapor was followed by 6 years of decline in the concentration of water vapor and average global temperature. This occurred without anthropogenic intervention).

Meanwhile there is a real urgency in coming to understand this problem and developing and implementing efficient and environmentally sound means of increasing precipitation, because, until then, the problem will only get worse.

As long as the ratio of average annual precipitation/evaporation $<1$, for the reasons set out above, this is likely to continue. Thus, by 2100 , the increase could be another $1.5^{\circ} \mathrm{C}$, which would be a very serious and ongoing concern to our grandchildren.

There is also the possibility that the rate of evaporation compared to precipitation will increase further which would make the problem even worse.

There is no certainty, this must be viewed as an existential threat to those populations most at risk to rising sea levels.

However, if the atmospheric density of CCN can be increased to the point that average annual precipitation can again equal or exceed average annual evaporation, global warming can not only be halted, it can be reversed. There can, at least in theory, be an immediate resolution.

Therefore, the goal should be a permanent $13 \%$ or $2.7 \mathrm{~kg} \cdot \mathrm{m}^{-2}, 2.7 \mathrm{~mm} \cdot \mathrm{m}^{-2}$, or $0.3 \%$ of average annual precipitation of $949 \mathrm{~mm} / \mathrm{yr}$., global reduction in TPW, which means reducing TPW slightly below the concentration level in 1976, before global warming accelerated, which should be achieved gradually.

If maintained, this would bring the increase in average global total heating since $1880, \Delta \mathrm{TH}$, to $\sim 2.41 \mathrm{Wm}^{-2}$, the increase in average global total heating by 1975 , and bring the average global temperature to the average global tempera- 
ture for that year, $14^{\circ} \mathrm{C}$.

It is important to recognize that and these numbers are averages. In terms of a solution to the effects of average increases in the concentration of water vapor, increased precipitation; the design, therefore, should not only be environmentally sound, efficient and minimize the risk of flooding, but comprise varied solutions, tailored to seasonal changes and the areas most affected by climate change, because, unlike other constituents of the atmosphere, water vapor is not well mixed. It is concentrated in the tropics, decreases with distance from the equator, differs between the seas and land and is affected by changes in topography and seasons. For this reason, changes in heating from changes in the concentration of water vapor are geographically and seasonally, quite disparate. It would not be surprising to find areas in which the evaporation/precipitation differences are orders of magnitude higher. Therefore, a total global response may not be required. However, it will take time to develop and implement practical and sensible solutions.

An immediate and intense focus on finding environmentally safe, effective and efficient mechanisms of increasing CCN sufficient to increase precipitation and reduce TPW could pay massive benefits and efforts to effect this are required. While changes in the concentration of $\mathrm{CO}_{2}$ have no effect on the changes in the concentration of water vapor, even if one incorrectly believed $\mathrm{CO}_{2}$ somehow affected the changes in the concentration of water vapor, increasing precipitation would nonetheless reduce TPW and therefore, heating.

That water vapor is the driver is totally at odds with the current "wisdom" so there is no focus on this as an issue. It is an understatement to say that these physics and conclusions will be controversial. However, the resolution of this problem cannot await a consensus that the solutions currently posited have failed, which given the vested interests and strongly held beliefs, is very, very unlikely in the near term and will take years to realize.

There is no need for a consensus. These physics comply with the laws of thermodynamics and are not assumption or probability based. They are straightforward mathematical formulations shown to be accurate calculations of annual global averages. There is no downside to finding efficient and environmentally friendly means of effecting and experimenting with increasing precipitation in those regions most at risk and no conflict with efforts aimed at reducing $\mathrm{CO}_{2}$, levels, at the same time.

To minimize delay what is required is leadership from academics from topflight institutions with the requisite expertise to affirm what is set out herein. When this is accepted, it will take time to design and implement solutions as the average global temperature continues to increase.

Meanwhile, the existential threat of continuing global warming is not being addressed and will likely continue to grow at the rate of $0.2^{\circ} \mathrm{C}$ per decade until effective intervention is undertaken. Time is truly of the essence. This is why I care. 


\section{Conflicts of Interest}

The author declares no conflicts of interest regarding the publication of this paper.

\section{References}

[1] NOAA National Centers for Environmental Information: Land Data, Climate at a Glance: Global Time Series. https://www.ncdc.noaa.gov/cag/time-series

[2] NOAA National Centers for Environmental Information: Ocean Data, Climate at a Glance: Global Time Series. https://www.ncdc.noaa.gov/cag/time-series

[3] GISTEMP Team (2019) GISS Surface Temperature Analysis (GISTEMP), Version 4. NASA Goddard Institute for Space Studies. https://data.giss.nasa.gov/gistemp

[4] Trenberth, K.E., Fasullo, J.T. and Kiehl, J. (2009) Earth's Global Energy Budget. Bulletin of the American Meteorological Society, 90, 311-324. https://doi.org/10.1175/2008BAMS2634.1

[5] 2018 Trends in Atmospheric Carbon Dioxide National Oceanic and Atmospheric Administration Earth System Research Laboratory Global Monitoring Division. https://www.esrl.noaa.gov/gmd/ccgg/trends/

[6] Earth Policy Institute. Climate, Energy, and Transportation: Atmospheric Carbon Dioxide Concentration 1000-2014. http://www.earth-policy.org/data_center/C23

[7] Lewandowsky, S., Cowtan, K., Risbey, J.S., Mann, M.E., Steinman, B.A., Oreskes, N. and Rahmstorf, S. (2018) The "Pause" in Global Warming in Historical Context: (II). Comparing Models to Observations. Environmental Research Letters, 13, Article ID: 123007. https://doi.org/10.1088/1748-9326/aaf372

[8] Myhre, G., Highwood, E.J., Shine, K.P. and Stordal, F. (1998) New Estimates of Radiative Forcing Due to Well Mixed Greenhouse Gases. Geophysical Research Letters, 25, 2715-2718. https://doi.org/10.1029/98GL01908

[9] Santer, B.D., et al. (2007) Identification of Human-Induced Changes in Atmospheric Moisture Content. Proceedings of the National Academy of Sciences of the United States of America, 104, 15248-15253. https://doi.org/10.1073/pnas.0702872104

[10] Liang, J. (2013) Climate Change. In: Chemical Modeling for Air Resources. Fundamentals, Applications, and Corroborative Analysis, Academic Press, Cambridge, 143-161. https://doi.org/10.1016/B978-0-12-408135-2.00007-0

[11] Mieruch, S., Noel, S., Bovensmann, H. and Burrows, J.P. (2008) Analysis of Global Water Vapour Trends from Satellite Measurements in the Visible Spectral Range. Atmospheric Chemistry and Physics, 8, 491-504. https://doi.org/10.5194/acp-8-491-2008

[12] Frank, J. (2015) Explaining How the Water Vapor Greenhouse Effect Works. Skeptical Science. https://skepticalscience.com/water-vapor-greenhouse-gas-intermediate.htm

[13] Hausfather, Z. (2008) The Water Vapor Feedback. Analysis, Yale Climate Connections.

https://www.yaleclimateconnections.org/2008/02/common-climate-misconceptions -the-water-vapor-feedback-2

[14] Cook, J. (2015) Explaining How the Water Vapor Greenhouse Effect Works Skeptical Science. https://skepticalscience.com/print.php? $\mathrm{r}=44$

[15] Evans, W.F. and Puckrin, E. (2006) Measurements of the Radiative Surface Forcing of Climate. 18th Conference on Climate Variability and Change, 30 January 2006. 
[16] Soares, P.C. (2010) Warming Power of $\mathrm{CO}_{2}$ and $\mathrm{H}_{2} \mathrm{O}$ : Correlations with Temperature Changes. International Journal of Geosciences, 1, 102-112. https://doi.org/10.4236/ijg.2010.13014

[17] Galashev, A.E. and Rakhmanova, O.R. (2013) Emissivity of the Main Greenhouse Gases. Russian Journal of Physical Chemistry B, 7, 346-353. https://doi.org/10.1134/S1990793113030020

[18] Anderson, T.R., Hawkins, E. and Jones, P.D. (2016) $\mathrm{CO}_{2}$, the Greenhouse Effect and Global Warming: from the Pioneering Work of Arrhenius and Callendar to Today's Earth System Models. Endeavour, 40, 178-187. https://doi.org/10.1016/j.endeavour.2016.07.002

[19] Cowtan, K., Jacobs, P., Thorne, P. and Wilkinson, R. (2018) Statistical Analysis of Coverage Error in Simple Global Temperature Estimators. Dynamics and Statistics of the Climate System, 3, dzy003. https://doi.org/10.1093/climsys/dzy003

[20] Ho, S., et al. (2018) Comparison of Global Observations and Trends of Total Precipitable Water Derived from Microwave Radiometers and COSMIC Radio Occultation from 2006 to 2013. Atmospheric Chemistry and Physics, 18, 259-274. https://doi.org/10.5194/acp-18-259-2018

[21] Ocean in the Global Water Cycle. https://www.ametsoc.org/ams/index.cfm/education-careers/education-program/un dergraduate-faculty/ocean-studies/course-components/investigations-manual/ocean-man ual-01b

[22] Trenberth, K.E. and Stepaniak, D.P. (2004) The Flow of Energy through the Earth's Climate System. Quarterly Journal of the Royal Meteorological Society, 130, 2677-2701. https://doi.org/10.1256/qj.04.83

[23] Wong, E.W. and Minnett, P.J. (2018) The Response of the Ocean Thermal Skin Layer to Variations in Incident Infrared Radiation. Journal of Geophysical Research: Oceans, 123, 2475-2493. https://doi.org/10.1002/2017JC013351

[24] Luciuk, M. (2013) Temperature and Radiation. http://www.asterism.org/tutorials/tut40RadiationTutorial.pdf

[25] Smith, T.M. and Arkin, P.A. (2015) Improved Historical Analysis of Oceanic Total Precipitable Water. Journal of Climate, 28, 3099-3121. https://doi.org/10.1175/JCLI-D-14-00601.1

[26] Finlayson-Pitts, B.J. and Pitts Jr., J.N. (2000) Global Tropospheric Chemistry and Climate Change. In: Chemistry of the Upper and Lower Atmosphere, Elsevier, Amsterdam, 762-843.

https://www.sciencedirect.com/topics/earth-and-planetary-sciences/infrared-absorp tion/pdf

[27] ACCRI Theme 7: Metrics for Comparison of Climate Impacts from Well Mixed Greenhouse Gases and Inhomogeneous Forcing Such as Those from UT/LS Ozone, Contrails and Contrail-Cirrus.

https://www.faa.gov/about/office_org/headquarters_offices/apl/research/science_int egrated_modeling/accri/media/ACCRI_SSWP_VII_Forster.pdf

[28] Schmidt, G.A. Observed Land Surface Precipitation Data: 1901-2000 (CRU TS 2.0). Goddard Institute for Space Studies, New York. https://data.giss.nasa.gov/precip_cru

[29] Babkin, V.I. (2002) Hydrological Cycle Vol. II, Evaporation from the Surface of the Globe. In: Encyclopedia of Life Support Systems, State Hydrological Institute, St. Petersburg. http://www.eolss.net/sample-chapters/c07/e2-02-03-02.pdf 
[30] Blunden, J. and Arndt, D.S. (2016) Precipitation Worldwide, 1901-2015. EPA's Climate Change Indicators in the United States.

http://www.epa.gov/climate-indicators 


\section{Appendix 1: Derivation of Formulations and Definition of Terms}

\section{Nomenclature}

Conv-heating flux that drives thermal convection, $\mathrm{Wm}^{-2}$.

$\Delta \mathrm{T}$-change in temperature, ${ }^{\circ} \mathrm{C}$.

Eff-heating efficiency - the fraction of total heating remaining after the deduction of evaporative and convective losses,

$$
\text { Eff }=1-(\text { Evap }+ \text { Conv }) / \mathrm{TH} .
$$

Evap-heating flux absorbed by evaporation, $\mathrm{Wm}^{-2}$.

GHG-Green House Gases.

IR-Infrared Radiation.

$\mathrm{NaH}-$ net absorbed heating flux, that fraction of total radiative heating remaining, after deducting the power driving evaporation and convection, $\mathrm{Wm}^{-2}$

$$
\mathrm{NaH}=\mathrm{TH}-\text { Evap }- \text { Conv }=\text { Eff } \cdot \mathrm{TH} .
$$

OLR—Outgoing Longwave Radiation.

Power-heating flux per square meter, $\mathrm{Wm}^{-2}$.

ppmv-parts per million, volume.

$\operatorname{Rad}_{\mathrm{U}}$-Radiant Emittance, $\mathrm{Wm}^{-2}$.

$\Delta \mathrm{TH}_{\mathrm{CO} 2}$ - Back-radiation flux solely from $\mathrm{CO}_{2}, \mathrm{Wm}^{-2}$.

$\sigma$-Stefan-Boltzmann constant, $5.67 \times 10^{-8} \mathrm{Wm}^{-2} \cdot \mathrm{K}^{-4}$.

Sol-Heating flux from solar radiation, $\mathrm{Wm}^{-2}$.

SST-Sea Surface Temperature.

$T$-absolute temperature, $\mathrm{K}$.

$\mathrm{TH}$-total radiative heating flux, including $\mathrm{WV}, \mathrm{Wm}^{-2}$.

$\mathrm{WV}-$ total heating flux from water vapor feedback effect, $\mathrm{Wm}^{-2}$.

Subscripts

Avg_global average.

$\mathrm{CO}_{2}$-indicates a factor driven solely by $\mathrm{CO}_{2}$.

L-land.

$\mathrm{N}-$ new.

o-original or initial.

$\mathrm{O}$-ocean.

Tot-total.

U-up.

WV—-water vapor.

\section{Derivations}

Total Heating

1) Changes in Total Heating

Total heating, $\mathrm{TH}$, is the sum of solar and back radiation absorbed by the surface.

2) The net absorbed heating for land, $\mathrm{NaH}_{\mathrm{L}}$ is total heating less the heating driving evaporation and thermal convection, $\operatorname{Evap}_{\mathrm{L}}$ and $\operatorname{Conv}_{\mathrm{L}}$. 


$$
\mathrm{NaH}_{\mathrm{L}}=\mathrm{TH}-\mathrm{Evap}_{\mathrm{L}}-\mathrm{Conv}_{\mathrm{L}}
$$

The heating efficiency of the land surface, $\mathrm{Eff}_{\mathrm{L}}$, is the ratio of the net absorbed heating $\mathrm{NaH}_{\mathrm{L}}$ to total heating, $\mathrm{TH}$,

$$
\mathrm{Eff}_{\mathrm{L}}=\mathrm{NaH}_{\mathrm{L}} / \mathrm{TH}
$$

Thus,

$$
\mathrm{NaH}_{\mathrm{L}}=\mathrm{Eff}_{\mathrm{L}} \mathrm{TH}
$$

As discussed above and shown in Table 2, the efficiency factor for land at steady state, Eff $_{\text {LSS, }}$

$$
\text { Eff }_{\text {LSS }}=0.73
$$

Since in accordance with Kirchhoff's law of thermal radiation and the First Law of Thermodynamics, the surface radiation, $\operatorname{Rad}_{U}$ from the surface cannot exceed the net heating absorbed by the surface,

$$
\Delta \operatorname{Rad}_{\mathrm{UL}} \ngtr \Delta \mathrm{NaH}_{\mathrm{UL}}
$$

it is assumed that the surface temperature is at equilibrium, the maximum surface temperature, therefore:

$$
\Delta \operatorname{Rad}_{\mathrm{UL}}=\Delta \mathrm{NaH}_{\mathrm{UL}}
$$

The efficiency of a change in heating for land, $\mathrm{Eff}_{\Delta \mathrm{THL}}$, is

$$
\mathrm{Eff}_{\Delta \mathrm{THL}}=\Delta \mathrm{Rad}_{\mathrm{UL}} / \Delta \mathrm{TH}
$$

thus, changes in total heating, $\Delta \mathrm{TH}$, can be gauged from changes in surface radiation

$$
\Delta \mathrm{TH}=\left(\operatorname{Rad}_{\mathrm{ULN}}-\operatorname{Rad}_{\mathrm{ULo}}\right) / \mathrm{Eff}_{\Delta \mathrm{THL}}
$$

Since the change for surface radiation, $\Delta \mathrm{Rad}_{\mathrm{UL}}$, as a function of changes in land temperature, is,

$$
\Delta \operatorname{Rad}_{\mathrm{UL}}=\sigma\left(T_{\mathrm{LN}}^{4}-T_{\mathrm{Lo}}^{4}\right)
$$

Therefore, changes in total heating can be gauged from changes in the surface temperature of land,

$$
\Delta \mathrm{TH}=\sigma\left(T_{\mathrm{LN}}^{4}-T_{\mathrm{Lo}}^{4}\right) / \mathrm{Eff}_{\Delta \mathrm{THL}}
$$

As discussed above and shown in Table 3, the efficiency of a change in heating for land, Eff $_{\Delta \mathrm{THL}}$,

$$
\mathrm{Eff}_{\Delta \mathrm{THL}}=0.8
$$

Thus,

$$
\Delta \mathrm{TH}=\sigma\left(T_{\mathrm{LN}}^{4}-T_{\mathrm{Lo}}^{4}\right) / 0.8
$$

This is different for the seas. At steady state, from Table 2,

$$
\mathrm{Eff}_{\text {OSS }}=0.8
$$

However, in response to changes in heating, taking the average of the efficiency factor for change of heating for the seas over the 1880-2019 period Eff $_{\Delta \mathrm{THO}}$ is 0.36. See Table S3. 


\section{3) Land Heating}

The determination of the maximum temperature response (which is the temperature calculated throughout) of the land surface to changes in heating is determined as the temperature at which the average surface radiation matches the average total heating less the power absorbed by evaporation and thermal convection, as shown in Figure 1. This is defined as the surface temperature limit or STL and the temperature utilized in these calculations.

The surface radiation from land, $\operatorname{Rad}_{\mathrm{UL}}$, is [24]

$$
\operatorname{Rad}_{\mathrm{UL}}=\sigma T_{\mathrm{L}}^{4}
$$

with

$$
\sigma=5.67 \times 10^{-8} \mathrm{~W}^{-1} \cdot \mathrm{m}^{2} \cdot \mathrm{K}^{-4}
$$

Since

$$
T_{\mathrm{LN}}=T_{\mathrm{Lo}}+\Delta T_{\mathrm{L}}
$$

then,

$$
\Delta \operatorname{Rad}_{\mathrm{UL}}=\sigma\left[\left(T_{\mathrm{Lo}}+\Delta T_{\mathrm{L}}\right)^{4}-T_{\mathrm{Lo}}^{4}\right] \mathrm{W} \cdot \mathrm{m}^{-2}
$$

where: $T_{\mathrm{Lo}}$ is the initial average global land temperature, and,

$\Delta T_{\mathrm{L}}$ is the change in average global land temperature,

Solving for $\Delta T_{\mathrm{L}}$

Therefore, the increase in surface temperature, $\Delta T_{\mathrm{L}}$, cannot exceed, and the average surface temperature limit increase for land (STL), is:

$$
\Delta T_{\text {STLL }}=\left(T_{\mathrm{Lo}}^{4}+\Delta \mathrm{NaH}_{\mathrm{L}} / \sigma\right)^{1 / 4}-T_{\mathrm{Lo}}{ }^{\circ} \mathrm{C}
$$

For land temperature in 1880 of $281.2 \mathrm{~K}$, the change in surface temperature limit, $\Delta T_{\text {STLL }}$ for land is:

$$
\begin{gathered}
\Delta T_{\text {STLL }}=\left(T_{\text {Lo }}^{4}+\Delta \mathrm{NaH}_{\mathrm{L}} / \sigma\right)^{1 / 4}-T_{\mathrm{Lo}} \\
\Delta T_{\mathrm{STLL}}=\left(281.2^{4}+\Delta \mathrm{NaH}_{\mathrm{L}} / 5.67 \times 10^{-8}\right)^{1 / 4}-281.2 \\
\Delta T_{\mathrm{STLL}}=\left(6.34 \times 10^{9}+\Delta \mathrm{NaH}_{\mathrm{L}} / 5.67 \times 10^{-8}\right)^{1 / 4}-281.2
\end{gathered}
$$

Since, the efficiency factor for land with respect to changes in total heating, $\mathrm{Eff}_{\triangle \mathrm{THL}}$ from Table 3, is 0.8, then

$$
\begin{gathered}
\Delta \mathrm{NaH}_{\mathrm{L}}=\operatorname{Eff}_{\Delta \mathrm{THL}} \Delta \mathrm{TH}=0.8 \Delta \mathrm{TH} \\
\Delta T_{\mathrm{STLL}}=\left(6.34 \times 10^{9}+0.73 \Delta \mathrm{TH} / 5.67 \times 10^{-8}\right)^{1 / 4}-281.2
\end{gathered}
$$

Another approach-taking the first derivative, the change for surface radiation, $\Delta \operatorname{Rad}_{\mathrm{UL}}$, as a function of changes in land temperature, is,

$$
\frac{\mathrm{d}}{\mathrm{d} T_{\mathrm{L}}} \operatorname{Rad}_{\mathrm{UL}}=4 \sigma T_{\mathrm{L}}^{3}
$$

Thus, for small changes in average land temperature, 


$$
\Delta \operatorname{Rad}_{\mathrm{UL}}=4 \sigma T_{\mathrm{Lo}}^{3} \Delta T_{\mathrm{L}}
$$

Therefore, a good approximation for the surface temperature limit (STL), for small changes in temperature, is

$$
\Delta T_{\text {STLL }}=\Delta \mathrm{NaH}_{\mathrm{L}} /\left(4 \sigma T_{\mathrm{Lo}}^{3}\right)^{\circ} \mathrm{C}
$$

And for land temperature in 1880 of $281.2 \mathrm{~K}$

$$
\begin{gathered}
4 \sigma T_{\mathrm{Lo}}^{3}=4 \times 5.67 \times 10^{-8} \times 281.23=5.04 \\
\therefore \Delta T_{\text {STLL }}=0.198 \Delta \mathrm{NaH}_{\mathrm{L}}
\end{gathered}
$$

with

$$
\Delta \mathrm{NaH}_{\mathrm{L}}=\mathrm{Eff}_{\Delta \mathrm{THL}} \Delta \mathrm{TH}
$$

In terms of changes in total heating, $\Delta \mathrm{TH}$,

$$
\begin{gathered}
\mathrm{NaH}_{\mathrm{LN}}=\mathrm{NaH}_{\mathrm{Lo}}+\Delta \mathrm{NaH}_{\mathrm{L}} \\
\mathrm{NaH}_{\mathrm{Lo}}=\mathrm{Eff}_{\mathrm{SSL}} \mathrm{TH}_{\mathrm{Lo}} \\
\mathrm{NaH}_{\mathrm{LN}}=\mathrm{Eff}_{\mathrm{SSL}} \mathrm{TH}_{\mathrm{Lo}}+\mathrm{Eff}_{\Delta \mathrm{THL}} \Delta \mathrm{TH}
\end{gathered}
$$

From Table 2 \& Table 3

$$
\begin{gathered}
\operatorname{Eff}_{\mathrm{SSL}}=0.73 \\
\operatorname{Eff}_{\Delta \mathrm{THL}}=0.8 \\
\mathrm{NaH}_{\mathrm{LN}}=0.73 \mathrm{TH}_{\mathrm{Lo}}+0.73 \Delta \mathrm{TH} \\
\mathrm{NaH}_{\mathrm{LN}}=\mathrm{NaH}_{\mathrm{Lo}}+\Delta \mathrm{NaH}_{\mathrm{L}} \\
\Delta \mathrm{NaH}_{\mathrm{L}}=\mathrm{NaH}_{\mathrm{LN}}-\mathrm{NaH}_{\mathrm{Lo}}=\mathrm{Eff}_{\mathrm{SSL}} \mathrm{TH}_{\mathrm{Lo}}+\mathrm{Eff}_{\Delta \mathrm{THL}} \Delta \mathrm{TH}-\mathrm{Eff}_{\mathrm{SSL}} \mathrm{TH}_{\mathrm{Lo}} \\
\Delta \mathrm{NaH}_{\mathrm{L}}=\mathrm{Eff}_{\Delta \mathrm{THL}} \Delta \mathrm{TH} \\
\Delta T_{\mathrm{STLL}}=0.198 \Delta \mathrm{NaH}_{\mathrm{L}}=0.198 \mathrm{Eff}_{\Delta \mathrm{THL}} \Delta \mathrm{TH}=0.198 \times 0.8 \Delta \mathrm{TH} \\
\Delta T_{\mathrm{STLL}}=0.158 \Delta \mathrm{TH}{ }^{\circ} \mathrm{C}
\end{gathered}
$$

4) Change in ocean temperature from changes in total heating, $\left.\Delta T_{\Delta \mathrm{THO}}\right)$.

Following the same analysis as for land:

For Ocean temperature in 1880 of $288.67 \mathrm{~K}$

The surface temperature limit for the seas is,

$$
\Delta T_{\text {STLO }}=\left(6.94 \times 10^{9}+\operatorname{Eff}_{\Delta \text { THO }} \Delta \mathrm{TH} / 5.67 \times 10^{-8}\right)^{1 / 4}-288.67
$$

From Table 3,

$$
\begin{gathered}
\operatorname{Eff}_{\Delta \mathrm{THO}}=0.36 \\
\Delta T_{\text {STLO }}=\left(6.94 \times 10^{9}+6.35 \times 10^{6} \Delta \mathrm{TH}\right)^{1 / 4}-288.67
\end{gathered}
$$

For small changes, $\Delta T_{\text {STLO }}$ is,

$$
\Delta T_{\text {STLO }}=\Delta \mathrm{NaH}_{\mathrm{O}} /\left(4 \sigma T_{\mathrm{Oo}}^{3}\right)^{\circ} \mathrm{C}
$$

Therefore, the average ocean surface temperature limit (STL) for changes in total heating, is:

$$
\Delta T_{\text {STLO }}=\Delta \mathrm{NaH}_{\mathrm{O}} /\left(4 \sigma T_{\mathrm{Oo}}^{3}\right)
$$


with

$$
\sigma=5.67 \times 10^{-8} \mathrm{~W}^{-1} \cdot \mathrm{m}^{2} \cdot \mathrm{K}^{-4}
$$

And for Ocean temperature in 1880 of $288.67 \mathrm{~K}$

$$
\begin{gathered}
4 \sigma T_{\mathrm{Oo}}^{3}=4 \times 5.67 \times 10^{-8} \times 288.67^{3}=5.46 \\
\Delta T_{\mathrm{STLO}}=\Delta \operatorname{Rad}_{\mathrm{UO}} /\left(4 \sigma T_{\mathrm{Oo}}^{3}\right)=0.183 \Delta \mathrm{Rad}_{\mathrm{UO}}
\end{gathered}
$$

For $\operatorname{Eff}_{\Delta \mathrm{THO}}=0.36$

$$
\begin{gathered}
\Delta \operatorname{Rad}_{\text {UO } 80-19}=0.36 \Delta \mathrm{TH} \\
\Delta T_{\text {STLO }}=0.183 \times 0.36 \Delta \mathrm{TH} \\
\Delta T_{\text {STLO }}=0.07 \Delta \mathrm{TH}^{\circ} \mathrm{C}
\end{gathered}
$$

5) Changes in the Concentration of Water Vapor

The total concentration of water vapor, total precipitable water $\left(\mathrm{TPW}_{\mathrm{Tot}}\right)$, is the sum of the concentration of water vapor from steady state evaporation as a function of sea surface temperature, $\mathrm{TPW}_{\mathrm{SST}}$ and changes in concentration in response to changes in total heating, $\Delta \mathrm{TPW}_{\Delta \mathrm{TH}}$.

$$
\mathrm{TPW}_{\mathrm{ToT}}=\mathrm{TPW}_{\mathrm{SST}}+\Delta \mathrm{TPW}_{\Delta \mathrm{TH}} \mathrm{kg} \cdot \mathrm{m}^{-2}
$$

6) Changes in concentration of Water Vapor from changes in steady state Sea Surface Temperature, SST.

The total precipitable water $\left(\mathrm{kg} \cdot \mathrm{m}^{-2}\right)$ from evaporation based solely on steady state sea surface temperature, SST, is determined as follows: [25]

$$
\mathrm{TPW}_{\mathrm{SST}}=10 \times 10.82[r /(1+\mu)] \mathrm{e}^{[a(\mathrm{SST}-288)]} \mathrm{kg} \cdot \mathrm{m}^{-2}
$$

The constants, $a$ and $r /(1+\mu)$ were estimated by the authors, as

$$
a=0.0686 \text { and } r /(1+\mu)=0.162 \text {, }
$$

thus,

$$
\mathrm{TPW}_{\text {SST }}=10 \times 10.82(0.162) \mathrm{e}^{[0.0686(\mathrm{SST}-288)]}=17.53 \mathrm{e}^{[0.0686(\mathrm{SST}-288)]}
$$

Therefore, the difference in steady state water vapor concentration at two different surface temperatures is,

$$
\Delta \mathrm{TPW}_{\mathrm{SST}}=17.53\left(\mathrm{e}^{[0.0686(\mathrm{SSTo}+\Delta \mathrm{SST}-288)]}-\mathrm{e}^{[0.0686(\mathrm{SSTo}-288)]}\right) \mathrm{kg} \cdot \mathrm{m}^{-2}
$$

The results from Equation (13), for sea surface temperatures for 1880 and 2019 , temperatures of 288.67 and $289.37 \mathrm{~K}$, are a $5 \%$ increase in water vapor concentration in 2019 over 1880.

$$
\Delta \mathrm{TPW}_{\text {SST }}=17.53\left(\mathrm{e}^{[0.0686(289.37-288)]}-\mathrm{e}^{[0.0686(288.67-288)]}\right)=0.9
$$

In 1880 , the initial water vapor concentration, $\mathrm{TPW}_{1880}$, calculated in accordance with Equation (12), for SST $=288.67 \mathrm{~K}$, was $18.35 \mathrm{~kg} \cdot \mathrm{m}^{-2}$.

Then, this increase was,

$$
0.9 / 18.35=0.05=5 \%
$$

7) Changes in Water Vapor Concentration Driven by Changes in Total Heat- 
ing

Referring to Table S1 and Figure 16, over the same period of time, the global average temperature change of the seas in response to the same changes in total heating was $\sim 40 \%$ of the global average temperature change for land, demonstrating that greater heating of the oceans is required to effect the same change in temperature as land.

While a change in surface temperature changes evaporation, Equation (13), that there is an additional change in evaporation from the seas in response to a change in total heating, $\Delta \mathrm{TH}$ (which of course includes changes in water vapor heating, $\Delta \mathrm{WV}$ ) is a new principle of climate physics. This is set out as Equation (14) which underlies all that follows.

From Table 3 and Table S2, the average heating efficiency of the seas since 1976 in response to an increase in total heating is 0.36 , $\mathrm{Eff}_{\triangle \mathrm{THTotO}}$, from Table 3 , which reflects the net absorbed heating that actually increases the surface temperature of the seas. The other $64 \%$ of change in total heating of the seas is allocated to the change in evaporative power.

Changes in water vapor concentration require an imbalance between average precipitation per year, PR, and evaporation per year, EV. The change in water vapor concentration over a one year period can be determined from this expression:

$$
\mathrm{TPW}=\mathrm{EV}-\mathrm{PR} \quad \mathrm{kg} \cdot \mathrm{m}^{-2}
$$

Set

$$
\mathrm{PR}=\beta \mathrm{EV}
$$

Then,

$$
\mathrm{TPW}=\mathrm{EV}(1-\beta)
$$

Using average rates and changes therefrom for the year in question, this is changed to:

$$
\Delta \mathrm{TPW}=\mathrm{EV}_{\mathrm{Avg}}+\Delta \mathrm{EV}-\mathrm{PR}_{\mathrm{Avg}}-\Delta \mathrm{PR}
$$

where, $\mathrm{EV}_{\mathrm{Avg}}$ is the average annual global evaporation, $\mathrm{mm} \cdot \mathrm{m}^{-2} / \mathrm{yr}$.

$\mathrm{PR}_{\mathrm{Avg}}$ is the average annual global precipitation, $\mathrm{mm} \cdot \mathrm{m}^{-2} / \mathrm{yr}$.

$\triangle \mathrm{EV}$ is the change in annual evaporation from average $\mathrm{mm} \cdot \mathrm{m}^{-2}$

$\triangle \mathrm{PR}$ is the change in annual precipitation from average $\mathrm{mm} \cdot \mathrm{m}^{-2}$

Set,

$$
\mathrm{EV}_{\mathrm{Avg}}=\mathrm{PR}_{\mathrm{Avg}}
$$

Then,

$$
\Delta \mathrm{TPW}=\Delta \mathrm{EV}-\Delta \mathrm{PR}
$$

Since for each year, precipitation is proportional to evaporation, then,

$$
\Delta \mathrm{PR}=\beta \Delta \mathrm{EV}
$$

Then, for that year,

$$
\Delta \mathrm{TPW}=\Delta \mathrm{EV}(1-\beta)
$$


Assume, the rate of evaporation is proportional to the fraction of heating flux driving evaporation from the seas, Evap $_{\mathrm{O}}$.

$$
\mathrm{EV} \propto \mathrm{Evap}_{\mathrm{O}}
$$

And changes in the concentration of water vapor are proportional to changes in the heating that drives evaporation.

$$
\therefore \Delta \mathrm{TPW} \propto \Delta \text { Evap }_{\mathrm{O}}
$$

with changes in water vapor concentration, $\triangle \mathrm{TPW}$, proportional to changes in evaporative power, this means that:

$$
\Delta \mathrm{TPW}_{\mathrm{o}}=\Gamma \Delta \text { Evap }_{\mathrm{o}}
$$

where $\Gamma$ is a constant.

The steady state power driving evaporation for the seas in 1880, $\mathrm{Evap}_{\mathrm{o}}$, from Table 2, was $89 \mathrm{Wm}^{-2}$. In 1880, when the change in average global temperature and therefore, total heating, was minor, ignoring changes in total heating for that year, the initial water vapor concentration, $\mathrm{TPW}_{1880}$, calculated in accordance with Equation (12) for SST $=288.67 \mathrm{~K}$, was $18.35 \mathrm{~kg} \cdot \mathrm{m}^{-2}$. So,

$$
\begin{gathered}
\mathrm{TPW}_{1880}=\Gamma_{\text {Evap }_{1880}} \\
18.35 \mathrm{~kg} \cdot \mathrm{m}^{-2}=\Gamma 89 \mathrm{~W} \cdot \mathrm{m}^{-2}
\end{gathered}
$$

Since changes in evaporative power are proportional to changes in total heating, And, for changes in the evaporative power, therefore changes in total heating, $\Delta \mathrm{TH}$, the change in water vapor concentration driven by changes in total heating, $\Delta \mathrm{TPW}_{\triangle \mathrm{THO}}$ is

$$
\Delta \mathrm{TPW}_{\Delta \mathrm{THO}}=\Gamma \Delta \mathrm{Evapo}
$$

From Table 2, the steady state power driving evaporation for the seas in 1880 , Evap $_{\mathrm{O}}$, was $89 \mathrm{Wm}^{-2}$ and for land, Evap $\mathrm{L}_{\mathrm{L}}, 42 \mathrm{Wm}^{-2}$. The total evaporative power is the area weighted average of the two,

$$
\begin{gathered}
\text { Evap }_{1880 \mathrm{Tot}}=\% \text { Area Ocean } \times \text { Evap }_{1880 \mathrm{O}}+\% \text { Area Land } \times \text { Evap }_{1880 \mathrm{~L}} \\
\operatorname{Evap}_{1880 \mathrm{Tot}}=71.11 \% \times 89+29.89 \% \times 42=75.3 \mathrm{~W} \cdot \mathrm{m}^{-2}
\end{gathered}
$$

For the seas, ignoring changes in thermal convection, the change in evaporative power, $\Delta \mathrm{Evap}_{\mathrm{O}}$, in response to changes in total heating, $\Delta \mathrm{TH}$, is the fraction of the change in total heating, $\Delta \mathrm{TH}$, that does not drive an increase in temperature, $\left(1-\mathrm{Eff}_{\Delta \mathrm{THO}}\right) \Delta \mathrm{TH}$, then

$$
\begin{gathered}
\Delta \text { Evapo }=\left(1-\mathrm{Eff}_{\Delta \mathrm{THO}}\right) \Delta \mathrm{TH}, \\
\therefore \mathrm{TPW}_{\Delta \mathrm{THо}}=\Gamma \Delta \text { Evapo }=\Gamma\left(1-\mathrm{Eff}_{\Delta \mathrm{THO}}\right) \Delta \mathrm{TH},
\end{gathered}
$$

Then, since

$$
\Gamma=\Delta \mathrm{TPW}_{\Delta \mathrm{THO}} /\left(\left(1-\mathrm{Eff}_{\Delta \mathrm{THO}}\right) \Delta \mathrm{TH}\right),
$$

Therefore,

$$
\Delta \mathrm{TPW}_{\Delta \mathrm{THO}}=\left(1-\mathrm{Eff}_{\Delta \mathrm{THO}}\right) \Delta \mathrm{TH} \mathrm{TPW}_{1880} / \mathrm{Evap}_{\mathrm{Tot1880}}
$$




$$
\begin{gathered}
\Delta \mathrm{TPW}_{\Delta \mathrm{THO}}=18.35(1-0.36) \Delta \mathrm{TH} / 75.3 \\
\Delta \mathrm{TPW}_{\Delta \mathrm{THTot}}=0.157 \Delta \mathrm{TH}
\end{gathered}
$$

8) Total Change in the Concentration of Water Vapor

Taking into account changes in evaporation from changes in total heating, $\Delta \mathrm{TH}$ and sea surface temperature, $\Delta \mathrm{SST}$, the total change in the concentration of water vapor is therefore,

$$
\begin{gathered}
\Delta \mathrm{TPW}_{\text {Tot }}=\Delta \mathrm{TPW}_{\Delta \mathrm{THTot}}+\Delta \mathrm{TPW}_{\mathrm{SST}} \\
\Delta \mathrm{TPW}_{\text {Tot }}=0.157 \Delta \mathrm{TH}+17.53\left\{\mathrm{e}^{[0.0686(\mathrm{SSTo}+\Delta \mathrm{SST}-288)]}-\mathrm{e}^{[0.0686(\mathrm{SSTo}-288)]}\right\} \mathrm{kg} \cdot \mathrm{m}^{-2}(1)
\end{gathered}
$$

9) Changes in Water Vapor Heating from Changes in Concentration of Water Vapor

The intensity of back radiation from water vapor depends on the extent to which surface radiation is absorbed by the water vapor, which is a function of the concentration, TPW [26].

Ignoring convection cooling and focusing on changes in temperature, the heating required to maintain sea surface temperature, is

$$
\mathrm{TH}_{\mathrm{SST}}=\mathrm{NaH}_{\text {OSST }} / \text { Eff }_{\text {SSTO }}
$$

And, since

$$
\begin{gathered}
\operatorname{Rad}_{\text {UOSST }}=\mathrm{NaH}_{\text {OSST }} \\
\mathrm{TH}_{\text {SST }}=\operatorname{Rad}_{\text {UOSST }} / \text { Eff } \\
\text { SSTO }
\end{gathered}
$$

thus,

$$
\operatorname{Rad}_{\text {UOSST }}=\text { Eff }_{\text {SSTO }} \mathrm{TH}_{\text {SST }}
$$

The change in total heating from changes in water vapor heating, $\Delta \mathrm{WV}$, is,

$$
\begin{gathered}
\Delta \mathrm{TH}_{\mathrm{WV}}=\Delta \mathrm{WV}, \text { then, } \\
\Delta \operatorname{Rad}_{\Delta \mathrm{WVO}}=\mathrm{Eff}_{\Delta \mathrm{THO}} \Delta \mathrm{WV}
\end{gathered}
$$

and, the water vapor heating power required to effect this change in up-radiation is,

$$
\Delta \mathrm{WV}=\Delta \mathrm{Rad}_{\mathrm{WvO}} / \mathrm{Eff}_{\Delta \mathrm{THO}}
$$

And, the surface temperature limit for the sea from this heating is,

$$
\Delta T_{\text {SSTL } \Delta \mathrm{WV}}=\Delta \operatorname{Rad}_{\Delta \mathrm{WVO}} / 4 \sigma \mathrm{SST}_{\mathrm{Oo}}^{3}
$$

With $\mathrm{SST}_{\mathrm{o}}$ in $1880=288.67$

$$
\Delta T_{\mathrm{SSTL} \Delta \mathrm{WV}}=\frac{\Delta \operatorname{Rad}_{\Delta \mathrm{WvO}}}{4 \sigma \mathrm{SST}_{\mathrm{Oo}}^{3}}=0.183 \Delta \operatorname{Rad}_{\Delta \mathrm{WvO}}
$$

and the net absorbed heating required to drive this change in the sea surface temperature,

$$
\mathrm{NaH}_{\Delta \mathrm{wVO}}=\operatorname{Rad}_{\Delta \mathrm{wvO}}
$$

To determine the change in water vapor heating:

From Table 2 


\begin{tabular}{cc}
\hline $\mathrm{BR}_{1880}$ & $\mathrm{BR}_{2002}$ \\
\hline 323.60 & 333 \\
\hline
\end{tabular}

Assume back radiation from the GHG, other than Water Vapor and $\mathrm{CO}_{2}$, and effects from cloud cover and other atmospheric factors net to zero [27] (p. 11, Table 2) and heating from $\mathrm{CO}_{2}$ in 1880 was,

$$
\mathrm{TH}_{\mathrm{CO} 21880}=5.35 \ln \left(\mathrm{Conc}_{\mathrm{CO} 21880}\right)=5.35 \ln (290.74)=30.35 \mathrm{~W} \cdot \mathrm{m}^{-2}
$$

Then to determine the change in water vapor heating, $\Delta \mathrm{WV}_{1880-2002}$, from Table 2 and om Table S1,

$$
\begin{gathered}
\mathrm{WV}_{\mathrm{Tot1880}}=\mathrm{BR}_{1880}-\mathrm{TH}_{\mathrm{CO} 21880}=322.73-30.35=292.38 \mathrm{~W} \cdot \mathrm{m}^{-2} \\
\mathrm{WV}_{2002}=\mathrm{BR}_{2002}-\mathrm{TH}_{\mathrm{CO} 22002}=\mathrm{BR}_{2002}-\left(\mathrm{TH}_{\mathrm{CO} 21880}+\mathrm{TH}_{\mathrm{CO} 21880-2002}\right) \\
\mathrm{WV}_{2002}=333-[30.35+5.35 \ln (373.22 / 290.74)]=301.31 \\
\Delta \mathrm{BR}_{1880-2002}=\mathrm{BR}_{2002}-\mathrm{BR}_{1880}=333-323.6=9.4 \\
\Delta \mathrm{TH}_{\mathrm{CO} 21880-2002}=5.35 \ln (373.22 / 290.74)=1.34 \\
\Delta \mathrm{WV}_{1880-2002}=\Delta \mathrm{BR}_{1880-2002}-\Delta \mathrm{TH}_{\mathrm{CO} 21880-2002}=9.4-1.34=8.06
\end{gathered}
$$

To calculate the change in water vapor heating, $\Delta \mathrm{WV}$, from a change in the concentration of water vapor, assume that, the absorption of surface radiation changes logarithmically with changes in the concentration of water vapor, TPW. ("For very strongly absorbing peaks such as those due to $\mathrm{CO}_{2}$ and $\mathrm{H}_{2} \mathrm{O}$, absorption only occurs at the fringes of the band and the net absorption varies with the logarithm of the absorber concentration" [26]).

$$
\mathrm{WV}=f[\ln (\mathrm{TPW})]
$$

then,

$$
\Delta \mathrm{WV}_{1880-2002}=X\left[\ln \left(\mathrm{TPW}_{2002}\right)-\ln \left(\mathrm{TPW}_{1880}\right)\right]
$$

Since,

$$
\mathrm{TPW}_{2002}=\mathrm{TPW}_{1880}+\Delta \mathrm{TPW}_{1880-2002}
$$

then,

$$
\begin{gathered}
\Delta \mathrm{WV}_{1880-2002}=X\left[\ln \left(\Delta \mathrm{TPW}_{1880-2002}+\mathrm{TPW}_{1880}\right)-\ln \left(\mathrm{TPW}_{1880}\right)\right] \\
\Delta \mathrm{WV}_{1880-2002}=X\left[\ln \left(1+\Delta \mathrm{TPW}_{1880-2002} / \mathrm{TPW}_{1880}\right)\right]
\end{gathered}
$$

solving for $X$,

$$
X=\Delta \mathrm{WV}_{1880-2002} / \ln \left(1+\Delta \mathrm{TPW}_{1880-2002} / \mathrm{TPW}_{1880}\right)
$$

as shown above,

$$
\begin{gathered}
\Delta \mathrm{WV}_{1880-2002}=8.06 \\
X=8.06 / \ln \left(1+\Delta \mathrm{TPW}_{1880-2002} / \mathrm{TPW}_{1880}\right) \\
\Delta \mathrm{TPW}_{1880-2002}=\Delta \mathrm{TPW}_{\Delta \mathrm{THW}_{1880-2002}}+\Delta \mathrm{TPW}_{\mathrm{SSTW}_{1880-2002}}
\end{gathered}
$$


From Equation (13)

$$
\Delta \mathrm{TPW}_{\mathrm{SST}}=17.53\left(\mathrm{e}^{[0.0686(\mathrm{SSTo}+\Delta \mathrm{SST}-288)]}-\mathrm{e}^{[0.0686(\mathrm{SSTo}-288)]}\right)
$$

And from Equation (14)

$$
\Delta \mathrm{TPW}_{\Delta \mathrm{TH}}=0.157 \Delta \mathrm{TH}
$$

From Table 1

$$
\Delta \mathrm{TH}_{1880-2002}=9.4
$$

Thus,

$$
\begin{gathered}
\Delta \mathrm{TPW}_{\Delta \mathrm{TH} 1880-2002}=0.157 \Delta \mathrm{TH}=0.157 \times 9.4=1.48 \\
\Delta \mathrm{TPW}_{\mathrm{SST}}=17.53\left(\mathrm{e}^{[00.0686(\mathrm{SSTo}+\Delta \mathrm{SST}-288)]}-\mathrm{e}^{[00.0686(\mathrm{SSTo}-288)]}\right) \\
\text { With } \mathrm{SST}_{1880}=288.67, \mathrm{SST}_{2002}=289.18, \Delta \mathrm{SST}=0.51^{\circ} \mathrm{C} \\
\Delta \mathrm{TPW}_{\mathrm{SST} 1880-2002}=17.53\left(\mathrm{e}^{[0.0686(\mathrm{SSTo}+\Delta \mathrm{SST}-288)]}-\mathrm{e}^{[0.0686(\mathrm{SSTo}-288)]}\right)
\end{gathered}
$$

with

$$
\begin{gathered}
0.0686\left(\mathrm{SST}_{\mathrm{o}}+\Delta \mathrm{SST}-288\right)=0.0686(288.67+0.51-288)=0.081 \\
0.0686\left(\mathrm{SST}_{\mathrm{o}}-288\right)=0.0686(288.67-288)=0.0686 \times 0.67=0.046
\end{gathered}
$$

Thus,

$$
\begin{gathered}
\Delta \mathrm{TPW}_{\mathrm{SST} 1880-2002}=17.53\left(\mathrm{e}^{0.081}-\mathrm{e}^{0.046}\right) \\
\Delta \mathrm{TPW}_{\mathrm{SST} 1880-2002}=17.53\left(\mathrm{e}^{0.081}-\mathrm{e}^{0.046}\right)=0.654 \\
\Delta \mathrm{TPW}_{\text {TotSST1880-2002 }}=\Delta \mathrm{TPW}_{\Delta \mathrm{THW} 1880-2002}+\Delta \mathrm{TPW}_{\text {SSTW1880-2002 }} \\
\Delta \mathrm{TPW}_{\text {TotSST1880-2002 }}=1.48+0.654=2.134
\end{gathered}
$$

Then to determine the water vapor heating in 1880 , set,

$$
\begin{gathered}
\mathrm{WV}_{1880}=X \ln \left(\mathrm{TPW}_{1880}\right)+Z \\
\text { From above, } \\
\mathrm{WV}_{1880}=292.38 \mathrm{~W} \cdot \mathrm{m}^{-2} \\
\therefore 292.38=X \ln \left(\mathrm{TPW}_{1880}\right)+Z
\end{gathered}
$$

and, the change in water vapor heating, is,

$$
\Delta \mathrm{WV}=X \ln \left(1+\Delta \mathrm{TPW} / \mathrm{TPW}_{1880}\right)
$$

Solving for $X$,

$$
X=\Delta \mathrm{WV} / \ln \left(1+\Delta \mathrm{TPW} / \mathrm{TPW}_{1880}\right)
$$

And, with

$$
\begin{gathered}
\Delta \mathrm{WV}_{1880-2002}=8.06 \\
X=8.06 / \ln \left(1+\Delta \mathrm{TPW}_{1880-2002} / \mathrm{TPW}_{1880}\right) \\
X=8.06 / \ln (1+2.134 / 18.35)=73.3
\end{gathered}
$$

Therefore, 


$$
Z=292.38-X \ln \left(\mathrm{TPW}_{1880}\right)=292.38-73.3 \ln (18.35)=79.1
$$

Thus,

$$
\mathrm{WV}=73.3 \ln (\mathrm{TPW})+79.1
$$

10) Changes in Water Vapor Heating from Changes in Total Heating

The change in water vapor heating from changes in total heating, $\Delta \mathrm{TH}$, is then calculated as:

$$
\begin{gathered}
\Delta \mathrm{WV}_{\Delta \mathrm{TH}}=73.3 \ln \left[\left(\mathrm{TPW}_{1880}+\Delta \mathrm{TPW}_{\Delta \mathrm{TH}}\right) / \mathrm{TPW}_{1880}\right] \\
\Delta \mathrm{WV}_{\Delta \mathrm{TH}}=73.3 \ln \left(1+\Delta \mathrm{TPW}_{\Delta \mathrm{TH}} / \mathrm{TPW}_{1880}\right)
\end{gathered}
$$

Substituting $\mathrm{TPW}_{1880}=18.35 \mathrm{~kg} \cdot \mathrm{m}^{-2}$ and from Equation (14),

$$
\Delta \mathrm{TPW}_{\Delta \mathrm{TH}}=0.157 \Delta \mathrm{TH} \mathrm{kg} \cdot \mathrm{m}^{-2}
$$

Therefore, the change in water vapor heating compared to 1880 as a result of the change in the concentration of water vapor, is calculated as:

$$
\begin{gathered}
\Delta \mathrm{WV}_{\Delta \mathrm{TH}}=73.3 \ln \left(18.35+\Delta \mathrm{TPW}_{\Delta \mathrm{TH}} / \mathrm{TPW}_{1880}\right) \\
\Delta \mathrm{WV}_{\Delta \mathrm{TH}}=73.3 \ln \left[\left(18.35+\Delta \mathrm{TPW}_{\Delta \mathrm{TH}}\right) / \mathrm{TPW}_{1880}\right] \\
\Delta \mathrm{WV}_{\Delta \mathrm{TH}}=73.3 \ln (1+0.157 \Delta \mathrm{TH} / 18.35) \\
\Delta \mathrm{WV}_{\Delta \mathrm{TH}}=73.3 \ln (1+0.0082 \Delta \mathrm{TH}) \mathrm{W} \cdot \mathrm{m}^{-2}
\end{gathered}
$$

11) Changes in Water Vapor Heating from Steady State Temperature Driven Evaporation

The change in water vapor heating compared to 1880 as a result of changes in sea surface temperature, $\Delta \mathrm{SST}$, is:

$$
\Delta \mathrm{WV}_{\mathrm{SST}}=73.3 \ln \left(\Delta \mathrm{TPW}_{\mathrm{SST}}\right)
$$

The change in concentration of water vapor solely in response to a change in surface temperature, is:

$$
\Delta \mathrm{TPW}_{\mathrm{SST}}=17.53\left(\mathrm{e}^{[0.0686(\mathrm{SSTo}+\Delta \mathrm{SST}-288)]}-\mathrm{e}^{[0.0686(\mathrm{SSTo}-288)]}\right)
$$

Then,

$$
\begin{gathered}
\Delta \mathrm{WV}_{\mathrm{SST}}=73.3 \ln \left[17.53\left(\mathrm{e}^{[0.0686(\mathrm{SSTo}+\Delta \mathrm{SST}-288)]}-\mathrm{e}^{[0.0686(\mathrm{SSTo}-288)]}\right)\right] \\
\Delta \mathrm{WV}_{\mathrm{SST}}=73.3 \ln \left[17.53 \mathrm{e}^{[0.0686(\mathrm{SSTo}+\Delta \mathrm{SST}-288)]} / 17.53 \mathrm{e}^{[0.0686(\mathrm{SSTo}-288)]}\right]
\end{gathered}
$$

Simplifying,

$$
\begin{gathered}
\Delta \mathrm{WV}_{\mathrm{SST}}=73.3 \ln \left[\mathrm{e}^{[0.0686(\mathrm{SSTo}+\Delta \mathrm{SST}-288)]} / \mathrm{e}^{[0.0686(\mathrm{SSTo}-288)]}\right] \\
\Delta \mathrm{WV}_{\mathrm{SST}}=73.3[0.0686(\mathrm{SSTo}+\mathrm{SST}-288)-0.0686(\mathrm{SSTo}-288)] \\
\Delta \mathrm{WV}_{\mathrm{SST}}=73.3 \times 0.0686 \Delta \mathrm{SST}=5.17 \Delta \mathrm{SST} \mathrm{W} \cdot \mathrm{m}^{-2}
\end{gathered}
$$

12) The Change in Water Vapor Heating compared to 1880 as a Result of Both Evaporative Responses 
Thus, the increase in water vapor heating compared to 1880 as a result of both evaporative responses, is calculated as:

$$
\begin{gathered}
\Delta \mathrm{WV}_{\text {Tot }}=\mathrm{WV}_{\Delta \mathrm{TH}}+\mathrm{WV}_{\Delta \mathrm{SST}} \\
\Delta \mathrm{WV}_{\text {Tot }}=73.3 \ln (1+0.0082 \Delta \mathrm{TH})+5.17 \Delta \mathrm{SST} \mathrm{W} \cdot \mathrm{m}^{-2}
\end{gathered}
$$

13) Change in Average Global Temperature, $\Delta T_{\text {Avg }}$

The change in average global temperature is the area weighted average of changes in land, $\mathrm{T}_{\mathrm{L}}$, and ocean temperature. Therefore, with the seas covering $71.11 \%$ of the surface and land $28.89 \%$, the change in average global temperature is,

$$
\Delta T_{\text {Avg }}=0.29 \Delta T_{\mathrm{L}}+0.71 \Delta T_{\mathrm{O}}
$$

From Equation (10),

$$
\Delta T_{\mathrm{L}}=0.158 \Delta \mathrm{TH}{ }^{\circ} \mathrm{C}
$$

From Equation (12), for the maximum increase, the surface temperature limit, $\Delta T_{\text {STLO }}$ for the seas,

$$
\Delta T_{\text {STLO }}=0.07 \Delta \mathrm{TH}{ }^{\circ} \mathrm{C}
$$

Since $\Delta \mathrm{TH}=\Delta T_{\mathrm{L}} / 0.158$

$$
\begin{gathered}
\Delta T_{\text {STLO }}=0.07 \times \Delta T_{\mathrm{L}} / 0.158 \\
\therefore \Delta T_{\text {Avg }}=0.29 \Delta T_{\mathrm{L}}+0.71 \times 0.07 / 0.158 \Delta T_{\mathrm{L}}
\end{gathered}
$$

thus,

$$
\Delta T_{\mathrm{Avg}}=\Delta T_{\mathrm{L}}(0.29+0.315)=0.605 \Delta T_{\mathrm{L}}
$$

Since

$$
\begin{gathered}
\Delta T_{\mathrm{L}}=0.158 \Delta \mathrm{TH} \\
\Delta T_{\text {Avg }}=0.605 \times 0.158 \Delta \mathrm{TH}=0.096 \Delta \mathrm{TH}
\end{gathered}
$$

Thus, the Temperature Response Factor, $k_{T}$, to changes in total heating, $\Delta \mathrm{TH}$, is,

$$
k_{T}=0.096 \mathrm{~K} \cdot \mathrm{m}^{2} \cdot \mathrm{W}^{-1}
$$

14) Changes in Heating Driven by Changes in the Concentration of $\mathrm{CO}_{2}$

The theoretical change in heating driven by changes in the concentration, $C$, of $\mathrm{CO}_{2}, \Delta \mathrm{TH}_{\mathrm{CO} 2}$, is

$$
\Delta \mathrm{TH}_{\mathrm{CO} 2}=5.35 \ln \left(C / C_{o}\right) \mathrm{W} \cdot \mathrm{m}^{-2}
$$

15) Change in Total Heating

If in the change in total heating, $\Delta \mathrm{TH}_{\mathrm{Tot}}, \mathrm{CO}_{2}$ were a factor, then the total change in heating would be,

$$
\Delta \mathrm{TH}_{\mathrm{Tot}}=5.35 \ln \left(C / C_{o}\right)+\Delta \mathrm{WV}_{\mathrm{Tot}}
$$

16) Change in Average Global Temperature

The total increase in average global temperature, $\Delta T_{\mathrm{Avg}}$, in response to the total change in heating, $\Delta \mathrm{TH}_{\mathrm{Tot}}$ is, therefore, 


$$
\Delta T_{\mathrm{Avg}}=k_{T} \Delta \mathrm{TH}_{\mathrm{Tot}}
$$

Thus, from Equation (19), the increase in average global temperature, $\Delta T_{\text {Avg }}$ from water vapor and heating from $\mathrm{CO}_{2}$ would be,

$$
\Delta T_{\text {Avg }}=0.096\left(5.35 \ln \left(C / C_{o}\right)+\Delta \mathrm{WV}_{\text {Tot }}\right){ }^{\circ} \mathrm{C}
$$

However, Equations $4 \& 5$ show that $\mathrm{CO}_{2}$ is not a factor and the correct expression is,

$$
\Delta T_{\text {Avg }}=0.4 \Delta \mathrm{TPW}-0.05^{\circ} \mathrm{C}
$$

\section{Appendix 2: Supplementary Materials}

\section{Background}

\section{Evaporation and Precipitation}

The data for changes from average in global land precipitation, $\Delta \mathrm{PR}_{\mathrm{L}}$, evaporation and concentration of water vapor are set out in Figure S1 and Table S5.

The relationship between annual changes in the concentration of water vapor, $\triangle \mathrm{TPW}$, and changes in the annual rates of evaporation, $\triangle \mathrm{EV}$ and global land precipitation, $\Delta \mathrm{PR}_{\mathrm{L}}$, which is $15 \%$ of global precipitation [28], is

$$
\Delta \mathrm{EV}=\Delta \mathrm{PR}_{\mathrm{L}}+0.15 \Delta \mathrm{TPW}
$$

Year over year changes in annual precipitation, evaporation and concentration of water vapor, as a percentage of average global precipitation, $949 \mathrm{~mm} \cdot \mathrm{m}^{-2}$ are set out in Table S5. The annual year over year percentage changes in evaporation, determined from the precipitation change data set out in Figure S2, calculated changes in the concentration of water vapor, $\triangle \mathrm{TPW}$, using NOAA data [2] [3] which is set out in Table $S 5$ and determined from the application of Equations 1 and S1 are shown in red in Figure S2, year over year changes in annual precipitation are set out in blue.

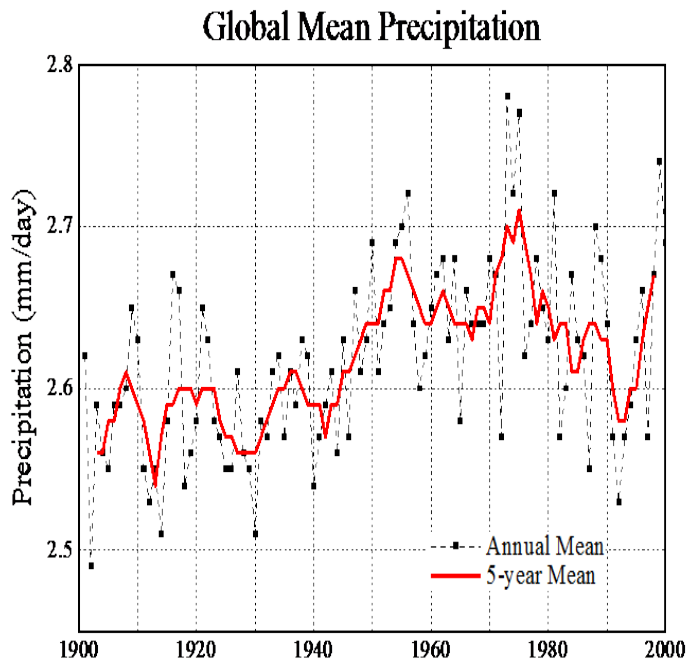

Figure S1. Global annual and five-year running mean precipitation [26] (Figure 3). 


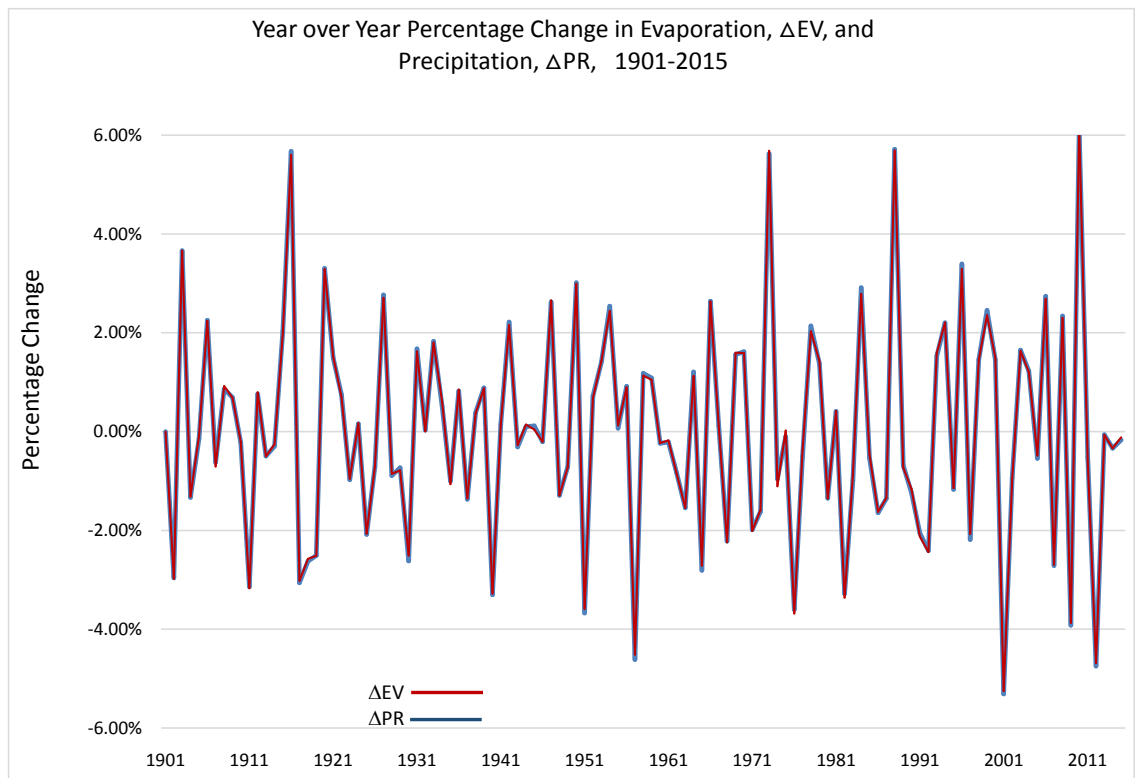

Figure S2. Comparison between year over year percentage changes in land precipitation and evaporation rates from 1901.

The precipitation (blue) and evaporation (red) lines are congruent. Thus, they merge into purple, which is the expectation [29]. If the calculated changes in the concentration of water vapor concentration were significantly incorrect, there would not be this match. For example, if, $\Delta \mathrm{PR}_{\mathrm{LN}}-\Delta \mathrm{PR}_{\mathrm{Lo}}$ were $1 \%$ and $0.15 \%$ $\left(\Delta \mathrm{TPW}_{\mathrm{N}}-\Delta \mathrm{TPW}_{\mathrm{o}}\right)$ were to be calculated as $-1 \%$, then,

$$
\begin{gathered}
\Delta \mathrm{EV}_{\mathrm{N}}-\Delta \mathrm{EV}_{\mathrm{o}}=\Delta \mathrm{PR}_{\mathrm{LN}}-\Delta \mathrm{PR}_{\mathrm{LO}}+0.15\left(\Delta \mathrm{TPW}_{\mathrm{N}}-\Delta \mathrm{TPW}_{\mathrm{o}}\right) \\
\Delta \mathrm{PR}_{\mathrm{LN}}-\Delta \mathrm{PR}_{\mathrm{LO}}=1 \% \\
\Delta \mathrm{EV}_{\mathrm{N}}-\Delta \mathrm{EV}_{\mathrm{o}}=\Delta \mathrm{PR}_{\mathrm{LN}}-\Delta \mathrm{PR}_{\mathrm{LO}}+0.15\left(\Delta \mathrm{TPW}_{\mathrm{N}}-\Delta \mathrm{TPW}_{\mathrm{o}}\right)=1 \%-1 \%=0
\end{gathered}
$$

Thus, in this case,

$$
\begin{aligned}
& \Delta \mathrm{EV}_{\mathrm{N}}-\Delta \mathrm{EV}_{\mathrm{o}}=-1 \% \\
& \Delta \mathrm{PR}_{\mathrm{LN}}-\Delta \mathrm{PR}_{\mathrm{LO}}=1 \%
\end{aligned}
$$

no match.

Referring to Table S5 and Figure S2, such differences do not occur. There is no significant disagreement between the computed results for $\Delta \mathrm{EV}$ relative to precipitation for the period 1901-2015. Thus, no significant errors in the application of Equation (1) and the 114 calculations of $\triangle \mathrm{TPW}$.

\section{Accuracy of Results}

That the water vapor concentration methodology set out in this paper is correct is proven by the almost exact match to the historic temperature record from the application of Equation (5) based on the calculated changes in the concentration of water vapor, $\triangle \mathrm{TPW}$ from Equation (1).

The results of the application of Equation (5) of this methodology based on the NOAA data [2] [3] set out in Table S1 for the period 1880-2018, are shown 
in Table S4 and compared to the average global temperature record in Figure 12. The results have an average accuracy of $\pm 0.14 \%$ compared to the actual change in average global temperature measured in degrees Celsius.

Referring to Figure 4, which shows percentage changes in TPW, from 1880 to 1976, the average global concentration of water vapor increased by $1.7 \%$ or $0.018 \%$ per year. Therefore, while there were short term variations, over this period, the average rate of precipitation was roughly equal to the average rate of evaporation, which is normal [29]. After 1976 the concentration of water vapor increased by $14 \%$ or $0.3 \%$ per year; a rate 18 times greater, which, as shown in Figure 4 \& Figure 11, drove recent global warming.

Moreover, referring to Table S5, the year over year changes in the concentration of water vapor is slight, $<0.2 \mathrm{~mm} \cdot \mathrm{m}^{-2}$. It is these slight changes that are responsible for changes in the average global temperature.

\section{Positive Feedback Loop}

In an audio system with a microphone connected to an amplifier which is, in turn, connected to a speaker, a signal from the speaker, if received by the microphone, passes to the amplifier, is amplified and emitted from the loudspeaker, at a greater volume. Each time sound from the loudspeaker is received by the microphone, it is louder, passed to the amplifier at increased volume and then further amplified and passed out through the loudspeaker at ever increasing volume, again and again. The increase in amplification comes from the increase in acoustic power supplied by the electrically powered amplifier. As long as it remains plugged in and the microphone remains in the same position, the volume of the sound will be increasing to or maintained at the maximum volume for the system. This is a positive feedback loop.

In the climate change loop, an increase in the concentration of water vapor increases water vapor heating, surface temperature and evaporation. To the extent the most recent increase in evaporation is not matched by an increase in precipitation, there is an increase in the concentration of water vapor, water vapor heating, surface temperature and evaporation, on and on. The evaporation > precipitation imbalance is the amplifier. This imbalance does not require any energy in addition to the energy driving evaporation occurring as a direct result of the increase in heating and surface temperature. Thus, as long the rate of evaporation exceeds the rate of precipitation, this imbalance and the positive feedback illustrated in Figure 15 will continue.

The physics are reinforcing. With the rate of change in concentration increasing, this has clearly been a positive feedback loop driven by water vapor heating resulting from the increasing concentration in water vapor shown in Figure 4, increasing water vapor heating, evaporation and in turn water vapor concentration and so on.

This feedback is driven by the average annual small excess in evaporation compared to precipitation.

Until such time as there is an increase in cloud condensing nuclei sufficient 
and/or some other factor(s), necessary to compensate for this slight difference and ensure that average precipitation again, continually equals or exceeds average evaporation, the buildup in atmospheric water vapor will continue increasing atmospheric heating, increasing evaporation, and so on, with a continuing increase in average global temperature of $0.2^{\circ} \mathrm{C} /$ decade, until limited by the average relative humidity building to a point that sufficiently retards the rate of evaporation. But, by this time, it is possible that the average global temperature will have increased to the point that the areas of habitable and food producing land has shrunk to the point that the very existence of much of humanity is in doubt. Thus, this relative decline in precipitation should be viewed as a threat to humankind.

As noted above, after 1976, there was a continuing slight imbalance between average precipitation and evaporation, with average annual evaporation exceeding annual precipitation of $0.06 \mathrm{~mm} \cdot \mathrm{m}^{-2} / \mathrm{yr}$.

This slight imbalance is the forcing function driving $>60 \%$ of the post 1976 increase in average global temperature stemming from the average rate of evaporation exceeding the average rate of precipitation and, possibly, a periodic insufficiency in the atmospheric density of cloud condensing nuclei, CCN, over certain parts of the globe as air pollution was reduced and precipitation increased, precipitating out more CCN.

The good news is that the solution is mathematically simple. If annual global precipitation can be increased by $3 \mathrm{~mm} \cdot \mathrm{m}^{-2}(0.3 \%$ of average annual precipitation of $949 \mathrm{~mm} / \mathrm{yr}$.) in excess of evaporation and thereafter maintained in equivalence with the evaporative rate, this is completely reversible and can be controlled.

Meanwhile there is a real urgency in coming to understand this problem and developing and implementing efficient and environmentally sound means of increasing precipitation, because, until then, the problem will only get worse.

As long as the average ratio of annual precipitation/evaporation $<1$, for the reasons set out above, this is likely to continue. Thus, by 2100 , the increase could be another $1.5^{\circ} \mathrm{C}$, which would be of very serious and ongoing concern to our grandchildren.

Table S1. Input data [1] [2] [3] [5], global average land, ocean and land/ocean temperature data and concentration of $\mathrm{CO}_{2}$, Figure 1, Figure 8, Figure 9, Figure 13, Figure 14, Figure 16 .

\begin{tabular}{ccccccc}
\hline \multirow{2}{*}{ Year } & $\begin{array}{c}\text { Avg. } \\
\text { Global }\end{array}$ & $\begin{array}{c}\text { Avg. } \\
\text { Global } \\
\text { Land }\end{array}$ & $\begin{array}{c}\text { NOAA } \\
\text { Global } \\
\text { Land }\end{array}$ & $\begin{array}{c}\text { Avg. } \\
\text { Global } \\
\text { Ocean }\end{array}$ & $\begin{array}{c}\text { NOAA } \\
\text { Global } \\
\text { Ocean }\end{array}$ & $\begin{array}{c}\text { Conc. } \\
\mathrm{CO}_{2}\end{array}$ \\
\cline { 2 - 7 } & Temp. K & Temp. K & $\begin{array}{c}\text { Anomaly }{ }^{\circ} \mathrm{C} \\
\text { to 20 } \\
\text { Century Avg. }\end{array}$ & Temp. K & $\begin{array}{c}\text { Anomaly }{ }^{\circ} \mathrm{C} \\
\text { to 20 } \\
\text { Century }\end{array}$ & ppmv \\
\hline 1880 & 286.49 & 281.14 & -0.52 & 288.67 & -0.02 & 290.74 \\
1881 & 286.53 & 281.2 & -0.46 & 288.7 & 0.01 & 290.97 \\
1882 & 286.52 & 281.19 & -0.47 & 288.69 & 0 & 291.19 \\
\hline
\end{tabular}




\section{Continued}

\begin{tabular}{|c|c|c|c|c|c|c|}
\hline 1883 & 286.43 & 280.97 & -0.69 & 288.65 & -0.04 & 291.41 \\
\hline 1884 & 286.35 & 280.94 & -0.72 & 288.55 & -0.14 & 291.63 \\
\hline 1885 & 286.37 & 281.08 & -0.58 & 288.52 & -0.17 & 291.86 \\
\hline 1886 & 286.39 & 281.14 & -0.52 & 288.52 & -0.17 & 292.08 \\
\hline 1887 & 286.35 & 281.17 & -0.49 & 288.46 & -0.23 & 292.30 \\
\hline 1888 & 286.50 & 281.23 & -0.43 & 288.64 & -0.05 & 292.59 \\
\hline 1889 & 286.56 & 281.35 & -0.31 & 288.67 & -0.03 & 292.88 \\
\hline 1890 & 286.30 & 281.14 & -0.52 & 288.4 & -0.29 & 293.18 \\
\hline 1891 & 286.40 & 281.13 & -0.53 & 288.54 & -0.15 & 293.47 \\
\hline 1892 & 286.35 & 281.14 & -0.52 & 288.46 & -0.23 & 293.76 \\
\hline 1893 & 286.33 & 281.1 & -0.56 & 288.45 & -0.24 & 294.05 \\
\hline 1894 & 286.35 & 281.24 & -0.42 & 288.42 & -0.27 & 294.34 \\
\hline 1895 & 286.42 & 281.25 & -0.41 & 288.52 & -0.17 & 294.63 \\
\hline 1896 & 286.56 & 281.3 & -0.36 & 288.69 & 0 & 294.93 \\
\hline 1897 & 286.56 & 281.38 & -0.28 & 288.66 & -0.03 & 295.22 \\
\hline 1898 & 286.39 & 281.26 & -0.4 & 288.47 & -0.22 & 295.51 \\
\hline 1899 & 286.50 & 281.43 & -0.23 & 288.56 & -0.13 & 295.80 \\
\hline 1900 & 286.58 & 281.5 & -0.16 & 288.64 & -0.05 & 295.55 \\
\hline 1901 & 286.50 & 281.54 & -0.12 & 288.52 & -0.17 & 295.30 \\
\hline 1902 & 286.41 & 281.38 & -0.28 & 288.45 & -0.24 & 295.05 \\
\hline 1903 & 286.29 & 281.28 & -0.38 & 288.32 & -0.37 & 294.80 \\
\hline 1904 & 286.20 & 281.21 & -0.45 & 288.23 & -0.46 & 295.85 \\
\hline 1905 & 286.38 & 281.31 & -0.35 & 288.44 & -0.25 & 296.90 \\
\hline 1906 & 286.45 & 281.48 & -0.18 & 288.47 & -0.22 & 297.48 \\
\hline 1907 & 286.28 & 281.05 & -0.61 & 288.4 & -0.29 & 298.05 \\
\hline 1908 & 286.23 & 281.22 & -0.44 & 288.26 & -0.43 & 298.63 \\
\hline 1909 & 286.22 & 281.25 & -0.41 & 288.24 & -0.45 & 299.20 \\
\hline 1910 & 286.26 & 281.31 & -0.35 & 288.27 & -0.42 & 299.42 \\
\hline 1911 & 286.21 & 281.18 & -0.48 & 288.26 & -0.43 & 299.63 \\
\hline 1912 & 286.32 & 281.18 & -0.48 & 288.41 & -0.28 & 299.85 \\
\hline 1913 & 286.34 & 281.35 & -0.31 & 288.37 & -0.32 & 300.07 \\
\hline 1914 & 286.52 & 281.61 & -0.05 & 288.52 & -0.17 & 300.28 \\
\hline 1915 & 286.56 & 281.58 & -0.08 & 288.59 & -0.1 & 300.50 \\
\hline 1916 & 286.34 & 281.19 & -0.47 & 288.43 & -0.26 & 300.68 \\
\hline 1917 & 286.27 & 281.02 & -0.64 & 288.4 & -0.29 & 300.87 \\
\hline
\end{tabular}




\section{Continued}

\begin{tabular}{|c|c|c|c|c|c|c|}
\hline 1918 & 286.37 & 281.16 & -0.5 & 288.48 & -0.21 & 301.05 \\
\hline 1919 & 286.41 & 281.32 & -0.34 & 288.48 & -0.21 & 301.23 \\
\hline 1920 & 286.43 & 281.31 & -0.35 & 288.51 & -0.18 & 301.42 \\
\hline 1921 & 286.50 & 281.52 & -0.14 & 288.52 & -0.17 & 301.60 \\
\hline 1922 & 286.42 & 281.41 & -0.25 & 288.45 & -0.24 & 302.25 \\
\hline 1923 & 286.40 & 281.37 & -0.29 & 288.45 & -0.24 & 302.90 \\
\hline 1924 & 286.42 & 281.41 & -0.25 & 288.45 & -0.24 & 303.55 \\
\hline 1925 & 286.48 & 281.51 & -0.15 & 288.5 & -0.19 & 304.20 \\
\hline 1926 & 286.58 & 281.64 & -0.02 & 288.59 & -0.1 & 304.85 \\
\hline 1927 & 286.48 & 281.43 & -0.23 & 288.53 & -0.16 & 305.50 \\
\hline 1928 & 286.47 & 281.51 & -0.15 & 288.49 & -0.2 & 305.64 \\
\hline 1929 & 286.33 & 281.17 & -0.49 & 288.42 & -0.27 & 305.76 \\
\hline 1930 & 286.55 & 281.54 & -0.12 & 288.58 & -0.11 & 305.91 \\
\hline 1931 & 286.61 & 281.67 & -0.01 & 288.61 & -0.08 & 306.05 \\
\hline 1932 & 286.53 & 281.64 & -0.02 & 288.52 & -0.17 & 306.19 \\
\hline 1933 & 286.40 & 281.31 & -0.35 & 288.47 & -0.22 & 306.33 \\
\hline 1934 & 286.55 & 281.6 & -0.06 & 288.56 & -0.13 & 306.46 \\
\hline 1935 & 286.50 & 281.48 & -0.18 & 288.54 & -0.15 & 306.60 \\
\hline 1936 & 286.54 & 281.53 & -0.13 & 288.57 & -0.12 & 306.76 \\
\hline 1937 & 286.64 & 281.63 & -0.03 & 288.68 & -0.01 & 306.93 \\
\hline 1938 & 286.63 & 281.82 & 0.16 & 288.59 & -0.1 & 307.09 \\
\hline 1939 & 286.66 & 281.74 & 0.08 & 288.66 & -0.03 & 307.25 \\
\hline 1940 & 286.82 & 281.73 & 0.07 & 288.89 & 0.2 & 307.41 \\
\hline 1941 & 286.93 & 281.75 & 0.09 & 289.04 & 0.35 & 307.58 \\
\hline 1942 & 286.77 & 281.71 & 0.05 & 288.82 & 0.13 & 307.74 \\
\hline 1943 & 286.76 & 281.72 & 0.06 & 288.81 & 0.12 & 307.90 \\
\hline 1944 & 286.94 & 281.85 & 0.19 & 289.01 & 0.32 & 308.38 \\
\hline 1945 & 286.85 & 281.58 & -0.08 & 288.99 & 0.3 & 308.86 \\
\hline 1946 & 286.65 & 281.66 & -0.01 & 288.68 & -0.01 & 309.34 \\
\hline 1947 & 286.62 & 281.7 & 0.04 & 288.62 & -0.07 & 309.82 \\
\hline 1948 & 286.60 & 281.71 & 0.05 & 288.59 & -0.1 & 310.30 \\
\hline 1949 & 286.58 & 281.59 & -0.07 & 288.61 & -0.08 & 310.76 \\
\hline 1950 & 286.50 & 281.33 & -0.33 & 288.6 & -0.09 & 311.26 \\
\hline 1951 & 286.66 & 281.6 & -0.06 & 288.71 & 0.02 & 311.74 \\
\hline
\end{tabular}




\section{Continued}

\begin{tabular}{|c|c|c|c|c|c|c|}
\hline 1952 & 286.70 & 281.61 & -0.05 & 288.77 & 0.08 & 312.22 \\
\hline 1953 & 286.79 & 281.86 & 0.2 & 288.79 & 0.1 & 312.70 \\
\hline 1954 & 286.56 & 281.53 & -0.13 & 288.6 & -0.09 & 313.22 \\
\hline 1955 & 286.52 & 281.54 & -0.12 & 288.55 & -0.14 & 313.73 \\
\hline 1956 & 286.47 & 281.26 & -0.4 & 288.59 & -0.1 & 314.25 \\
\hline 1957 & 286.73 & 281.62 & -0.04 & 288.8 & 0.11 & 314.77 \\
\hline 1958 & 286.79 & 281.81 & 0.15 & 288.81 & 0.12 & 315.28 \\
\hline 1959 & 286.74 & 281.74 & 0.08 & 288.77 & 0.08 & 315.97 \\
\hline 1960 & 286.71 & 281.65 & -0.01 & 288.76 & 0.07 & 316.91 \\
\hline 1961 & 286.75 & 281.77 & 0.11 & 288.78 & 0.09 & 317.64 \\
\hline 1962 & 286.77 & 281.81 & 0.15 & 288.78 & 0.09 & 318.45 \\
\hline 1963 & 286.78 & 281.87 & 0.21 & 288.77 & 0.08 & 318.99 \\
\hline 1964 & 286.52 & 281.44 & -0.22 & 288.58 & -0.11 & 319.62 \\
\hline 1965 & 286.59 & 281.53 & -0.13 & 288.64 & -0.05 & 320.04 \\
\hline 1966 & 286.64 & 281.6 & -0.06 & 288.69 & 0 & 321.38 \\
\hline 1967 & 286.65 & 281.67 & 0.01 & 288.68 & -0.01 & 322.16 \\
\hline 1968 & 286.63 & 281.55 & -0.11 & 288.7 & 0.01 & 323.04 \\
\hline 1969 & 286.76 & 281.58 & -0.08 & 288.86 & 0.17 & 324.62 \\
\hline 1970 & 286.72 & 281.71 & 0.05 & 288.75 & 0.06 & 325.68 \\
\hline 1971 & 286.60 & 281.64 & -0.02 & 288.61 & -0.08 & 326.32 \\
\hline 1972 & 286.69 & 281.5 & -0.16 & 288.8 & 0.11 & 327.45 \\
\hline 1973 & 286.86 & 282 & 0.34 & 288.83 & 0.14 & 329.68 \\
\hline 1974 & 286.59 & 281.48 & -0.18 & 288.67 & -0.02 & 330.18 \\
\hline 1975 & 286.67 & 281.8 & 0.14 & 288.65 & -0.04 & 331.08 \\
\hline 1976 & 286.59 & 281.43 & -0.23 & 288.68 & -0.01 & 332.05 \\
\hline 1977 & 286.87 & 281.92 & 0.26 & 288.88 & 0.19 & 333.76 \\
\hline 1976 & 286.78 & 281.77 & 0.11 & 288.81 & 0.12 & 335.41 \\
\hline 1979 & 286.88 & 281.84 & 0.18 & 288.93 & 0.24 & 336.76 \\
\hline 1980 & 286.94 & 281.98 & 0.32 & 288.95 & 0.26 & 338.68 \\
\hline 1981 & 286.99 & 282.19 & 0.53 & 288.94 & 0.25 & 340.10 \\
\hline 1982 & 286.85 & 281.78 & 0.12 & 288.91 & 0.22 & 341.44 \\
\hline 1983 & 287.02 & 282.17 & 0.51 & 288.99 & 0.3 & 343.03 \\
\hline 1984 & 286.82 & 281.73 & 0.07 & 288.89 & 0.2 & 344.58 \\
\hline 1985 & 286.82 & 281.77 & 0.11 & 288.87 & 0.18 & 346.04 \\
\hline
\end{tabular}




\section{Continued}

\begin{tabular}{|c|c|c|c|c|c|c|}
\hline 1986 & 286.90 & 281.97 & 0.31 & 288.9 & 0.21 & 347.39 \\
\hline 1987 & 287.05 & 282.11 & 0.45 & 289.05 & 0.36 & 349.16 \\
\hline 1988 & 287.06 & 282.25 & 0.59 & 289.01 & 0.32 & 351.56 \\
\hline 1989 & 286.96 & 282.03 & 0.37 & 288.96 & 0.27 & 353.07 \\
\hline 1990 & 287.11 & 282.32 & 0.66 & 289.06 & 0.37 & 354.35 \\
\hline 1991 & 287.05 & 282.19 & 0.53 & 289.03 & 0.34 & 355.57 \\
\hline 1992 & 286.89 & 281.91 & 0.25 & 288.92 & 0.23 & 356.38 \\
\hline 1993 & 286.95 & 282.01 & 0.35 & 288.95 & 0.25 & 357.07 \\
\hline 1994 & 287.01 & 282.15 & 0.49 & 288.98 & 0.29 & 358.82 \\
\hline 1995 & 287.13 & 282.44 & 0.78 & 289.04 & 0.35 & 360.80 \\
\hline 1996 & 286.98 & 282.01 & 0.35 & 289 & 0.31 & 362.59 \\
\hline 1997 & 287.18 & 282.3 & 0.64 & 289.16 & 0.47 & 363.71 \\
\hline 1998 & 287.32 & 282.65 & 0.99 & 289.22 & 0.52 & 366.65 \\
\hline 1999 & 287.11 & 282.45 & 0.79 & 289 & 0.31 & 368.33 \\
\hline 2000 & 287.09 & 282.3 & 0.64 & 289.03 & 0.34 & 369.52 \\
\hline 2001 & 287.23 & 282.52 & 0.86 & 289.15 & 0.46 & 371.13 \\
\hline 2002 & 287.29 & 282.64 & 0.98 & 289.18 & 0.49 & 373.22 \\
\hline 2003 & 287.31 & 282.62 & 0.96 & 289.21 & 0.52 & 375.77 \\
\hline 2004 & 287.25 & 282.49 & 0.83 & 289.18 & 0.49 & 377.49 \\
\hline 2005 & 287.34 & 282.77 & 1.11 & 289.2 & 0.5 & 379.80 \\
\hline 2006 & 287.30 & 282.66 & 1 & 289.19 & 0.5 & 381.90 \\
\hline 2007 & 287.29 & 282.8 & 1.14 & 289.12 & 0.43 & 383.77 \\
\hline 2008 & 287.21 & 282.57 & 0.91 & 289.1 & 0.41 & 385.59 \\
\hline 2009 & 287.31 & 282.59 & 0.93 & 289.23 & 0.54 & 387.37 \\
\hline 2010 & 287.40 & 282.83 & 1.17 & 289.25 & 0.56 & 389.85 \\
\hline 2011 & 287.24 & 282.6 & 0.94 & 289.13 & 0.44 & 391.62 \\
\hline 2012 & 287.30 & 282.64 & 0.98 & 289.2 & 0.51 & 393.81 \\
\hline 2013 & 287.34 & 282.71 & 1.05 & 289.22 & 0.53 & 396.52 \\
\hline 2014 & 287.40 & 282.69 & 1.03 & 289.32 & 0.63 & 398.65 \\
\hline 2015 & 287.60 & 283.08 & 1.42 & 289.44 & 0.75 & 400.83 \\
\hline 2016 & 287.67 & 283.2 & 1.54 & 289.48 & 0.79 & 404.24 \\
\hline 2017 & 287.58 & 283.08 & 1.42 & 289.41 & 0.72 & 406.55 \\
\hline 2018 & 287.50 & 282.88 & 1.22 & 289.37 & 0.68 & 408.52 \\
\hline 2019 & 287.62 & 283.08 & 1.42 & 289.46 & 0.77 & 410.44 \\
\hline
\end{tabular}


Table S2. Changes in concentration of water vapor, average global temperature, back radiation from water vapor and theoretical $\mathrm{CO}_{2}$ heating, Figure 4, Figure 6, Figure 11 \& Figure 14.

\begin{tabular}{|c|c|c|c|c|c|c|c|}
\hline Year & $\begin{array}{l}\Delta \mathrm{TPW} \% \\
\text { from } 1880\end{array}$ & $\begin{array}{c}\Delta \mathrm{T}_{\mathrm{Avg}} \% \\
\text { from } 1880\end{array}$ & $\begin{array}{c}\text { TPW } \\
\text { kgm }^{-2}\end{array}$ & $\begin{array}{c}\Delta \mathrm{TPW} \\
\text { from } 1880 \\
\mathrm{kgm}^{-2}\end{array}$ & $\begin{array}{c}\Delta \text { Tavg } \\
\text { from } 1880 \\
\text { Deg. C }\end{array}$ & $\begin{array}{c}\Delta \mathrm{WV} \\
\text { from } 1880 \\
\mathrm{Wm}^{-2}\end{array}$ & $\begin{array}{l}\mathrm{TH}_{\mathrm{CO} 2} \\
\mathrm{Wm}^{-2}\end{array}$ \\
\hline 1880 & $0.00 \%$ & $0.00 \%$ & 18.35 & 0.00 & 0.00 & 0.00 & 0 \\
\hline 1881 & $0.53 \%$ & $0.29 \%$ & 18.45 & 0.10 & 0.04 & 0.39 & 0.00 \\
\hline 1882 & $0.41 \%$ & $0.21 \%$ & 18.43 & 0.07 & 0.03 & 0.30 & 0.01 \\
\hline 1883 & $-1.05 \%$ & $-0.47 \%$ & 18.16 & -0.19 & -0.06 & -0.77 & 0.01 \\
\hline 1884 & $-1.90 \%$ & $-1.07 \%$ & 18.00 & -0.35 & -0.14 & -1.40 & 0.02 \\
\hline 1885 & $-1.35 \%$ & $-0.93 \%$ & 18.11 & -0.25 & -0.12 & -0.99 & 0.02 \\
\hline 1886 & $-1.02 \%$ & $-0.80 \%$ & 18.16 & -0.19 & -0.11 & -0.75 & 0.02 \\
\hline 1887 & $-1.27 \%$ & $-1.05 \%$ & 18.12 & -0.23 & -0.14 & -0.94 & 0.03 \\
\hline 1888 & $0.28 \%$ & $0.03 \%$ & 18.40 & 0.05 & 0.00 & 0.20 & 0.03 \\
\hline 1889 & $1.13 \%$ & $0.45 \%$ & 18.56 & 0.21 & 0.06 & 0.83 & 0.04 \\
\hline 1890 & $-1.84 \%$ & $-1.44 \%$ & 18.02 & -0.34 & -0.19 & -1.36 & 0.04 \\
\hline 1891 & $-0.94 \%$ & $-0.71 \%$ & 18.18 & -0.17 & -0.10 & -0.69 & 0.05 \\
\hline 1892 & $-1.43 \%$ & $-1.12 \%$ & 18.09 & -0.26 & -0.15 & -1.06 & 0.06 \\
\hline 1893 & $-1.71 \%$ & $-1.26 \%$ & 18.04 & -0.31 & -0.17 & -1.26 & 0.06 \\
\hline 1894 & $-1.16 \%$ & $-1.12 \%$ & 18.14 & -0.21 & -0.15 & -0.86 & 0.07 \\
\hline 1895 & $-0.43 \%$ & $-0.56 \%$ & 18.27 & -0.08 & -0.07 & -0.32 & 0.07 \\
\hline 1896 & $1.00 \%$ & $0.45 \%$ & 18.54 & 0.18 & 0.06 & 0.73 & 0.08 \\
\hline 1897 & $1.23 \%$ & $0.47 \%$ & 18.58 & 0.23 & 0.06 & 0.89 & 0.08 \\
\hline 1898 & $-0.72 \%$ & $-0.81 \%$ & 18.22 & -0.13 & -0.11 & -0.53 & 0.09 \\
\hline 1899 & $0.81 \%$ & $0.04 \%$ & 18.50 & 0.15 & 0.01 & 0.59 & 0.09 \\
\hline 1900 & $1.74 \%$ & $0.62 \%$ & 18.67 & 0.32 & 0.08 & 1.26 & 0.09 \\
\hline 1901 & $1.14 \%$ & $0.07 \%$ & 18.56 & 0.21 & 0.01 & 0.81 & 0.08 \\
\hline 1902 & $-0.20 \%$ & $-0.65 \%$ & 18.32 & -0.04 & -0.09 & -0.16 & 0.08 \\
\hline 1903 & $-1.62 \%$ & $-1.56 \%$ & 18.06 & -0.30 & -0.21 & -1.21 & 0.07 \\
\hline 1904 & $-2.60 \%$ & $-2.19 \%$ & 17.88 & -0.48 & -0.29 & -1.94 & 0.09 \\
\hline 1905 & $-0.65 \%$ & $-0.86 \%$ & 18.23 & -0.12 & -0.11 & -0.49 & 0.11 \\
\hline 1906 & $0.47 \%$ & $-0.33 \%$ & 18.44 & 0.09 & -0.04 & 0.33 & 0.12 \\
\hline 1907 & $-2.32 \%$ & $-1.63 \%$ & 17.93 & -0.43 & -0.22 & -1.71 & 0.13 \\
\hline 1908 & $-2.34 \%$ & $-2.01 \%$ & 17.92 & -0.43 & -0.27 & -1.75 & 0.14 \\
\hline 1909 & $-2.31 \%$ & $-2.05 \%$ & 17.93 & -0.42 & -0.27 & -1.73 & 0.15 \\
\hline 1910 & $-1.79 \%$ & $-1.76 \%$ & 18.02 & -0.33 & -0.24 & -1.34 & 0.16 \\
\hline 1911 & $-2.56 \%$ & $-2.10 \%$ & 17.88 & -0.47 & -0.28 & -1.90 & 0.16 \\
\hline 1912 & $-1.55 \%$ & $-1.30 \%$ & 18.07 & -0.28 & -0.17 & -1.15 & 0.16 \\
\hline 1913 & $-0.90 \%$ & $-1.14 \%$ & 18.19 & -0.17 & -0.15 & -0.68 & 0.17 \\
\hline
\end{tabular}




\section{Continued}

\begin{tabular}{|c|c|c|c|c|c|c|c|}
\hline 1914 & $1.52 \%$ & $0.22 \%$ & 18.63 & 0.28 & 0.03 & 1.08 & 0.17 \\
\hline 1915 & $1.83 \%$ & $0.53 \%$ & 18.69 & 0.34 & 0.07 & 1.32 & 0.18 \\
\hline 1916 & $-1.36 \%$ & $-1.17 \%$ & 18.10 & -0.25 & -0.16 & -1.01 & 0.18 \\
\hline 1917 & $-2.48 \%$ & $-1.70 \%$ & 17.90 & -0.46 & -0.23 & -1.83 & 0.18 \\
\hline 1918 & $-1.19 \%$ & $-0.97 \%$ & 18.13 & -0.22 & -0.13 & -0.88 & 0.19 \\
\hline 1919 & $-0.32 \%$ & $-0.62 \%$ & 18.29 & -0.06 & -0.08 & -0.25 & 0.19 \\
\hline 1920 & $-0.17 \%$ & $-0.48 \%$ & 18.32 & -0.03 & -0.06 & -0.14 & 0.19 \\
\hline 1921 & $1.03 \%$ & $0.02 \%$ & 18.54 & 0.19 & 0.00 & 0.73 & 0.20 \\
\hline 1922 & $-0.04 \%$ & $-0.59 \%$ & 18.35 & -0.01 & -0.08 & -0.05 & 0.21 \\
\hline 1923 & $-0.26 \%$ & $-0.67 \%$ & 18.31 & -0.05 & -0.09 & -0.20 & 0.22 \\
\hline 1924 & $-0.04 \%$ & $-0.59 \%$ & 18.35 & -0.01 & -0.08 & -0.05 & 0.23 \\
\hline 1925 & $0.84 \%$ & $-0.10 \%$ & 18.51 & 0.15 & -0.01 & 0.60 & 0.24 \\
\hline 1926 & $2.15 \%$ & $0.66 \%$ & 18.75 & 0.40 & 0.09 & 1.55 & 0.25 \\
\hline 1927 & $0.61 \%$ & $-0.12 \%$ & 18.46 & 0.11 & -0.02 & 0.43 & 0.26 \\
\hline 1928 & $0.77 \%$ & $-0.16 \%$ & 18.49 & 0.14 & -0.02 & 0.54 & 0.27 \\
\hline 1929 & $-1.54 \%$ & $-1.27 \%$ & 18.07 & -0.28 & -0.17 & -1.14 & 0.27 \\
\hline 1930 & $1.54 \%$ & $0.39 \%$ & 18.64 & 0.28 & 0.05 & 1.11 & 0.27 \\
\hline 1931 & $2.45 \%$ & $0.83 \%$ & 18.80 & 0.45 & 0.11 & 1.77 & 0.27 \\
\hline 1932 & $1.68 \%$ & $0.28 \%$ & 18.66 & 0.31 & 0.04 & 1.20 & 0.28 \\
\hline 1933 & $-0.45 \%$ & $-0.70 \%$ & 18.27 & -0.08 & -0.09 & -0.34 & 0.28 \\
\hline 1934 & $1.73 \%$ & $0.41 \%$ & 18.67 & 0.32 & 0.05 & 1.25 & 0.28 \\
\hline 1935 & $0.95 \%$ & $0.04 \%$ & 18.53 & 0.17 & 0.01 & 0.68 & 0.28 \\
\hline 1936 & $1.42 \%$ & $0.31 \%$ & 18.61 & 0.26 & 0.04 & 1.02 & 0.29 \\
\hline 1937 & $2.72 \%$ & $1.11 \%$ & 18.85 & 0.50 & 0.15 & 1.97 & 0.29 \\
\hline 1938 & $3.13 \%$ & $1.05 \%$ & 18.93 & 0.57 & 0.14 & 2.25 & 0.29 \\
\hline 1939 & $3.18 \%$ & $1.25 \%$ & 18.94 & 0.58 & 0.17 & 2.29 & 0.30 \\
\hline 1940 & $4.71 \%$ & $2.45 \%$ & 19.22 & 0.86 & 0.33 & 3.41 & 0.30 \\
\hline 1941 & $5.87 \%$ & $3.29 \%$ & 19.43 & 1.08 & 0.44 & 4.24 & 0.30 \\
\hline 1942 & $4.12 \%$ & $2.03 \%$ & 19.11 & 0.76 & 0.27 & 2.98 & 0.30 \\
\hline 1943 & $4.10 \%$ & $2.00 \%$ & 19.11 & 0.75 & 0.27 & 2.97 & 0.31 \\
\hline 1944 & $6.20 \%$ & $3.35 \%$ & 19.49 & 1.14 & 0.45 & 4.47 & 0.32 \\
\hline 1945 & $4.60 \%$ & $2.66 \%$ & 19.20 & 0.84 & 0.35 & 3.33 & 0.32 \\
\hline 1946 & $2.88 \%$ & $1.18 \%$ & 18.88 & 0.53 & 0.16 & 2.08 & 0.33 \\
\hline 1947 & $2.68 \%$ & $0.95 \%$ & 18.85 & 0.49 & 0.13 & 1.93 & 0.34 \\
\hline 1948 & $2.53 \%$ & $0.81 \%$ & 18.82 & 0.47 & 0.11 & 1.82 & 0.35 \\
\hline 1949 & $2.02 \%$ & $0.65 \%$ & 18.72 & 0.37 & 0.09 & 1.46 & 0.36 \\
\hline
\end{tabular}




\section{Continued}

\begin{tabular}{|c|c|c|c|c|c|c|c|}
\hline 1950 & $0.55 \%$ & $0.04 \%$ & 18.45 & 0.10 & 0.01 & 0.40 & 0.36 \\
\hline 1951 & $2.76 \%$ & $1.21 \%$ & 18.86 & 0.51 & 0.16 & 2.00 & 0.37 \\
\hline 1952 & $3.23 \%$ & $1.55 \%$ & 18.95 & 0.59 & 0.21 & 2.34 & 0.38 \\
\hline 1953 & $4.72 \%$ & $2.20 \%$ & 19.22 & 0.87 & 0.29 & 3.40 & 0.39 \\
\hline 1954 & $1.63 \%$ & $0.47 \%$ & 18.65 & 0.30 & 0.06 & 1.18 & 0.40 \\
\hline 1955 & $1.34 \%$ & $0.23 \%$ & 18.60 & 0.25 & 0.03 & 0.96 & 0.41 \\
\hline 1956 & $0.10 \%$ & $-0.17 \%$ & 18.37 & 0.02 & -0.02 & 0.07 & 0.42 \\
\hline 1957 & $3.49 \%$ & $1.73 \%$ & 18.99 & 0.64 & 0.23 & 2.53 & 0.42 \\
\hline 1958 & $4.59 \%$ & $2.20 \%$ & 19.19 & 0.84 & 0.29 & 3.31 & 0.43 \\
\hline 1959 & $3.93 \%$ & $1.83 \%$ & 19.07 & 0.72 & 0.24 & 2.84 & 0.45 \\
\hline 1960 & $3.38 \%$ & $1.58 \%$ & 18.97 & 0.62 & 0.21 & 2.45 & 0.46 \\
\hline 1961 & $4.16 \%$ & $1.95 \%$ & 19.12 & 0.76 & 0.26 & 3.01 & 0.47 \\
\hline 1962 & $4.38 \%$ & $2.04 \%$ & 19.16 & 0.80 & 0.27 & 3.16 & 0.49 \\
\hline 1963 & $4.64 \%$ & $2.11 \%$ & 19.20 & 0.85 & 0.28 & 3.34 & 0.50 \\
\hline 1964 & $1.00 \%$ & $0.17 \%$ & 18.54 & 0.18 & 0.02 & 0.72 & 0.51 \\
\hline 1965 & $1.90 \%$ & $0.68 \%$ & 18.70 & 0.35 & 0.09 & 1.38 & 0.51 \\
\hline 1966 & $2.62 \%$ & $1.10 \%$ & 18.83 & 0.48 & 0.15 & 1.90 & 0.54 \\
\hline 1967 & $2.93 \%$ & $1.20 \%$ & 18.89 & 0.54 & 0.16 & 2.12 & 0.55 \\
\hline 1968 & $2.42 \%$ & $1.05 \%$ & 18.80 & 0.44 & 0.14 & 1.76 & 0.56 \\
\hline 1969 & $3.69 \%$ & $1.97 \%$ & 19.03 & 0.68 & 0.26 & 2.68 & 0.59 \\
\hline 1970 & $3.63 \%$ & $1.66 \%$ & 19.02 & 0.67 & 0.22 & 2.63 & 0.61 \\
\hline 1971 & $2.29 \%$ & $0.76 \%$ & 18.77 & 0.42 & 0.10 & 1.65 & 0.62 \\
\hline 1972 & $2.84 \%$ & $1.47 \%$ & 18.87 & 0.52 & 0.20 & 2.06 & 0.64 \\
\hline 1973 & $5.76 \%$ & $2.71 \%$ & 19.41 & 1.06 & 0.36 & 4.14 & 0.67 \\
\hline 1974 & $1.84 \%$ & $0.74 \%$ & 18.69 & 0.34 & 0.10 & 1.33 & 0.68 \\
\hline 1975 & $3.43 \%$ & $1.32 \%$ & 18.98 & 0.63 & 0.18 & 2.47 & 0.70 \\
\hline 1976 & $1.63 \%$ & $0.68 \%$ & 18.65 & 0.30 & 0.09 & 1.19 & 0.71 \\
\hline 1977 & $5.67 \%$ & $2.81 \%$ & 19.39 & 1.04 & 0.37 & 4.09 & 0.74 \\
\hline 1976 & $4.37 \%$ & $2.11 \%$ & 19.16 & 0.80 & 0.28 & 3.16 & 0.76 \\
\hline 1979 & $5.59 \%$ & $2.90 \%$ & 19.38 & 1.03 & 0.39 & 4.03 & 0.79 \\
\hline 1980 & $6.49 \%$ & $3.31 \%$ & 19.54 & 1.19 & 0.44 & 4.67 & 0.82 \\
\hline 1981 & $7.56 \%$ & $3.71 \%$ & 19.74 & 1.39 & 0.50 & 5.41 & 0.84 \\
\hline 1982 & $5.12 \%$ & $2.66 \%$ & 19.29 & 0.94 & 0.36 & 3.70 & 0.86 \\
\hline 1983 & $7.80 \%$ & $3.94 \%$ & 19.78 & 1.43 & 0.53 & 5.59 & 0.88 \\
\hline 1984 & $4.71 \%$ & $2.45 \%$ & 19.22 & 0.86 & 0.33 & 3.41 & 0.91 \\
\hline
\end{tabular}




\section{Continued}

\begin{tabular}{|c|c|c|c|c|c|c|c|}
\hline 1985 & $4.79 \%$ & $2.43 \%$ & 19.23 & 0.88 & 0.32 & 3.46 & 0.93 \\
\hline 1986 & $6.08 \%$ & $3.02 \%$ & 19.47 & 1.12 & 0.40 & 4.38 & 0.95 \\
\hline 1987 & $7.90 \%$ & $4.12 \%$ & 19.80 & 1.45 & 0.55 & 5.66 & 0.98 \\
\hline 1988 & $8.38 \%$ & $4.21 \%$ & 19.89 & 1.54 & 0.56 & 5.99 & 1.02 \\
\hline 1989 & $6.83 \%$ & $3.47 \%$ & 19.61 & 1.25 & 0.46 & 4.91 & 1.04 \\
\hline 1990 & $9.11 \%$ & $4.63 \%$ & 20.02 & 1.67 & 0.62 & 6.51 & 1.06 \\
\hline 1991 & $8.19 \%$ & $4.19 \%$ & 19.86 & 1.50 & 0.56 & 5.87 & 1.08 \\
\hline 1992 & $5.90 \%$ & $3.00 \%$ & 19.44 & 1.08 & 0.40 & 4.25 & 1.09 \\
\hline 1993 & $6.65 \%$ & $3.38 \%$ & 19.57 & 1.22 & 0.45 & 4.78 & 1.10 \\
\hline 1994 & $7.62 \%$ & $3.84 \%$ & 19.75 & 1.40 & 0.51 & 5.46 & 1.13 \\
\hline 1995 & $9.63 \%$ & $4.79 \%$ & 20.12 & 1.77 & 0.64 & 6.86 & 1.15 \\
\hline 1996 & $7.00 \%$ & $3.64 \%$ & 19.64 & 1.28 & 0.49 & 5.03 & 1.18 \\
\hline 1997 & $9.71 \%$ & $5.12 \%$ & 20.13 & 1.78 & 0.68 & 6.94 & 1.20 \\
\hline 1998 & $12.05 \%$ & $6.20 \%$ & 20.56 & 2.21 & 0.83 & 8.54 & 1.24 \\
\hline 1999 & $9.40 \%$ & $4.59 \%$ & 20.08 & 1.72 & 0.61 & 6.69 & 1.27 \\
\hline 2000 & $8.79 \%$ & $4.43 \%$ & 19.97 & 1.61 & 0.59 & 6.28 & 1.28 \\
\hline 2001 & $10.84 \%$ & $5.55 \%$ & 20.34 & 1.99 & 0.74 & 7.71 & 1.31 \\
\hline 2002 & $11.71 \%$ & $5.97 \%$ & 20.50 & 2.15 & 0.80 & 8.31 & 1.34 \\
\hline 2003 & $11.81 \%$ & $6.08 \%$ & 20.52 & 2.17 & 0.81 & 8.38 & 1.37 \\
\hline 2004 & $10.89 \%$ & $5.64 \%$ & 20.35 & 2.00 & 0.75 & 7.75 & 1.40 \\
\hline 2005 & $12.56 \%$ & $6.35 \%$ & 20.66 & 2.31 & 0.85 & 8.89 & 1.43 \\
\hline 2006 & $11.89 \%$ & $6.06 \%$ & 20.53 & 2.18 & 0.81 & 8.43 & 1.46 \\
\hline 2007 & $12.16 \%$ & $5.99 \%$ & 20.58 & 2.23 & 0.80 & 8.60 & 1.49 \\
\hline 2008 & $10.76 \%$ & $5.39 \%$ & 20.33 & 1.97 & 0.72 & 7.64 & 1.51 \\
\hline 2009 & $11.79 \%$ & $6.12 \%$ & 20.52 & 2.16 & 0.82 & 8.37 & 1.54 \\
\hline 2010 & $13.25 \%$ & $6.75 \%$ & 20.78 & 2.43 & 0.90 & 9.36 & 1.57 \\
\hline 2011 & $11.14 \%$ & $5.61 \%$ & 20.40 & 2.04 & 0.75 & 7.91 & 1.59 \\
\hline 2012 & $11.85 \%$ & $6.07 \%$ & 20.53 & 2.18 & 0.81 & 8.41 & 1.62 \\
\hline 2013 & $12.38 \%$ & $6.33 \%$ & 20.62 & 2.27 & 0.84 & 8.77 & 1.66 \\
\hline 2014 & $12.98 \%$ & $6.82 \%$ & 20.74 & 2.38 & 0.91 & 9.20 & 1.69 \\
\hline 2015 & $15.99 \%$ & $8.30 \%$ & 21.29 & 2.93 & 1.11 & 11.23 & 1.72 \\
\hline 2016 & $16.94 \%$ & $8.78 \%$ & 21.46 & 3.11 & 1.17 & 11.87 & 1.76 \\
\hline 2017 & $15.77 \%$ & $8.14 \%$ & 21.25 & 2.89 & 1.09 & 11.08 & 1.79 \\
\hline 2018 & $14.38 \%$ & $7.50 \%$ & 20.99 & 2.64 & 1.00 & 10.15 & 1.82 \\
\hline 2019 & $16.13 \%$ & $8.41 \%$ & 21.31 & 2.96 & 1.12 & 11.33 & 1.84 \\
\hline
\end{tabular}


Table S3. Year over year changes in water vapor heating, $\Delta \mathrm{WV}$, compared to changes in heating from $\mathrm{CO}_{2}, \Delta \mathrm{TH}_{\mathrm{CO} 2}$, for the same year and changes in efficiency of ocean heating, Eff $_{\Delta \mathrm{THO}}$, Figure 7.

\begin{tabular}{|c|c|}
\hline YoY $\Delta \mathrm{TH}_{\mathrm{CO} 2}$ & YoY $\Delta \mathrm{WV}$ \\
\hline $\mathrm{Wm}^{-2}$ & $\mathrm{Wm}^{-2}$ \\
\hline-0.005 & -1.05 \\
\hline-0.005 & -0.98 \\
\hline-0.005 & -0.45 \\
\hline-0.005 & 0.67 \\
\hline 0.002 & -0.57 \\
\hline 0.002 & 1.58 \\
\hline 0.002 & -1.54 \\
\hline 0.002 & -0.57 \\
\hline 0.002 & 0.65 \\
\hline 0.002 & 2.25 \\
\hline 0.002 & -1.68 \\
\hline 0.002 & 0.11 \\
\hline 0.003 & -0.01 \\
\hline 0.003 & -1.26 \\
\hline 0.003 & 0.83 \\
\hline 0.003 & 1.12 \\
\hline 0.003 & 0.04 \\
\hline 0.003 & 0.28 \\
\hline 0.003 & 0.94 \\
\hline 0.003 & 0.35 \\
\hline 0.003 & 0.87 \\
\hline 0.003 & 0.11 \\
\hline 0.003 & 0.63 \\
\hline 0.003 & 0.96 \\
\hline 0.003 & -0.82 \\
\hline 0.003 & -2.33 \\
\hline 0.004 & 0.24 \\
\hline 0.004 & 1.77 \\
\hline 0.004 & 0.47 \\
\hline 0.004 & 0.75 \\
\hline 0.004 & -0.56 \\
\hline 0.004 & 0.39 \\
\hline
\end{tabular}




\section{Continued}

\begin{tabular}{|c|c|}
\hline 0.004 & -0.18 \\
\hline 0.004 & 0.24 \\
\hline 0.004 & 0.41 \\
\hline 0.004 & -0.62 \\
\hline 0.004 & -1.07 \\
\hline 0.004 & -0.09 \\
\hline 0.004 & 0.39 \\
\hline 0.005 & 1.12 \\
\hline 0.005 & -1.43 \\
\hline 0.005 & 0.16 \\
\hline 0.005 & 1.05 \\
\hline 0.005 & 0.54 \\
\hline 0.005 & 0.40 \\
\hline 0.005 & -0.21 \\
\hline 0.005 & -0.36 \\
\hline 0.005 & 0.66 \\
\hline 0.005 & -2.18 \\
\hline 0.005 & 0.62 \\
\hline 0.005 & 1.14 \\
\hline 0.007 & 0.65 \\
\hline 0.008 & -2.81 \\
\hline 0.008 & 1.06 \\
\hline 0.008 & 0.34 \\
\hline 0.008 & 1.60 \\
\hline 0.008 & -1.06 \\
\hline 0.008 & -0.36 \\
\hline 0.008 & -0.11 \\
\hline 0.008 & -0.15 \\
\hline 0.008 & -1.25 \\
\hline 0.008 & -1.14 \\
\hline 0.008 & 1.51 \\
\hline 0.009 & 0.78 \\
\hline 0.009 & 2.46 \\
\hline 0.009 & -0.89 \\
\hline 0.009 & -0.21 \\
\hline 0.009 & -2.23 \\
\hline
\end{tabular}




\section{Continued}

\begin{tabular}{|c|c|}
\hline 0.009 & 0.18 \\
\hline 0.010 & 0.02 \\
\hline 0.010 & -0.03 \\
\hline 0.010 & -2.04 \\
\hline 0.010 & 0.53 \\
\hline 0.010 & 0.82 \\
\hline 0.011 & -0.97 \\
\hline 0.011 & -2.62 \\
\hline 0.011 & -1.12 \\
\hline 0.011 & 0.96 \\
\hline 0.011 & 0.64 \\
\hline 0.011 & 0.16 \\
\hline 0.011 & -0.16 \\
\hline 0.012 & -0.78 \\
\hline 0.012 & -0.47 \\
\hline 0.012 & -1.62 \\
\hline 0.012 & 0.56 \\
\hline 0.013 & 0.22 \\
\hline 0.014 & 0.15 \\
\hline 0.015 & 1.14 \\
\hline 0.015 & -0.36 \\
\hline 0.016 & -1.28 \\
\hline 0.016 & -0.40 \\
\hline 0.017 & 1.90 \\
\hline 0.017 & -0.41 \\
\hline 0.017 & -0.05 \\
\hline 0.018 & -0.64 \\
\hline 0.018 & 0.41 \\
\hline 0.019 & 1.45 \\
\hline 0.019 & -0.73 \\
\hline 0.019 & 1.60 \\
\hline 0.021 & 0.92 \\
\hline 0.021 & -1.71 \\
\hline 0.022 & 0.87 \\
\hline 0.022 & 0.52 \\
\hline 0.022 & 0.75 \\
\hline
\end{tabular}




\section{Continued}

\begin{tabular}{|c|c|}
\hline 0.023 & 0.05 \\
\hline 0.023 & -1.08 \\
\hline 0.023 & 1.43 \\
\hline 0.024 & -2.18 \\
\hline 0.024 & -1.45 \\
\hline 0.024 & -0.63 \\
\hline 0.024 & -1.85 \\
\hline 0.025 & 0.73 \\
\hline 0.025 & 1.89 \\
\hline 0.025 & 1.18 \\
\hline 0.025 & -0.95 \\
\hline 0.026 & -0.93 \\
\hline 0.026 & -0.93 \\
\hline 0.026 & 0.92 \\
\hline 0.026 & 0.17 \\
\hline 0.026 & 0.68 \\
\hline 0.026 & -1.82 \\
\hline 0.027 & 1.29 \\
\hline 0.028 & 2.90 \\
\hline 0.029 & 0.43 \\
\hline 0.029 & 2.04 \\
\hline 0.029 & 1.39 \\
\hline 0.029 & -0.46 \\
\hline 0.030 & 0.50 \\
\hline 0.030 & 0.60 \\
\hline 0.030 & 0.64 \\
\hline 0.030 & -0.79 \\
\hline 0.033 & 1.14 \\
\hline 0.034 & 0.99 \\
\hline 0.036 & 2.08 \\
\hline 0.036 & 0.08 \\
\hline 0.037 & 0.33 \\
\hline 0.037 & 0.36 \\
\hline 0.043 & 1.61 \\
\hline 0.045 & 0.64 \\
\hline
\end{tabular}


Table S4. Comparison between the average global temperature record [1] [2] [3] and the calculated changes in the average global temperature from Equations (3)-(5), Figure 8, Figure 9 \& Figure 12.

\begin{tabular}{|c|c|c|c|c|}
\hline \multirow[t]{2}{*}{ Year } & Avg. Global & $\begin{array}{l}\text { Avg. Global Temp. } \\
\text { from Equation ( } 3 \text { ) }\end{array}$ & $\begin{array}{l}\text { Avg. Global Temp. } \\
\text { from Equation (4) }\end{array}$ & $\begin{array}{l}\text { Avg. Global Temp. } \\
\text { from Equation (5) }\end{array}$ \\
\hline & Temp. Deg. C & Temp. Deg. C & Temp. Deg. C & Temp. Deg. C \\
\hline 1880 & 13.34 & 13.34 & 13.34 & 13.29 \\
\hline 1881 & 13.38 & 13.38 & 13.38 & 13.33 \\
\hline 1882 & 13.37 & 13.37 & 13.37 & 13.32 \\
\hline 1883 & 13.28 & 13.27 & 13.27 & 13.22 \\
\hline 1884 & 13.20 & 13.21 & 13.21 & 13.16 \\
\hline 1885 & 13.22 & 13.25 & 13.25 & 13.20 \\
\hline 1886 & 13.24 & 13.27 & 13.27 & 13.22 \\
\hline 1887 & 13.20 & 13.26 & 13.25 & 13.20 \\
\hline 1888 & 13.35 & 13.37 & 13.36 & 13.31 \\
\hline 1889 & 13.41 & 13.43 & 13.42 & 13.38 \\
\hline 1890 & 13.15 & 13.22 & 13.21 & 13.16 \\
\hline 1891 & 13.25 & 13.28 & 13.28 & 13.23 \\
\hline 1892 & 13.20 & 13.25 & 13.24 & 13.19 \\
\hline 1893 & 13.18 & 13.23 & 13.22 & 13.17 \\
\hline 1894 & 13.20 & 13.27 & 13.26 & 13.21 \\
\hline 1895 & 13.27 & 13.32 & 13.31 & 13.26 \\
\hline 1896 & 13.41 & 13.42 & 13.41 & 13.37 \\
\hline 1897 & 13.41 & 13.44 & 13.43 & 13.38 \\
\hline 1898 & 13.24 & 13.30 & 13.29 & 13.24 \\
\hline 1899 & 13.35 & 13.41 & 13.40 & 13.35 \\
\hline 1900 & 13.43 & 13.47 & 13.47 & 13.42 \\
\hline 1901 & 13.35 & 13.43 & 13.42 & 13.38 \\
\hline 1902 & 13.26 & 13.34 & 13.33 & 13.28 \\
\hline 1903 & 13.14 & 13.24 & 13.23 & 13.18 \\
\hline 1904 & 13.05 & 13.17 & 13.16 & 13.10 \\
\hline 1905 & 13.23 & 13.31 & 13.30 & 13.25 \\
\hline 1906 & 13.30 & 13.39 & 13.38 & 13.33 \\
\hline 1907 & 13.13 & 13.19 & 13.18 & 13.12 \\
\hline 1908 & 13.08 & 13.19 & 13.18 & 13.12 \\
\hline 1909 & 13.07 & 13.19 & 13.18 & 13.12 \\
\hline 1910 & 13.11 & 13.23 & 13.22 & 13.16 \\
\hline 1911 & 13.06 & 13.18 & 13.16 & 13.11 \\
\hline
\end{tabular}




\section{Continued}

\begin{tabular}{|c|c|c|c|c|}
\hline 1912 & 13.17 & 13.25 & 13.23 & 13.18 \\
\hline 1913 & 13.19 & 13.30 & 13.28 & 13.23 \\
\hline 1914 & 13.37 & 13.47 & 13.45 & 13.41 \\
\hline 1915 & 13.41 & 13.49 & 13.47 & 13.43 \\
\hline 1916 & 13.19 & 13.26 & 13.25 & 13.19 \\
\hline 1917 & 13.12 & 13.19 & 13.17 & 13.11 \\
\hline 1918 & 13.22 & 13.28 & 13.26 & 13.21 \\
\hline 1919 & 13.26 & 13.34 & 13.32 & 13.27 \\
\hline 1920 & 13.28 & 13.35 & 13.33 & 13.28 \\
\hline 1921 & 13.35 & 13.43 & 13.42 & 13.37 \\
\hline 1922 & 13.27 & 13.36 & 13.34 & 13.29 \\
\hline 1923 & 13.25 & 13.35 & 13.33 & 13.28 \\
\hline 1924 & 13.27 & 13.36 & 13.34 & 13.29 \\
\hline 1925 & 13.33 & 13.42 & 13.40 & 13.36 \\
\hline 1926 & 13.43 & 13.52 & 13.49 & 13.45 \\
\hline 1927 & 13.33 & 13.41 & 13.39 & 13.34 \\
\hline 1928 & 13.32 & 13.42 & 13.40 & 13.35 \\
\hline 1929 & 13.18 & 13.26 & 13.24 & 13.18 \\
\hline 1930 & 13.40 & 13.48 & 13.45 & 13.41 \\
\hline 1931 & 13.46 & 13.54 & 13.51 & 13.47 \\
\hline 1932 & 13.38 & 13.49 & 13.46 & 13.42 \\
\hline 1933 & 13.25 & 13.34 & 13.31 & 13.26 \\
\hline 1934 & 13.40 & 13.49 & 13.46 & 13.42 \\
\hline 1935 & 13.35 & 13.44 & 13.41 & 13.36 \\
\hline 1936 & 13.39 & 13.47 & 13.44 & 13.40 \\
\hline 1937 & 13.49 & 13.56 & 13.53 & 13.49 \\
\hline 1938 & 13.48 & 13.59 & 13.56 & 13.52 \\
\hline 1939 & 13.51 & 13.59 & 13.56 & 13.53 \\
\hline 1940 & 13.67 & 13.70 & 13.67 & 13.64 \\
\hline 1941 & 13.78 & 13.78 & 13.75 & 13.72 \\
\hline 1942 & 13.62 & 13.66 & 13.63 & 13.60 \\
\hline 1943 & 13.61 & 13.66 & 13.63 & 13.59 \\
\hline 1944 & 13.79 & 13.80 & 13.77 & 13.75 \\
\hline 1945 & 13.70 & 13.70 & 13.66 & 13.63 \\
\hline 1946 & 13.50 & 13.58 & 13.54 & 13.51 \\
\hline 1947 & 13.47 & 13.56 & 13.53 & 13.49 \\
\hline
\end{tabular}




\section{Continued}

\begin{tabular}{|c|c|c|c|c|}
\hline 1948 & 13.45 & 13.55 & 13.52 & 13.48 \\
\hline 1949 & 13.43 & 13.52 & 13.48 & 13.44 \\
\hline 1950 & 13.35 & 13.42 & 13.38 & 13.33 \\
\hline 1951 & 13.51 & 13.57 & 13.54 & 13.50 \\
\hline 1952 & 13.55 & 13.61 & 13.57 & 13.53 \\
\hline 1953 & 13.64 & 13.71 & 13.67 & 13.64 \\
\hline 1954 & 13.41 & 13.50 & 13.46 & 13.41 \\
\hline 1955 & 13.37 & 13.48 & 13.44 & 13.39 \\
\hline 1956 & 13.32 & 13.39 & 13.35 & 13.30 \\
\hline 1957 & 13.58 & 13.63 & 13.59 & 13.55 \\
\hline 1958 & 13.64 & 13.70 & 13.66 & 13.63 \\
\hline 1959 & 13.59 & 13.66 & 13.62 & 13.58 \\
\hline 1960 & 13.56 & 13.62 & 13.58 & 13.54 \\
\hline 1961 & 13.60 & 13.68 & 13.63 & 13.60 \\
\hline 1962 & 13.62 & 13.69 & 13.65 & 13.62 \\
\hline 1963 & 13.63 & 13.71 & 13.67 & 13.63 \\
\hline 1964 & 13.37 & 13.46 & 13.41 & 13.37 \\
\hline 1965 & 13.44 & 13.53 & 13.48 & 13.43 \\
\hline 1966 & 13.49 & 13.58 & 13.53 & 13.49 \\
\hline 1967 & 13.50 & 13.60 & 13.55 & 13.51 \\
\hline 1968 & 13.48 & 13.57 & 13.51 & 13.47 \\
\hline 1969 & 13.61 & 13.66 & 13.60 & 13.56 \\
\hline 1970 & 13.57 & 13.66 & 13.60 & 13.56 \\
\hline 1971 & 13.45 & 13.56 & 13.50 & 13.46 \\
\hline 1972 & 13.54 & 13.60 & 13.54 & 13.50 \\
\hline 1973 & 13.71 & 13.81 & 13.74 & 13.72 \\
\hline 1974 & 13.44 & 13.54 & 13.47 & 13.43 \\
\hline 1975 & 13.52 & 13.65 & 13.58 & 13.55 \\
\hline 1976 & 13.44 & 13.53 & 13.46 & 13.41 \\
\hline 1977 & 13.72 & 13.81 & 13.74 & 13.71 \\
\hline 1976 & 13.63 & 13.72 & 13.65 & 13.61 \\
\hline 1979 & 13.73 & 13.81 & 13.73 & 13.70 \\
\hline 1980 & 13.79 & 13.87 & 13.79 & 13.77 \\
\hline 1981 & 13.84 & 13.94 & 13.86 & 13.85 \\
\hline 1982 & 13.70 & 13.78 & 13.70 & 13.67 \\
\hline 1983 & 13.87 & 13.97 & 13.88 & 13.87 \\
\hline
\end{tabular}




\section{Continued}

\begin{tabular}{|c|c|c|c|c|}
\hline 1984 & 13.67 & 13.76 & 13.67 & 13.64 \\
\hline 1985 & 13.67 & 13.77 & 13.68 & 13.65 \\
\hline 1986 & 13.75 & 13.86 & 13.76 & 13.74 \\
\hline 1987 & 13.90 & 13.98 & 13.89 & 13.87 \\
\hline 1988 & 13.91 & 14.02 & 13.92 & 13.91 \\
\hline 1989 & 13.81 & 13.92 & 13.82 & 13.79 \\
\hline 1990 & 13.96 & 14.07 & 13.97 & 13.96 \\
\hline 1991 & 13.90 & 14.01 & 13.91 & 13.89 \\
\hline 1992 & 13.74 & 13.86 & 13.75 & 13.73 \\
\hline 1993 & 13.80 & 13.91 & 13.80 & 13.78 \\
\hline 1994 & 13.86 & 13.98 & 13.87 & 13.85 \\
\hline 1995 & 13.98 & 14.11 & 14.00 & 14.00 \\
\hline 1996 & 13.83 & 13.94 & 13.83 & 13.81 \\
\hline 1997 & 14.03 & 14.13 & 14.01 & 14.01 \\
\hline 1998 & 14.17 & 14.28 & 14.16 & 13.29 \\
\hline 1999 & 13.96 & 14.11 & 13.99 & 13.33 \\
\hline 2000 & 13.94 & 14.07 & 13.95 & 13.32 \\
\hline 2001 & 14.08 & 14.21 & 14.08 & 13.22 \\
\hline 2002 & 14.14 & 14.27 & 14.14 & 14.18 \\
\hline 2003 & 14.16 & 14.28 & 14.15 & 14.18 \\
\hline 2004 & 14.10 & 14.22 & 14.09 & 14.11 \\
\hline 2005 & 14.19 & 14.34 & 14.20 & 14.24 \\
\hline 2006 & 14.15 & 14.29 & 14.15 & 14.19 \\
\hline 2007 & 14.14 & 14.31 & 14.17 & 14.21 \\
\hline 2008 & 14.06 & 14.22 & 14.08 & 14.10 \\
\hline 2009 & 14.16 & 14.30 & 14.15 & 14.18 \\
\hline 2010 & 14.25 & 14.39 & 14.24 & 14.29 \\
\hline 2011 & 14.09 & 14.26 & 14.10 & 14.13 \\
\hline 2012 & 14.15 & 14.31 & 14.15 & 14.19 \\
\hline 2013 & 14.19 & 14.35 & 14.19 & 14.23 \\
\hline 2014 & 14.25 & 14.39 & 14.23 & 14.27 \\
\hline 2015 & 14.45 & 14.59 & 14.42 & 14.50 \\
\hline 2016 & 14.52 & 14.65 & 14.48 & 14.57 \\
\hline 2017 & 14.43 & 14.58 & 14.41 & 14.48 \\
\hline 2018 & 14.35 & 14.49 & 14.32 & 14.38 \\
\hline 2019 & 14.47 & 14.61 & 14.43 & 14.51 \\
\hline
\end{tabular}


Table S5. Annual changes and percentage changes from average $(949 \mathrm{~mm})$ for land precipitation data and computed changes in concentration of water vapor and evaporation 1901-2015 [30], Figure S2.

\begin{tabular}{|c|c|c|c|c|c|c|}
\hline Year & $\begin{array}{c}\Delta \text { Precip } \\
\mathrm{mm}\end{array}$ & $\begin{array}{c}\Delta \text { Precip } \\
\%\end{array}$ & $\begin{array}{c}\Delta \text { Evap } \\
\mathrm{mm}\end{array}$ & $\begin{array}{c}\Delta \text { Evap } \\
\%\end{array}$ & $\begin{array}{c}\Delta \mathrm{TPW} \\
\mathrm{mm}\end{array}$ & $\begin{array}{c}\Delta \mathrm{TPW} \\
\%\end{array}$ \\
\hline 1901 & -20.97 & $-2.21 \%$ & -20.99 & $0.00 \%$ & 0 & 0 \\
\hline 1902 & -49.04 & $-5.17 \%$ & -49.08 & $-2.95 \%$ & -0.24 & $-0.03 \%$ \\
\hline 1903 & -14.28 & $-1.50 \%$ & -14.32 & $3.67 \%$ & -0.26 & $-0.03 \%$ \\
\hline 1904 & -26.91 & $-2.84 \%$ & -26.93 & $-1.32 \%$ & -0.18 & $-0.02 \%$ \\
\hline 1905 & -28.24 & $-2.98 \%$ & -28.18 & $-0.12 \%$ & 0.35 & $0.04 \%$ \\
\hline 1906 & -6.81 & $-0.72 \%$ & -6.78 & $2.27 \%$ & 0.20 & $0.02 \%$ \\
\hline 1907 & -12.72 & $-1.34 \%$ & -12.80 & $-0.62 \%$ & -0.49 & $-0.05 \%$ \\
\hline 1908 & -4.53 & $-0.48 \%$ & -4.52 & $0.88 \%$ & -0.01 & $0.00 \%$ \\
\hline 1909 & 2.01 & $0.21 \%$ & 2.01 & $0.70 \%$ & 0.00 & $0.00 \%$ \\
\hline 1910 & -0.11 & $-0.01 \%$ & -0.09 & $-0.21 \%$ & 0.09 & $0.01 \%$ \\
\hline 1911 & -29.90 & $-3.15 \%$ & -29.92 & $-3.13 \%$ & -0.14 & $-0.01 \%$ \\
\hline 1912 & -22.70 & $-2.39 \%$ & -22.67 & $0.77 \%$ & 0.18 & $0.02 \%$ \\
\hline 1913 & -27.37 & $-2.88 \%$ & -27.35 & $-0.48 \%$ & 0.11 & $0.01 \%$ \\
\hline 1914 & -30.15 & $-3.18 \%$ & -30.07 & $-0.28 \%$ & 0.43 & $0.05 \%$ \\
\hline 1915 & -10.82 & $-1.14 \%$ & -10.81 & $2.04 \%$ & 0.06 & $0.01 \%$ \\
\hline 1916 & 43.04 & $4.54 \%$ & 42.95 & $5.67 \%$ & -0.57 & $-0.06 \%$ \\
\hline 1917 & 14.01 & $1.48 \%$ & 13.97 & $-3.04 \%$ & -0.20 & $-0.02 \%$ \\
\hline 1918 & -10.88 & $-1.15 \%$ & -10.85 & $-2.61 \%$ & 0.23 & $0.02 \%$ \\
\hline 1919 & -34.68 & $-3.65 \%$ & -34.66 & $-2.50 \%$ & 0.15 & $0.02 \%$ \\
\hline 1920 & -3.32 & $-0.35 \%$ & -3.31 & $3.31 \%$ & 0.03 & $0.00 \%$ \\
\hline 1921 & 10.86 & $1.14 \%$ & 10.90 & $1.51 \%$ & 0.21 & $0.02 \%$ \\
\hline 1922 & 17.97 & $1.89 \%$ & 17.94 & $0.75 \%$ & -0.19 & $-0.02 \%$ \\
\hline 1923 & 8.75 & $0.92 \%$ & 8.74 & $-0.96 \%$ & -0.04 & $0.00 \%$ \\
\hline 1924 & 10.27 & $1.08 \%$ & 10.27 & $0.17 \%$ & 0.04 & $0.00 \%$ \\
\hline 1925 & -9.45 & $-1.00 \%$ & -9.42 & $-2.07 \%$ & 0.16 & $0.02 \%$ \\
\hline 1926 & -16.15 & $-1.70 \%$ & -16.11 & $-0.69 \%$ & 0.24 & $0.02 \%$ \\
\hline 1927 & 10.13 & $1.07 \%$ & 10.08 & $2.77 \%$ & -0.27 & $-0.03 \%$ \\
\hline 1928 & 1.71 & $0.18 \%$ & 1.72 & $-0.87 \%$ & 0.03 & $0.00 \%$ \\
\hline 1929 & -5.22 & $-0.55 \%$ & -5.29 & $-0.73 \%$ & -0.41 & $-0.04 \%$ \\
\hline 1930 & -30.07 & $-3.17 \%$ & -29.97 & $-2.59 \%$ & 0.55 & $0.06 \%$ \\
\hline 1931 & -14.18 & $-1.49 \%$ & -14.16 & $1.68 \%$ & 0.16 & $0.02 \%$ \\
\hline 1932 & -13.85 & $-1.46 \%$ & -13.87 & $0.04 \%$ & -0.14 & $-0.01 \%$ \\
\hline 1933 & 3.53 & $0.37 \%$ & 3.47 & $1.84 \%$ & -0.38 & $-0.04 \%$ \\
\hline
\end{tabular}




\section{Continued}

\begin{tabular}{|c|c|c|c|c|c|c|}
\hline 1934 & 8.38 & $0.88 \%$ & 8.44 & $0.53 \%$ & 0.39 & $0.04 \%$ \\
\hline 1935 & -1.12 & $-0.12 \%$ & -1.14 & $-1.00 \%$ & -0.14 & $-0.01 \%$ \\
\hline 1936 & 6.69 & $0.71 \%$ & 6.71 & $0.84 \%$ & 0.08 & $0.01 \%$ \\
\hline 1937 & -6.30 & $-0.66 \%$ & -6.26 & $-1.36 \%$ & 0.23 & $0.02 \%$ \\
\hline 1938 & -2.64 & $-0.28 \%$ & -2.62 & $0.39 \%$ & 0.07 & $0.01 \%$ \\
\hline 1939 & 5.77 & $0.61 \%$ & 5.77 & $0.89 \%$ & 0.01 & $0.00 \%$ \\
\hline 1940 & -25.58 & $-2.70 \%$ & -25.54 & $-3.29 \%$ & 0.28 & $0.03 \%$ \\
\hline 1941 & -24.18 & $-2.55 \%$ & -24.15 & $0.16 \%$ & 0.21 & $0.02 \%$ \\
\hline 1942 & -3.15 & $-0.33 \%$ & -3.20 & $2.22 \%$ & -0.32 & $-0.03 \%$ \\
\hline 1943 & -6.08 & $-0.64 \%$ & -6.08 & $-0.29 \%$ & 0.00 & $0.00 \%$ \\
\hline 1944 & -5.11 & $-0.54 \%$ & -5.05 & $0.12 \%$ & 0.38 & $0.04 \%$ \\
\hline 1945 & -3.98 & $-0.42 \%$ & -4.02 & $0.12 \%$ & -0.28 & $-0.03 \%$ \\
\hline 1946 & -5.89 & $-0.62 \%$ & -5.94 & $-0.19 \%$ & -0.32 & $-0.03 \%$ \\
\hline 1947 & 19.01 & $2.00 \%$ & 19.00 & $2.64 \%$ & -0.04 & $0.00 \%$ \\
\hline 1948 & 6.78 & $0.71 \%$ & 6.78 & $-1.28 \%$ & -0.03 & $0.00 \%$ \\
\hline 1949 & 0.06 & $0.01 \%$ & 0.04 & $-0.70 \%$ & -0.09 & $-0.01 \%$ \\
\hline 1950 & 28.66 & $3.02 \%$ & 28.61 & $3.02 \%$ & -0.26 & $-0.03 \%$ \\
\hline 1951 & -6.15 & $-0.65 \%$ & -6.08 & $-3.65 \%$ & 0.39 & $0.04 \%$ \\
\hline 1952 & 0.65 & $0.07 \%$ & 0.66 & $0.72 \%$ & 0.09 & $0.01 \%$ \\
\hline 1953 & 14.05 & $1.48 \%$ & 14.09 & $1.43 \%$ & 0.26 & $0.03 \%$ \\
\hline 1954 & 38.16 & $4.02 \%$ & 38.07 & $2.54 \%$ & -0.55 & $-0.06 \%$ \\
\hline 1955 & 38.81 & $4.09 \%$ & 38.80 & $0.09 \%$ & -0.05 & $-0.01 \%$ \\
\hline 1956 & 47.53 & $5.01 \%$ & 47.49 & $0.93 \%$ & -0.22 & $-0.02 \%$ \\
\hline 1957 & 3.73 & $0.39 \%$ & 3.83 & $-4.59 \%$ & 0.61 & $0.06 \%$ \\
\hline 1958 & 14.93 & $1.57 \%$ & 14.96 & $1.18 \%$ & 0.19 & $0.02 \%$ \\
\hline 1959 & 25.22 & $2.66 \%$ & 25.20 & $1.09 \%$ & -0.12 & $-0.01 \%$ \\
\hline 1960 & 22.99 & $2.42 \%$ & 22.98 & $-0.22 \%$ & -0.10 & $-0.01 \%$ \\
\hline 1961 & 21.00 & $2.21 \%$ & 21.02 & $-0.20 \%$ & 0.14 & $0.01 \%$ \\
\hline 1962 & 13.03 & $1.37 \%$ & 13.04 & $-0.83 \%$ & 0.04 & $0.00 \%$ \\
\hline 1963 & -1.60 & $-0.17 \%$ & -1.60 & $-1.53 \%$ & 0.04 & $0.00 \%$ \\
\hline 1964 & 9.87 & $1.04 \%$ & 9.76 & $1.21 \%$ & -0.65 & $-0.07 \%$ \\
\hline 1965 & -16.76 & $-1.77 \%$ & -16.73 & $-2.78 \%$ & 0.16 & $0.02 \%$ \\
\hline 1966 & 8.28 & $0.87 \%$ & 8.30 & $2.65 \%$ & 0.13 & $0.01 \%$ \\
\hline 1967 & 9.41 & $0.99 \%$ & 9.42 & $0.13 \%$ & 0.05 & $0.01 \%$ \\
\hline 1968 & -11.64 & $-1.23 \%$ & -11.66 & $-2.21 \%$ & -0.09 & $-0.01 \%$ \\
\hline 1969 & 3.16 & $0.33 \%$ & 3.20 & $1.58 \%$ & 0.23 & $0.02 \%$ \\
\hline
\end{tabular}




\section{Continued}

\begin{tabular}{|c|c|c|c|c|c|c|}
\hline 1970 & 18.52 & $1.95 \%$ & 18.52 & $1.63 \%$ & -0.02 & $0.00 \%$ \\
\hline 1971 & -0.30 & $-0.03 \%$ & -0.34 & $-1.98 \%$ & -0.24 & $-0.03 \%$ \\
\hline 1972 & -15.66 & $-1.65 \%$ & -15.65 & $-1.60 \%$ & 0.11 & $0.01 \%$ \\
\hline 1973 & 37.75 & $3.98 \%$ & 37.84 & $5.65 \%$ & 0.51 & $0.05 \%$ \\
\hline 1974 & 28.67 & $3.02 \%$ & 28.55 & $-0.97 \%$ & -0.70 & $-0.07 \%$ \\
\hline 1975 & 27.76 & $2.92 \%$ & 27.81 & $-0.07 \%$ & 0.28 & $0.03 \%$ \\
\hline 1976 & -6.45 & $-0.68 \%$ & -6.50 & $-3.61 \%$ & -0.31 & $-0.03 \%$ \\
\hline 1977 & -11.18 & $-1.18 \%$ & -11.06 & $-0.47 \%$ & 0.72 & $0.08 \%$ \\
\hline 1978 & 9.13 & $0.96 \%$ & 9.10 & $2.13 \%$ & -0.23 & $-0.02 \%$ \\
\hline 1979 & 22.22 & $2.34 \%$ & 22.25 & $1.40 \%$ & 0.22 & $0.02 \%$ \\
\hline 1980 & 9.43 & $0.99 \%$ & 9.46 & $-1.34 \%$ & 0.16 & $0.02 \%$ \\
\hline 1981 & 13.34 & $1.41 \%$ & 13.37 & $0.42 \%$ & 0.19 & $0.02 \%$ \\
\hline 1982 & -17.80 & $-1.88 \%$ & -17.88 & $-3.28 \%$ & -0.43 & $-0.05 \%$ \\
\hline 1983 & -27.15 & $-2.86 \%$ & -27.07 & $-0.96 \%$ & 0.47 & $0.05 \%$ \\
\hline 1984 & 0.48 & $0.05 \%$ & 0.39 & $2.90 \%$ & -0.55 & $-0.06 \%$ \\
\hline 1985 & -4.62 & $-0.49 \%$ & -4.61 & $-0.52 \%$ & 0.01 & $0.00 \%$ \\
\hline 1986 & -20.23 & $-2.13 \%$ & -20.19 & $-1.63 \%$ & 0.23 & $0.02 \%$ \\
\hline 1987 & -33.06 & $-3.48 \%$ & -33.01 & $-1.34 \%$ & 0.33 & $0.03 \%$ \\
\hline 1988 & 21.19 & $2.23 \%$ & 21.21 & $5.72 \%$ & 0.08 & $0.01 \%$ \\
\hline 1989 & 14.73 & $1.55 \%$ & 14.68 & $-0.68 \%$ & -0.27 & $-0.03 \%$ \\
\hline 1990 & 2.93 & $0.31 \%$ & 3.00 & $-1.22 \%$ & 0.41 & $0.04 \%$ \\
\hline 1991 & -16.56 & $-1.75 \%$ & -16.59 & $-2.05 \%$ & -0.16 & $-0.02 \%$ \\
\hline 1992 & -39.38 & $-4.15 \%$ & -39.45 & $-2.40 \%$ & -0.41 & $-0.04 \%$ \\
\hline 1993 & -24.94 & $-2.63 \%$ & -24.92 & $1.54 \%$ & 0.13 & $0.01 \%$ \\
\hline 1994 & -4.04 & $-0.43 \%$ & -4.01 & $2.21 \%$ & 0.17 & $0.02 \%$ \\
\hline 1995 & -15.11 & $-1.59 \%$ & -15.05 & $-1.15 \%$ & 0.35 & $0.04 \%$ \\
\hline 1996 & 17.10 & $1.80 \%$ & 17.02 & $3.39 \%$ & -0.46 & $-0.05 \%$ \\
\hline 1997 & -3.65 & $-0.38 \%$ & -3.57 & $-2.16 \%$ & 0.48 & $0.05 \%$ \\
\hline 1998 & 10.18 & $1.07 \%$ & 10.25 & $1.47 \%$ & 0.41 & $0.04 \%$ \\
\hline 1999 & 33.50 & $3.53 \%$ & 33.42 & $2.45 \%$ & -0.48 & $-0.05 \%$ \\
\hline 2000 & 47.26 & $4.98 \%$ & 47.24 & $1.47 \%$ & -0.10 & $-0.01 \%$ \\
\hline 2001 & -3.13 & $-0.33 \%$ & -3.07 & $-5.29 \%$ & 0.37 & $0.04 \%$ \\
\hline 2002 & -11.94 & $-1.26 \%$ & -11.91 & $-0.92 \%$ & 0.15 & $0.02 \%$ \\
\hline 2003 & 3.70 & $0.39 \%$ & 3.71 & $1.66 \%$ & 0.02 & $0.00 \%$ \\
\hline 2004 & 15.37 & $1.62 \%$ & 15.34 & $1.24 \%$ & -0.16 & $-0.02 \%$ \\
\hline 2005 & 10.25 & $1.08 \%$ & 10.30 & $-0.52 \%$ & 0.29 & $0.03 \%$ \\
\hline
\end{tabular}




\begin{tabular}{ccccccc} 
Continued & & & & & & \\
\hline 2006 & 36.23 & $3.82 \%$ & 36.21 & $2.74 \%$ & -0.12 & $-0.01 \%$ \\
2007 & 10.51 & $1.11 \%$ & 10.52 & $-2.70 \%$ & 0.04 & $0.00 \%$ \\
2008 & 32.71 & $3.45 \%$ & 32.66 & $2.34 \%$ & -0.25 & $-0.03 \%$ \\
2009 & -4.50 & $-0.47 \%$ & -4.47 & $-3.90 \%$ & 0.19 & $0.02 \%$ \\
2010 & 53.87 & $5.68 \%$ & 53.91 & $6.16 \%$ & 0.26 & $0.03 \%$ \\
2011 & 49.00 & $5.16 \%$ & 48.93 & $-0.51 \%$ & -0.38 & $-0.04 \%$ \\
2012 & 3.97 & $0.42 \%$ & 3.99 & $-4.73 \%$ & 0.13 & $0.01 \%$ \\
2013 & 3.37 & $0.35 \%$ & 3.38 & $-0.05 \%$ & 0.09 & $0.01 \%$ \\
2014 & 0.18 & $0.02 \%$ & 0.20 & $-0.33 \%$ & 0.11 & $0.01 \%$ \\
2015 & -1.39 & $-0.15 \%$ & -1.30 & $-0.15 \%$ & 0.53 & $0.06 \%$ \\
\hline
\end{tabular}

